\title{
Review Article \\ The West African Sahel: A Review of Recent Studies on the Rainfall Regime and Its Interannual Variability
}

\author{
Sharon E. Nicholson \\ Earth, Ocean, and Atmospheric Sciences Department, Florida State University, Tallahassee, FL 32306, USA \\ Correspondence should be addressed to Sharon E. Nicholson; snicholson@fsu.edu
}

Received 23 October 2012; Accepted 20 November 2012

Academic Editors: F. Acs, I. Bordi, and D.-Y. Wang

Copyright ( 2013 Sharon E. Nicholson. This is an open access article distributed under the Creative Commons Attribution License, which permits unrestricted use, distribution, and reproduction in any medium, provided the original work is properly cited.

\begin{abstract}
The West African Sahel is well known for the severe droughts that ravaged the region in the 1970s and 1980s. Meteorological research on the region has flourished during the last decade as a result of several major field experiments. This paper provides an overview of the results that have ensued. A major focus has been on the West African monsoon, a phenomenon that links all of West Africa. The characteristics and revised picture of the West African monsoon are emphasized. Other topics include the interannual variability of rainfall, the atmospheric circulation systems that govern interannual variability, characteristics of precipitation and convection, wave activity, large-scale factors in variability (including sea-surface temperatures), and land-atmosphere relationships. New paradigms for the monsoon and associated ITCZ and for interannual variability have emerged. These emphasize features in the upper atmosphere, as well as the Saharan Heat Low. Feedback mechanisms have also been emphasized, especially the coupling of convection with atmospheric dynamics and with land surface characteristics. New results also include the contrast between the premonsoon and peak monsoon seasons, two preferred modes of interannual variability (a latitudinal displacement of the tropical rainbelt versus changes in its intensity), and the critical importance of the Tropical Easterly Jet.
\end{abstract}

\section{Introduction}

The Sahel region of West African is a semi-arid expanse of grassland, shrubs, and small, thorny trees lying just to the south of the Sahara desert (Figure 1). The term is often applied to the general region extending some $5000 \mathrm{~km}$ across the east-west extent of Africa and from the Sahara to the humid savanna at roughly $10^{\circ}$ North. "Sahel" more properly applies to a smaller region (Figure 2) between the latitudes of roughly $14^{\circ} \mathrm{N}$ and $18^{\circ} \mathrm{N}$. It includes much of the countries of Mauritania, Senegal, Mali, Niger, Chad, the Sudan, and the northern fringes of Burkina Faso and Nigeria. The Sahel's highly diverse inhabitants have a long history, its fabled cities such as Timbuktoo and Djenne having prospered as centers of trade, education, and political empires many centuries ago. Today the region is home to major cities such as Dakar (Senegal), Niamey (Niger), Bamako (Mali), and Khartoum (Sudan), but most of the inhabitants live in rural areas and practice agriculture. Hence, the vagaries of climate are of great importance to the region.

Mean annual rainfall in the Sahel is on the order of 100 to $200 \mathrm{~mm}$ in the north, where the Sahel gives way to desert, and
500 to $600 \mathrm{~mm}$ at its southern limit (Figure 2). Throughout the region rainfall is generally limited to the boreal summer months, with maximum rainfall occurring in August. In the Sahel proper, the season length ranges from 1 to 2 months in the north to 4 to 5 months in the south. Occasional winter rains of extratropical origin can occur, but these generally bring less than $25 \mathrm{~mm}$ of rainfall.

Within the region there is a strong east-west uniformity of climate and vegetation conditions. This is well illustrated by the isohyets of rainfall (Figure 2), which also show a very strong north-south gradient. Because of the east-west uniformity the Sahel region is often considered as one entity in the meteorological context. However, notable contrasts appear across the region, particularly with respect to factors in yearto-year variability and the prevailing circulation systems $[1$, 2]. This is particularly true in the eastern extreme of the Sudan and Ethiopia, where complex topography overrides the large-scale patterns. For this reason, most analyses of Sahel climate do not extend across the region's east-west extent. Those of Nicholson (e.g., [3]) generally cease at $30^{\circ}$ to $35^{\circ} \mathrm{E}$. Those of Lamb (e.g., $[4,5])$ are confined to the region lying 


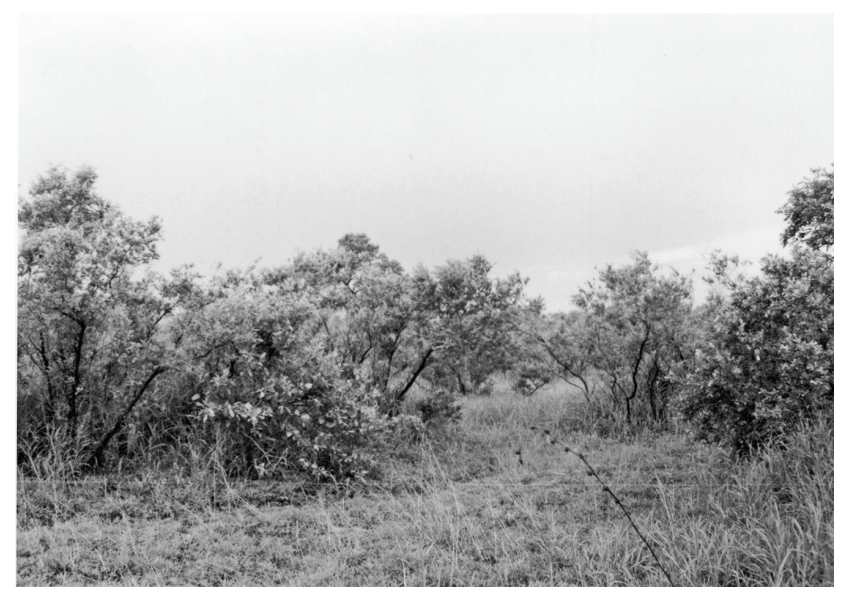

FIGURE 1: Typical low tree and shrub savanna landscape of the Sahel (from [57]).

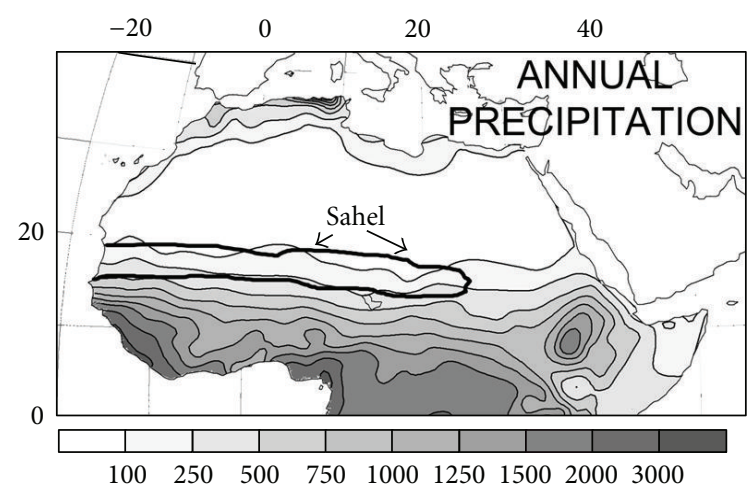

FIgURE 2: Mean annual precipitation over West Africa (in mm). Location of the Sahel is indicated.

between the Atlantic coast and $10^{\circ}$ E. Several studies have shown significant contrasts in various sectors of the Sahel (e.g., [6-8]).

Scientific attention was focused on the Sahel in the 1970s and 1980s because of the long period of drought that had ravaged the region and the controversial issue of desertification. During the past few years the Sahel once again received much meteorological attention, at least in part because of major field experiments carried out to better understand variability in the region. These include the AMMA (African monsoon multidisciplinary analysis) experiment, that took place in $2006[9,10]$, the associated model intercomparison project (ALMIP, [11]), the AMMA Catch Experiment [12], which extended AMMA southward into Benin, and the JET2000 Experiment, that focused on the African Easterly Jet [13].

This paper presents a review of studies that have been published in roughly the last decade, a period during which our meteorological understanding of the region increased tremendously. The conclusions within this paper are generally valid for the broader region termed "Sahel", from the Sahara to the more humid savanna, and from the far west to roughly $30^{\circ} \mathrm{E}$.

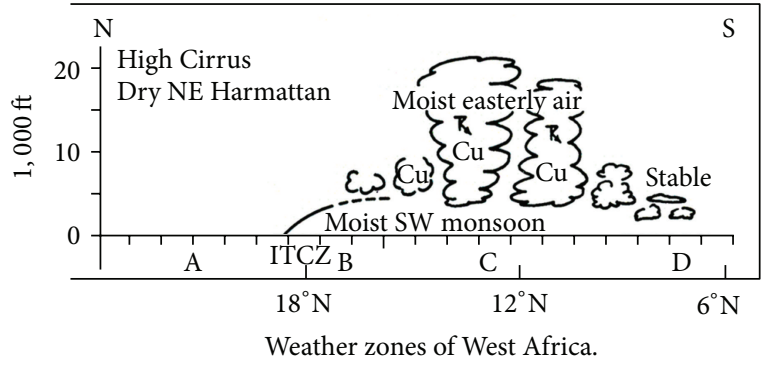

FIGURE 3: Classical picture of the ITCZ over Africa during the boreal summer (from [14]).

The Sahel is inextricably linked to the West Africa monsoon, the circulation regime that brings most of its rainfall. This paper therefore begins with an overview of the concept of the West African monsoon and the new picture that has emerged in recent years. The paper focuses on interannual and intraseasonal variability in the Sahel and factors governing this variability, including links to large-scale phenomena such as ENSO, SSTs, and atmospheric circulation. The impact of aerosols and feedback from the Sahelian land surface are also considered. The paper further describes new characteristics that have been demonstrated about the region's storm systems and new circulation features that have been documented. The paper is limited to precipitation and related phenomena.

\section{The West African Monsoon}

2.1. Classic Picture of the West African Monsoon. The classical picture of the West African monsoon is illustrated in Figure 3. In this scenario, rainfall is associated with a surface feature termed the Intertropical Convergence Zone or ITCZ. This zone "follows the sun", moving northward into West Africa in the boreal summer and southward into southern Africa in the austral summer, twice traversing the equatorial regions. In this classic picture, the ITCZ over West Africa is marked by the convergence of the northeasterly Harmattan winds that originate in the Sahara and the southwest monsoon flow that emanates from the Atlantic. Rain production was assumed to result from local thermal instability, facilitated by the lowlevel wind convergence within this zone. The rapid increase in rainfall from the Sahara to the humid equatorial zone was assumed to relate to a rapidly increasing depth of the moist layer equator-ward from the ITCZ (e.g, [14]).

This picture of the West African monsoon has several shortcomings. For one, its origin lies in the concept of the global Hadley circulation, with rising motion in the equatorial latitudes where the trade winds converge and subsidence (sinking motion) in the subtropical latitudes where the subtropical highs prevail. That concept was developed to describe the global mean state and not individual regions. Moreover, it is primarily valid over the oceans [15], where the trade winds are well developed. The scheme works poorly over the continents, where the trade winds are generally absent. This picture of the ITCZ was also developed at a time 


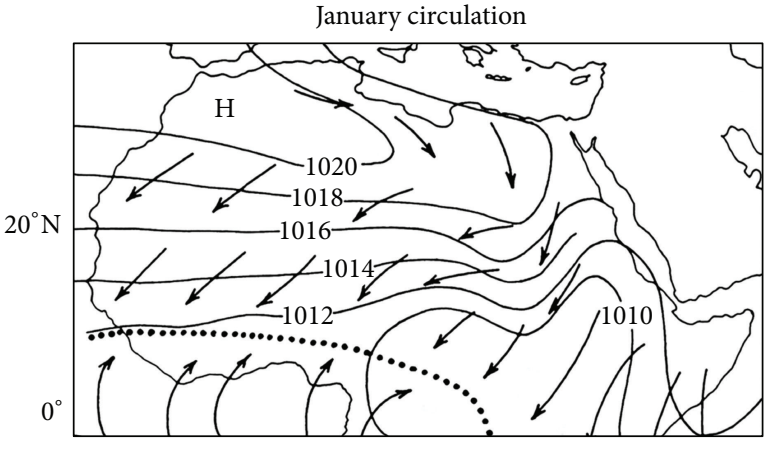

(a)

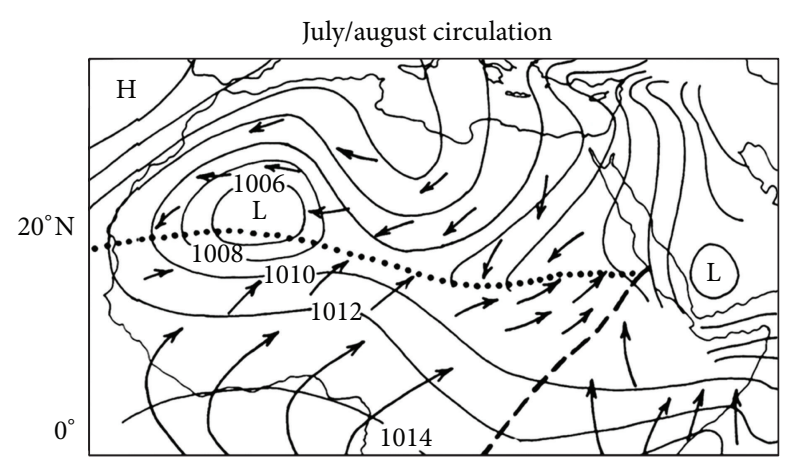

(b)

FIGURE 4: Schematic of surface wind (arrows) and pressure (mb) over West Africa during winter and at the peak of the summer monsoon.

when tropical rainfall was assumed to be local in origin, a result of thermal instability in warm and humid air, with ascent facilitated by surface wind convergence. As of the 1970s, following tropical meteorological experiments such as GATE (the GARP Atlantic Tropical Experiment, [16]), it became well established that tropical rainfall is instead linked to large-scale disturbances often associated with traveling waves.

A second shortcoming is the ambiguity of the term "ITCZ". In the literature three very different definitions are given, based respectively on wind convergence, surface air pressure and rainfall or outgoing longwave radiation. In the Encyclopedia of World Climatology, Yan and Oliver [17] states that the ITCZ is "an east-west oriented low-pressure region near the equator where surface northeasterly and southeasterly trade winds meets. When they converge, moist air is forced upward, producing cumulus clouds and heavy precipitation." According to Miller and Schneider [18] in the Encyclopedia of Weather and Climate, it is "a region near the equator where the trade winds converge." Holton et al. [19], in their widely used textbook, define the ITCZ as the "loci of cloud clusters associated with westward-propagating tropical wave disturbances". Consequently, some authors now avoid the use of the term. For example, Zhang et al. [15] instead use the term "rain band" and Nicholson [20] substitutes the term "tropical rainbelt". The latter term will be used in this paper.

As a result of the ambiguity in the definition of the ITCZ, its tracking may be based on a pressure minimum, a surface wind convergence, a maximum in rainfall, a minimum in outgoing longwave radiation, or a maximum in cloudiness. The use of so many different parameters has been justified by the assumptions that (1) the pressure minimum and rainfall maximum are colocated with each other and with the wind convergence, (2) maximum cloudiness is roughly colocated with maximum rainfall, and (3) longwave radiation is at a minimum at that location. Unfortunately, these assumptions, especially the first one, do not stand up to close scrutiny. Even over the ocean regions the zone of minimum pressure does not generally coincide with that of the wind convergence or the rainfall maximum [21].

This picture is particularly problematic over West Africa, as new research on the West African monsoon has dramatically shown. For one, the ITCZ (as defined by surface wind convergence) lies some 1000 kilometers to the north of the zone of maximum rainfall, as does the zone of maximum ascent [20]. For another, rainfall over the Sahel is associated with African easterly waves and with large Mesoscale Convective Systems (MCSs), rather than local thunderstorms. Lebel et al. [22] estimate that some $12 \%$ of the total number of MCSs produce $90 \%$ of the rainfall during the peak rainy season. Very intense MCSs, which comprise some 3 to $4 \%$ of the all rain events, produce up to $80 \%$ of the rainfall that occurs in the Sahel [23].

2.2. Revised View of the West African Monsoon. The circulation over West Africa exhibits the most basic characteristics of a monsoon: a pronounced seasonal wind shift that is produced by thermodynamic contrasts between the land (i.e., the Sahara) and ocean (i.e., the equatorial Atlantic). Southwesterly flow is established between the Atlantic cold tongue (cool water close to the equator between the boreal spring and summer) and the Saharan heat low, bringing moisture into the continent $[24,25]$. The annual evolution of moisture fluxes, convergence and rainfall is closely tied to these two systems. The basic surface circulation is illustrated in Figure 4. During the boreal summer, an intense heat low develops over the western Sahara. The cyclonic flow around this low includes the southwesterly "monsoon" flow to the south and the northeasterly Harmattan to the west of its core [26]. Termed the Saharan Heat Low or West African Heat Low, this system plays an important role in controlling the northward penetration of the monsoon [27].

The main contrasts with the classic picture of the monsoon are the diminished importance of the ITCZ and the inclusion of several jetstreams and shear zones, the African Easterly Waves (AEWs), the Saharan Heat Low, and the aforementioned Mesoscale Convective Systems, as opposed to local rainfall induced by thermal instability. Overviews are presented by Nicholson and Grist [1], Gu and Adler [28], Parker et al. [29], Zhang et al. [15], Nicholson [20], and Thorncroft et al. [25]. The circulation and convective features associated with the West African monsoon and influencing the Sahel are discussed in detail in Sections 4 and 5.

The main tropical circulation features associated with the West African monsoon (Figures 5(a) and 5(b)) are the upper-level Tropical Easterly Jet (TEJ), the mid-level African 

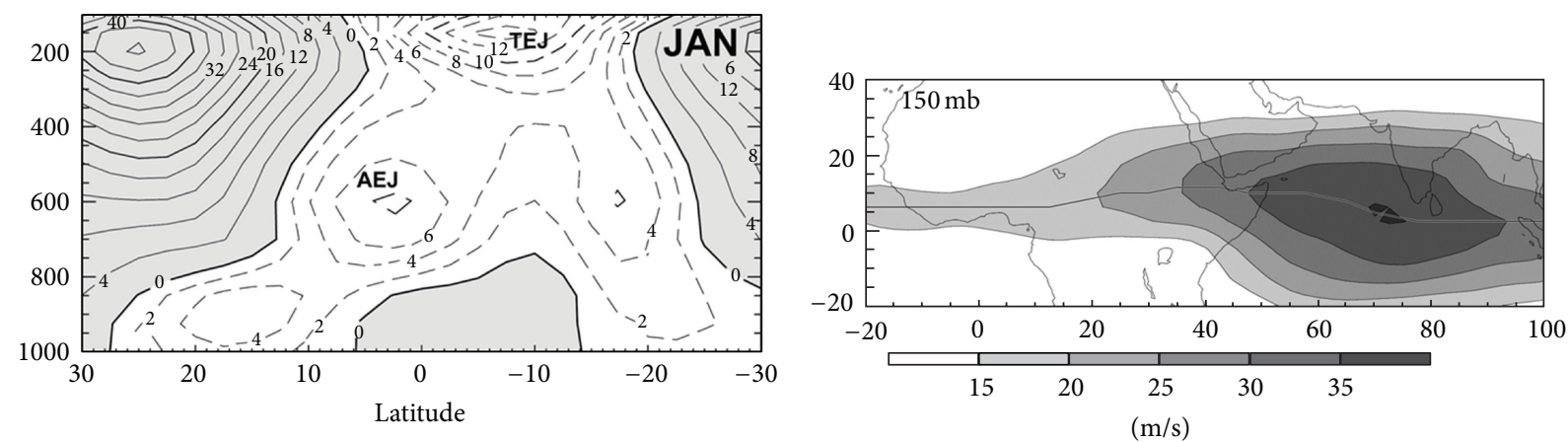

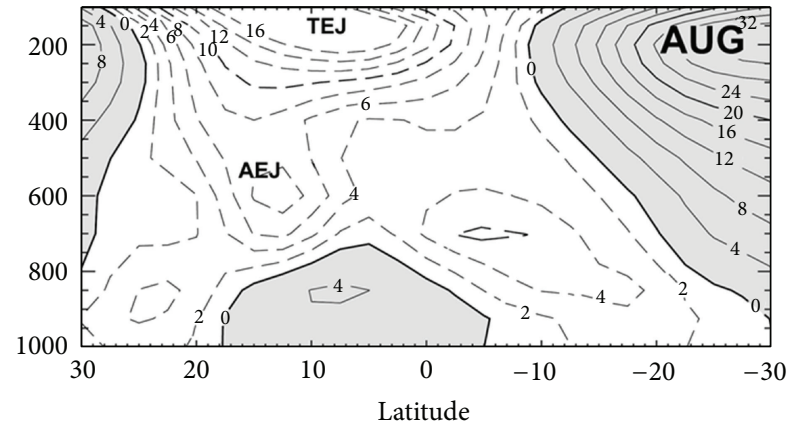

(a)

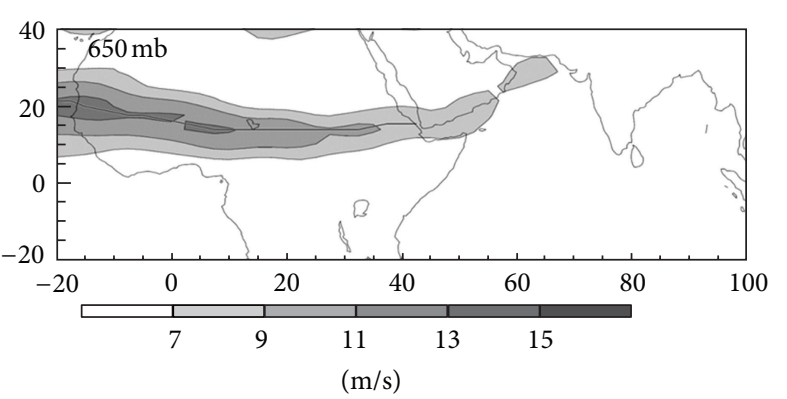

(b)

Figure 5: (a) Latitudinal transect of mean zonal wind $\left(\mathrm{m} \mathrm{s}^{-1}\right)$ over Africa during January and August (from [57]). The Tropical Easterly Jet and African Easterly Jet are indicated. Westerly winds are shaded. (b) Mean easterly wind speed ( $\mathrm{m} \mathrm{s}^{-1}$ ) in August at 600 and $150 \mathrm{hPa}$, showing the African Easterly Jet and Tropical Easterly Jet, respectively (from [20]).

Easterly Jet (AEJ), and low-level equatorial westerlies associated with the southwest monsoon flow [1]. In wet years these westerlies become a bona fide jet stream that has a core near $850 \mathrm{mb}$ and is independent of the low-level monsoon flow [30]. The AEJ and monsoon westerlies are stronger over the western portion of the region, while the TEJ is stronger over the eastern portion of the region (Figure 5(b)). Superimposed upon these zonal flows are two meridional overturning circulations: a deep circulation associated with low-level contrasts in deep moist convection and a shallow circulation associated with contrasts in dry convection [25] (Figure 6). Both consist of southerly flow at low levels and northerly flow at higher levels. The shallow cell is associated with the Saharan heat low and transports dry air towards the rainbelt at mid-levels of the atmosphere [20].

The core of the AEJ is between 650 and $700 \mathrm{mb}$. It lies in a region of strong latitudinal temperature gradient in the lower troposphere. The jet is thermally induced by the contrast between the hot Sahara and the Atlantic Ocean, but maintained by the juxtaposition of moist convection to the south and dry convection to the north [31-33]. It is also associated with zones of intense horizontal and vertical shear $[1,28]$. The horizontal shear is particularly strong in August and September, while the vertical shear is most intense from May through July, when it is of roughly the same magnitude as the horizontal shear.

The TEJ is best developed at about the $200 \mathrm{mb}$ level. It has a sizable meridional component [30] that is part of the deep meridional overturning described by Thorncroft et al. [25]. Over West Africa during the monsoon season, the meridional component is northerly south of its core (maximum is near 10 degrees South), but southerly north of the core. This creates a region of strong divergence around $200 \mathrm{mb}$, which appears to play a role in the development of the rainbelt over West Africa $[1,20]$. It intensifies during the monsoon season.

A major role of the West African monsoon system is transporting moisture into West Africa from the Atlantic. This transport takes place in periodic northward excursions of moisture flux that have a 3 to 5 day time scale [34]. These "bursts" of the monsoon can bring copious rainfall to the northern fringes of the Sahel [35]. The intraseasonal excursions in moisture flux can be stationary or exhibit a westward propagation [34]. The dynamics of the Saharan Heat Low are a major driver in the stationary perturbations. They follow maxima in the intensity of the heat low and the associated acceleration of the low-level meridional wind. The propagating excursions of moisture flux are related to easterly waves. Horizontal advection is the main process in the moisture flux, but vertical turbulent exchange plays some role.

Within the monsoon are two areas of peak moisture flux convergence and vertical motion $[25,36]$. The dominant one lies between the axes of the AEJ and TEJ (Figure 7). It is associated with the deep meridional overturning described by Thorncroft et al. [25] and with the core of the rainbelt over West Africa [1]. The mean August location of this deep column of ascent is roughly $10^{\circ}$ North. This region of moisture flux convergence and ascent is associated with a deep column of moist air in which relative humidity is $60 \%$ to $80 \%$ throughout the troposphere $[20,37]$. It also corresponds 


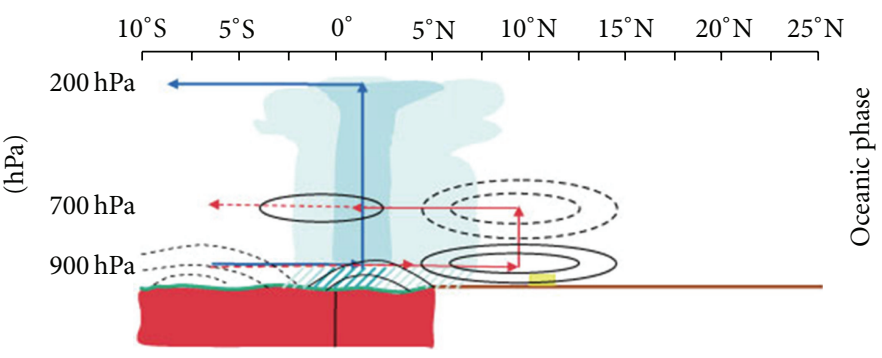

(a)

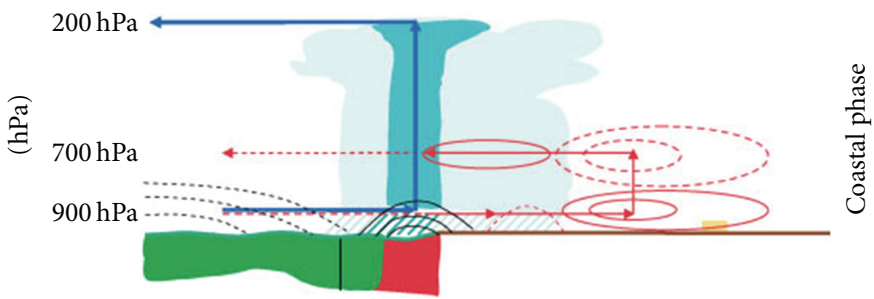

(b)

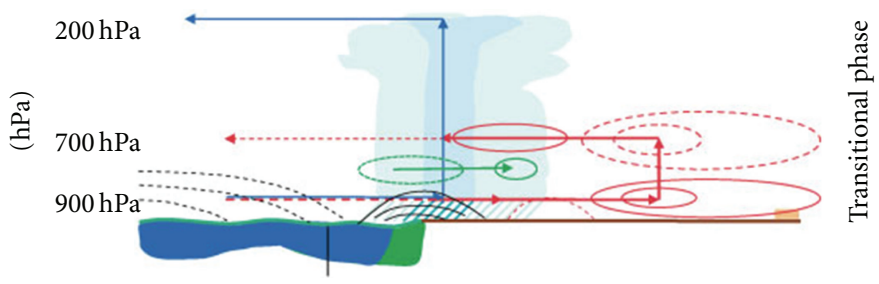

(c)

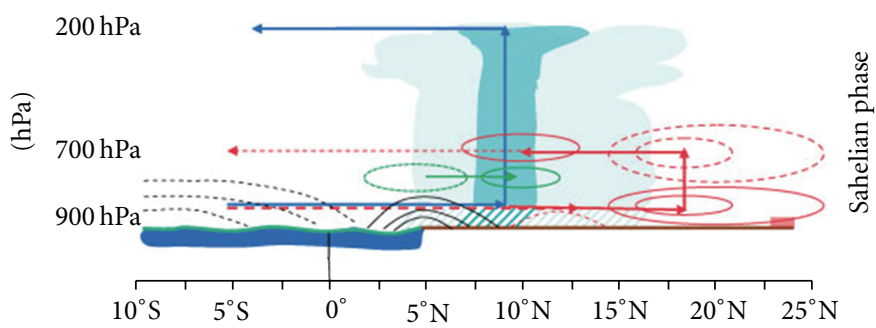

(d)

Figure 6: Schematic showing the four key phases of the annual cycle of the west African monsoon. Included for each phase are the following: location of the main rain band (indicated by clouds and rainfall with peak values highlighted by darker shaded clouds and rainfall), the location of the Saharan heat-low (indicated by yellow, orange, and red shading at the surface poleward of the rain band, with increased redness indicating increased intensity). Atlantic ocean temperature and associated mix-layer depth (with decreased temperatures indicated by the red-to-green-to-blue transition). Moisture flux convergence maxima and minima (solid contours indicate moisture flux convergence and dashed contours indicate moisture flux divergence), and the deep and shallow meridional circulations (blue and red lines with arrows); dashed lines suggest some uncertainty about the extent to which Shallow Meridional Circulation return flow penetrates the latitude of the main rain band or not. The moisture flux convergence quadrupole structure is highlighted by red contours and the dipole at $850 \mathrm{hPa}$ structure is highlighted by green contours (from [25]).

to the southerly track of African Easterly Waves (Figure 8). Notably, at low levels both the moisture convergence and the vertical motion peak at the West African coast. Frictional uplift when the low-level southwesterlies meet the land surface probably plays some role.

A second area of ascent and moisture flux convergence is associated with the heat low over the Sahara $[20,25]$. It is confined to low levels (Figures 6 and 9) and is part of the shallow meridional overturning described by Nolan et al. [32] and Zhang et al. [33]. This second region of ascent corresponds to the northerly track of African Easterly Waves, but waves in this track seldom produce rainfall. This region lies some 8 degrees poleward of the rainfall maximum. It also coincides with the surface manifestation of the ITCZ, that is, the convergence of the southwesterly monsoon flow and the northeasterly Harmattan. The ITCZ and the rainfall maximum are separated by a region of subsidence (Figures 7 and 9), indicating that the ITCZ is effectively "decoupled" 

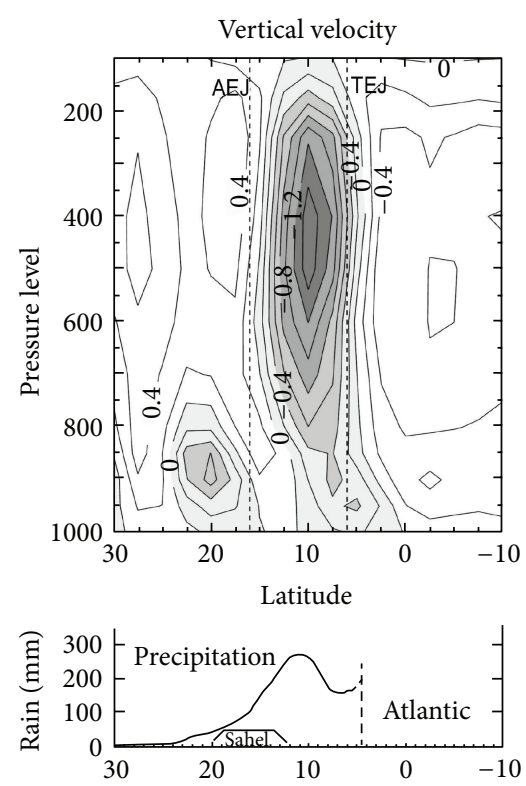

FIgURE 7: Schematic of the rainbelt over West Africa (from [20]). Top diagram is a vertical cross-section of mean vertical motion $\left(10^{-2}\right.$ $\mathrm{hPas}^{-1}$ ) in August. The main region of ascent lies between the axes of the African easterly jet (AEJ) and the tropical easterly jet (TEJ). A shallow region of ascent corresponds to the surface position of the Intertropical Convergence Zone (ITCZ) and the center of the Saharan heat low. The bottom diagram gives mean August rainfall $\left(\mathrm{mm} \mathrm{mo}^{-1}\right.$, averaged for $10^{\circ} \mathrm{W}$ to $10^{\circ} \mathrm{E}$ ) as a function of latitude, with the location of the Sahel indicated on the latitudinal axis.

from the rainbelt. The Sahel lies, on average, in this region of subsidence. The two regions of ascent merge in the wettest years in the Sahel [36].

2.3. The Monsoon Onset. Another topic that has received much attention in the last decade is the onset of the West African monsoon, including its predictability (e.g., [38]) and association with atmospheric dynamics [39]. A difficulty has been in the approach to defining this onset and several varied parameters have been utilized to do so. Some have defined it in terms of simple rainfall characteristics. Marteau et al. [40], for example, use threshold values of daily rainfall at individual stations to quantify the magnitude and length of the initial wet spell and any subsequent breaks.

The mean onset date over the Sahel is June $24[41,42]$. The onset proceeds slowly and is characterized by a succession of active and inactive phases (breaks in the monsoon) [43]. There is little spatial coherence in the onset dates and, consequently, little predictability [40]. The lack of coherence is a result of the fragmented nature of the active and break phases [44]. The withdrawal phase is relatively abrupt and rather uniformly distributed throughout the entire monsoon region.

Model simulations of Flaounas et al. [45] suggest that large-scale dynamics, extending beyond West Africa, control the monsoon onset and its timing. The onset may be related

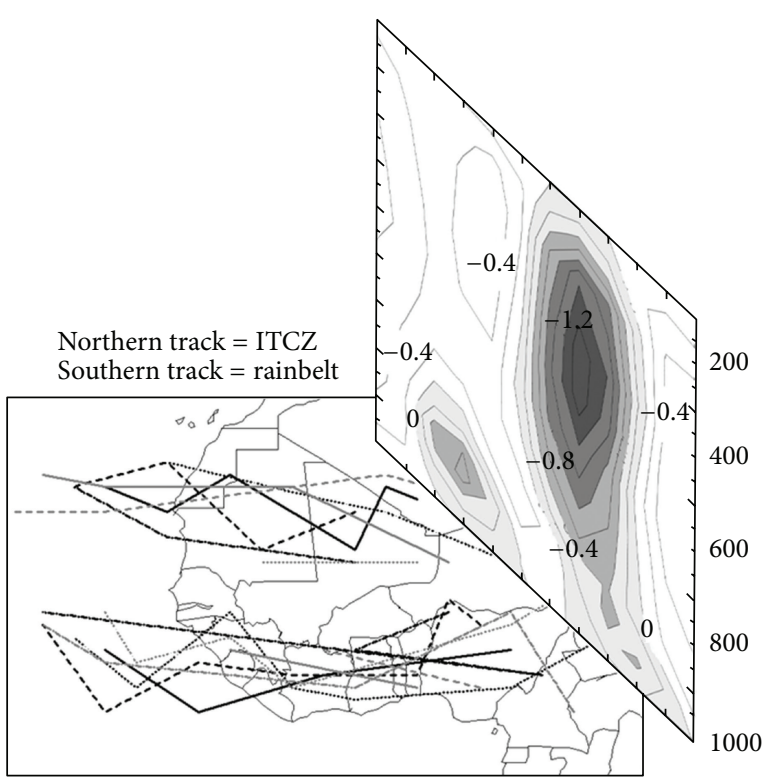

FIGURE 8: The relationship between tracks of African Easterly Waves and the vertical motion fields (omega) over West Africa (based on [36]). The tracks are illustrated using waves of August 1982.

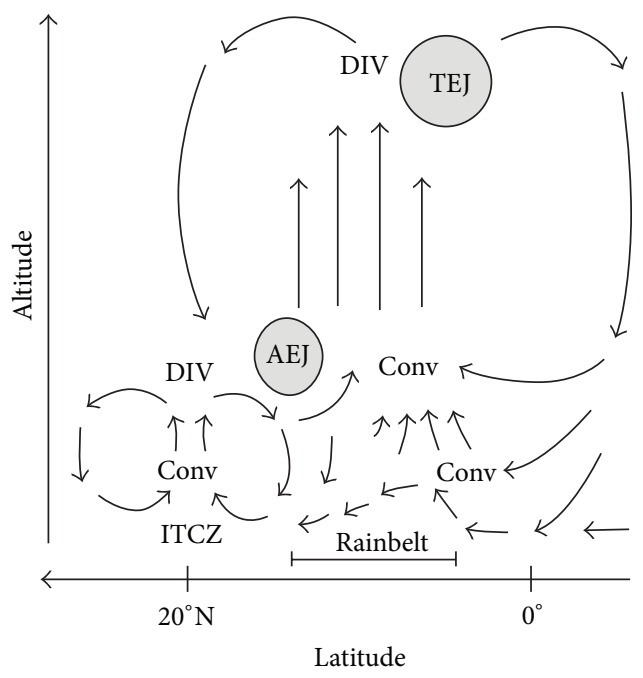

FIgURE 9: Schematic illustration of the revised picture of the West African monsoon (from [20]).

to the Indian monsoon $[46,47]$. The associated convection north of $15^{\circ} \mathrm{N}$ forces a westward propagating Rossby wave that reaches West Africa some 7 to 15 days later, with the wave passage triggering convection in the Sahel.

Drobinski et al. [42] examine a case of late monsoon onset in Niger and Mali and demonstrated additional factors. During 2006 the onset there was delayed until July 3. The delay was associated with an anomalous direction of the AEJ, which flowed northeasterly in a band over the Hoggar and Aír Mountains. There was also an unusually strong northeast Harmattan in the lee of the mountains. The delay appeared to be related to the interaction of the AEJ and orography. 
2.4. Rainfall Distribution in the West African Monsoon. Thorncroft et al. [25] define four phases of the West African monsoon, depending on the location of the rainfall peak: oceanic, coastal, transitional, and Sahelian. During the oceanic phase, between November and mid-April, a broad rainbelt lies just north of the equator. During the subsequent coastal phase, which generally prevails to mid-June, peak rainfall lies over the ocean but in the near-coastal region around 4 to $5^{\circ}$ North $[25,28,48-50]$. The transition phase, when a decrease in rainfall is observed, occurs in early July. Lebel et al. [22] refer to these first three phases collectively as the oceanic regime. The Sahelian phase lasts from mid-July to September. Throughout this phase the rainfall peak is more intense and remains just to the south of the Sahel, around $10^{\circ}$ North. Rainfall in the Sahel is associated with this maximum, which Lebel et al. [22] term the continental regime.

The shift between the maximum at $5^{\circ}$ North in the coastal phase and $10^{\circ}$ North in the continental phase is very abrupt $[41,49]$, evoking the term "monsoon jump". Several authors have proposed explanations for the abrupt shift. Sultan and Janicot [41] suggest it is triggered by westward-propagating disturbances. Sijikumar et al. [51] and Ramel et al. [52] implicate the Saharan heat low, which intensifies and shifts northward at the time of the "jump". Gu and Adler [28] point out that the shift is associated with a northward shift of the African Easterly Jet and associated horizontal and vertical shear zones, as well as the development of westwardpropagating waves. Okumura and Xie [53] suggest that the shift is related to the interaction of the Atlantic equatorial cold tongue and the African monsoon. Sultan et al. [50] suggest that complex interactions among convection, AEJ dynamics and local topography, especially the Ahaggar Plateau and Tibesti highlands, play a role. They also point out that when the heat low is sufficiently intense, the result is a reversal in the potential vorticity gradient and, consequently, the generation of AEWs and convection. Accordingly, the shift commences with a release of potential instability. Then inertial instability shifts the rain band to $10^{\circ} \mathrm{N}[54]$.

What underlies all of these mechanisms is a northward shift and intensification of the latitudinal temperature and pressure gradients over West Africa. The changes in the heat low and the instability mechanisms are probably direct consequences of the increased gradients. The northward shift of the AEJ, shear zones, waves disturbances, and convection can be viewed as results of the aforementioned factors.

There are notable contrasts between the characteristics associated with the two spatial rainfall maxima. One is in the origin of precipitation [28]. Early in the rainy season (MayJune), when the maximum is near the Gulf of Guinea, rainbearing synoptic systems tend to be eastward-propagating wave signals. In the late rainy season, when the maximum lies well into the continental interior, westward-propagating wave signals (i.e., the AEWs) are the dominant rain-bearing synoptic systems. The convective rain rate and the percent of area covered by cumulonimbus anvils are lower and the stratiform fraction of rainfall is higher in the second spatial maximum (which receives the bulk of its rain during the peak monsoon season) $[48,55]$. Consistent with this, the size and organization of convective systems is greater during the peak monsoon season, but rainfall intensity is lower than earlier in the season [56].

The two spatial maxima also differ in the patterns of variability in recent years, with the second maximum (associated with the continental regime) exhibiting much more change. The rainfall peak associated with this regime has also appeared increasingly early in the season [58], with the August peak disappearing in recent years [8].

2.5. Intraseasonal Variability of the Monsoon. Most recent research on the West African monsoon's intraseasonal variability (time scale of 10 to 90 days) has centered on the Madden-Julian Oscillation or MJO. Its origin is generally over the Pacific warm pool, from which an eastward-propagating Kelvin wave and a westward-propagating Rossby wave emanate. A similar phenomenon can also occur over the Indian Ocean [59], providing a link between the African and Indian monsoons [60]. Occurring in the boreal summer, these waves meet over West Africa, where they spawn convection and modulate the wind regime, easterly wave activity, and moisture transport [60-62]. Of the two waves, the westward propagating Rossby waves appear to be most important for West Africa [59, 63, 64]. The intraseasonal variability peaks in two distinct frequency bands, 10 to 30 days and 30 to 90 days. The former is best developed in the Sahel region. Variance is maximized around 15 days $[61,65]$, so that it may be part of the quasi-biweekly zonal dipole in convection identified by Mounier et al. [66].

The MJO does influence Sahel rainfall $[63,65]$, as well as the systems that modulate its variability, such as AEWs, the AEJ, and the low-level monsoon westerlies [64]. However, the MJO's greatest impact is in the latitudes to the south of the Sahel, a result of the near-equatorial track of both the Kelvin and Rossby waves. Intraseasonal variance in the Sahel itself is comparatively small [67], so that the MJO's overall impact on Sahel rainfall (as opposed to the monsoon overall) may be small. There also seems to be little relationship between interannual variability of MJO amplitude and the year-toyear variability on the 30 to 90 day time scale. This has not yet been examined for the shorter 10 to 30 day time scale, which has higher variance in the Sahel.

Several other factors modulate the intraseasonal variability of the West African monsoon. These include two-way interactions between the AEJ and transient systems [68], convection in the "trigger" region near Darfur [69], and intraseasonal variations of the Saharan heat low on the 10 to 25 day time scale [70]. The SHL variations appear to be linked to mid-latitude events [71], such as Mediterranean cold surges [72] and dry air intrusions [73]. Northward bursts of the monsoon also operate on intraseasonal time scales, bringing summer rainfall as far north as the Hoggar [35].

\section{Interannual Variability}

The interannual variability of rainfall in the Sahel became a topic of great concern as a result of the drought conditions that began in the late 1960s. One of the results of early research on the region was identification of several important-and perhaps unique-features of rainfall variability in the region. 


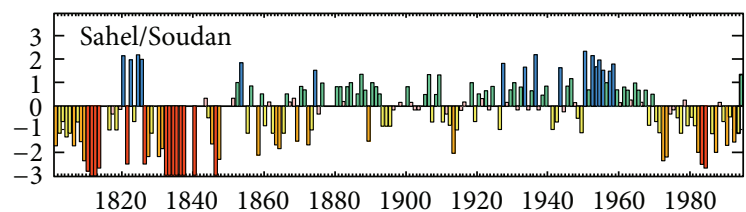

FIgURE 10: Precipitation variations in the Sahel/Soudan region of West Africa during the nineteenth and twentieth century. Precipitation is indicated as a "wetness" index, which varies from -3 to +3 (from [82]).

These include an extremely large spatial scale of annual and decadal anomalies [7,74], decadal and interdecadal persistence of anomalies that is especially pronounced in the central Sahel $[4,6,75]$, extreme magnitude of variability [76] and a dominant contribution of only two of the rainy season months (August and September) to the interannual/ interdecadal variability $[6,77]$. This section commences with a description of the variability of annual rainfall over the course of the last two centuries, including the debate about recent trends, and follows with a discussion of these general spatiotemporal characteristics of Sahel rainfall.

3.1. Temporal Trends. There has been nearly unanimous agreement about the course of Sahel rainfall from the 1950s to the 1990s (e.g., [5, 78-80]). Indices derived independently from diverse data sets are strongly correlated [81] and indicate that the 1970s and 1980s were markedly drier than the two previous decades. The most intense drought occurred in the early 1980s. Recent work $[82,83]$ puts these droughts in the context of fluctuations during the last two centuries (Figure 10) and suggests that even more extreme conditions prevailed in most of the first half of the nineteenth century.

Early works on the region's rainfall variability described two prior periods of drought within the twentieth century. The first was in the 1910s and the second was in the 1940s. The roughly 30 -year spread between each drought interval unfortunately gave way in the 1970 s to speculation that a 30 year cycle existed in the region and that it was robust enough to serve in a predictive capacity (e.g., [84]).

The recurrence of drought in the 1980s showed the fallacy of that idea. It also demonstrated that the "droughts" of the 1910s and 1940s were weak, compared to those of the 1970s and 1980s (Figure 10). In the early 1980s rainfall fell to some $60 \%$ of the long-term mean [3]. In contrast, rainfall conditions were very good in the 1950s and early 1960s.

Conditions post-1990 have received less attention, in part because of the difficulty of obtaining gauge data since that time. Nicholson et al. [76] and L'Hôte et al. [81] conclude that the drought continued through the 1990s, with the exception of high rainfall in 1994 and 1999. Ozer et al. [86] suggested that, in fact, the region was entering a more humid period, citing flooding as a point of evidence. L'Hote et al. [79] conclusively showed that the flooding had causes other than high rainfall. Hastenrath and Polzen [87] show a continual increase of rainfall since the 1980s, with several very wet years in the 1990s. Fontaine et al. [88] concluded that deep convection significantly increased since the mid-1990s and also moved northwestward, in conjunction with a similar shift in the Saharan Heat Low.

The most comprehensive analyses of more recent conditions are those of Nicholson [3], Ali and Lebel [2], and Lebel and Ali [8]. These analyses, as well as that of Mahé and Paturel [89] generally indicated conditions of improved rainfall in the late 1990s and a few following years. A greening up in the regime, as shown by vegetation index data, seemed to confirm this (e.g., [90-93]). However, the degree of improvement varied geographically.

Nicholson [3] examined the season as a whole and the month of August for eight sectors of the Sahel. These included four latitudinal strips, each spanning two degrees of latitude, and the strips were divided into east and west sectors (with a division at $15^{\circ} \mathrm{E}$ ). Updating century-long gauge time series with TRMM satellite data for the years 1999 to 2003, she concluded that recovery was greater in the western Sahel (west of $15^{\circ} \mathrm{E}$ ) than in the eastern Sahel and that the recovery was relatively weak in the month of August (Figure 11). In all but the northern-most regions, the rainfall during the period 1998 to 2003 was roughly comparable to that of the 1950s wet period. In the east the patterns in rainfall were more strongly dependent upon latitude. The years 2000 to 2003 were relatively dry in the north and near the long-term mean in the central Sahel, while the years 1994 to 1999 were relatively wet and comparable to the 1950s. In the southernmost latitudes of the eastern Sahel, 1998 to 2003 appear to have experienced record rainfall.

A weakness of that study was that the rainfall conditions of the years 1998 to 2003 were established from satellite data from the Tropical Rainfall Measuring Mission (TRMM), while earlier rainfall conditions were established from gauges. However, a validation of TRMM that compared gauges and satellite estimates for the year 1998 [94] showed zero bias in the TRMM estimates (i.e., the magnitude of TRMM matches that of the gauges) and the root mean square error of the TRMM estimates is $0.7 / 0.9 \mathrm{~mm} /$ day for seasonal/August rainfall.

Lebel and Ali [8] provided further detail, examining conditions through 2007 and considering three longitudinal sectors within the region termed "western Sahel" by Nicholson. Their time series, shown in Figure 12, were more homogeneous, as they were produced solely from gauge data. Some recovery was shown in recent years, but it was confined to the eastern-most regions. The drought continued unabated in the west (longitudes $10^{\circ} \mathrm{W}$ to $15^{\circ} \mathrm{W}$ ), where mean rainfall for the period 1990-2007 was roughly equal to the mean for the acknowledged drought period 1970-1989. In the central Sahel $\left(0\right.$ to $\left.5^{\circ} \mathrm{E}\right)$ there was limited recovery. Rainfall for 1990 2007 was only some $10 \%$ above the mean for $1970-89$ and well below the average for the period 1950-1969. That study also noted the disappearance of the pronounced August peak, consistent with the finding of Nicholson [3] that the recovery in August was very weak. In addition, interannual variability was greater in recent years than in the previous 40 years $[2,87]$.

Few studies have examined post-2007 years. Fontaine et al. [88] suggest that in 2008 rainfall in the central Sahel was near or just above the long-term mean. A website maintained 

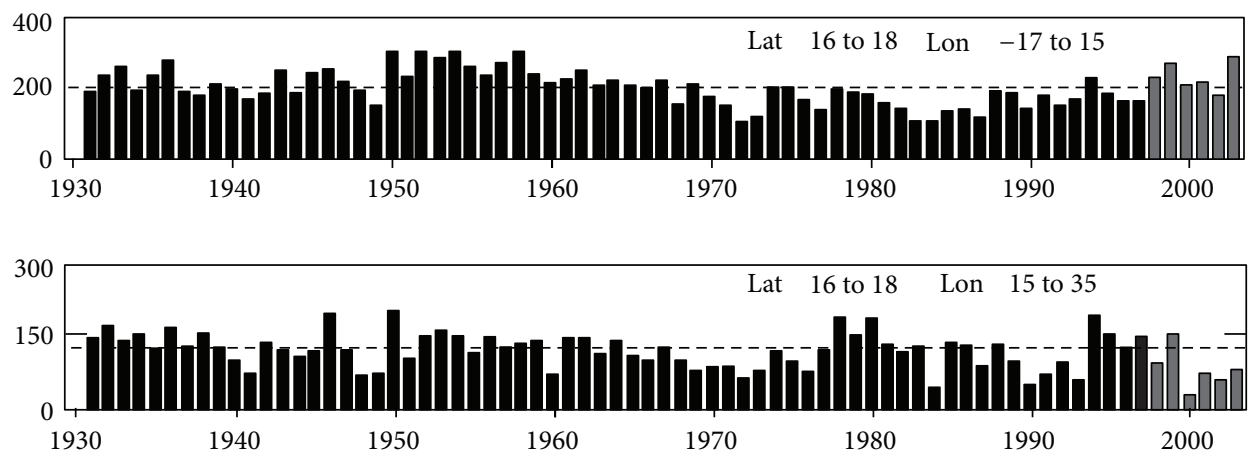

FIGURE 11: Mean annual rainfall (mm) in the eastern (top) and western (bottom) Sahel in the latitudinal band from $16^{\circ} \mathrm{N}$ to $18^{\circ} \mathrm{N}$ (from [3]).

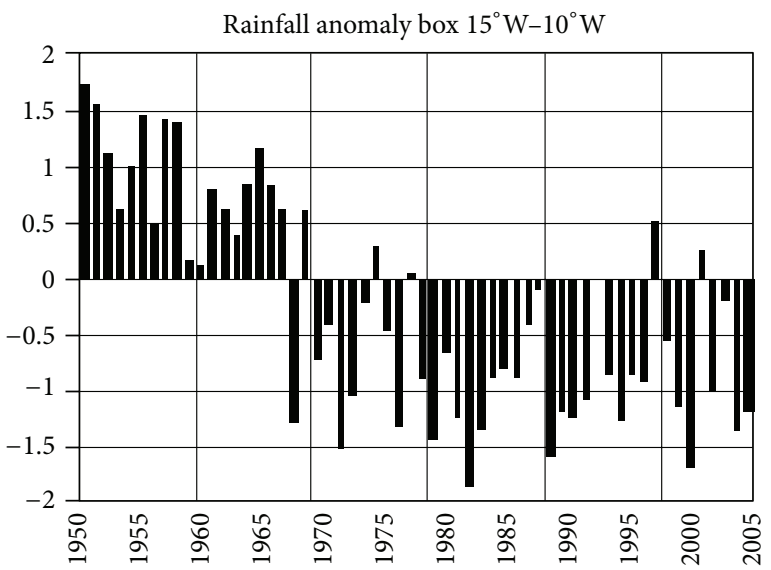

(a)

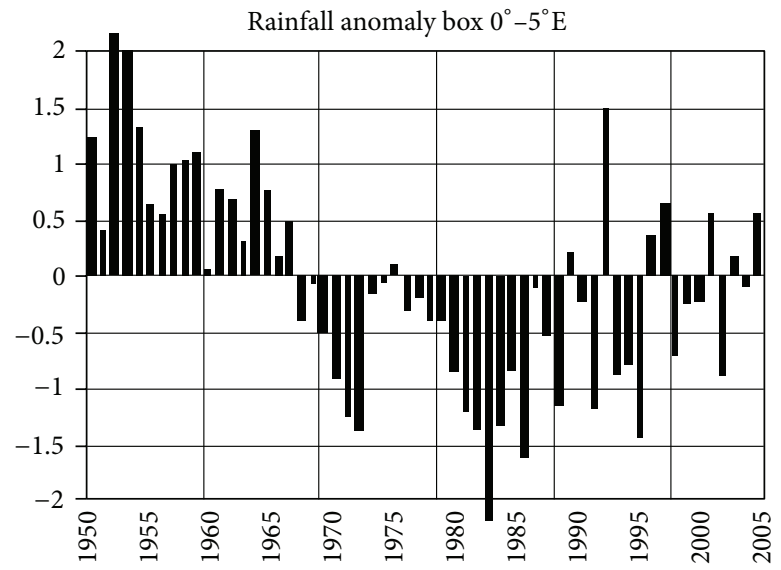

(b)

FIGURE 12: Rainfall anomalies in the far western and central Sahel, with rainfall expressed in units of standard deviations (from [8]).

by the University of Washington (http://jisao.washington .edu/data/sahel/) confirms this for the region as a whole and indicates near normal rainfall in 2009, extremely high rainfall (comparable to the 1950s) in 2010 and abnormally dry conditions again in 2011. Fontaine et al. [88] also showed that the circulation characteristics associated with previous wet conditions in the Sahel have again been occurring since the 1990s. These include a reinforcement of the low-level westerly winds south of the Sahel, a northward shift in the latitude of the African Easterly Jet, and an intensification of the Tropical Easterly Jet $[30,36]$.

Another controversial point concerning interannual variability is whether, in fact, the long, dry interval has ended [101]. Nicholson [3] confirmed a recovery of wetter conditions in much of the Sahel during the period 1998 to 2003. Ozer et al. [86] also indicated that the Sahel drought ended in the 1990s. On the other hand, L'Hôte et al. [81], examining a Sahel rainfall index that extends from 1896 to 2000, concluded that the drought continued through the 1990s.

The controversy stems in part from changes in the character of rainfall conditions during the last decade or so. The spatial continuity was much weaker than in previous years, as was the year-to year-persistence. Thus, the answer to whether or not the drought ended in the 1990s depends in part on the region, years, and even months evaluated.

3.2. Spatiotemporal Characteristics of Rainfall Variability in the Sahel. The change in rainfall conditions starting 1968 was very abrupt and very extreme. For the Sahel latitudes of $15^{\circ} \mathrm{N}$ to $20^{\circ} \mathrm{N}$ mean August rainfall from 1968 to 1997 was roughly $37 \%$ lower than the mean for the thirty-year period 1931 to 1960 . In the Sahelo-Saharan zone just to the north, the reduction was 55\% [76]. There is probably nowhere else in the world where decadal means change so dramatically. There was a general shift of the rainfall isohyets of roughly 1 to 2 degrees of latitude $[5,102]$. Several early studies (e.g., [77]) showed the decline in rainfall is associated mainly with conditions in August and September, despite the fact that those months contribute only $50 \%$ to $60 \%$ of the rainfall in the Sahel.

A related, perhaps unique, characteristic of interannual variability in the Sahel is its decadal to multidecadal persistence $[4,75]$. Rainfall was near or above the long-term mean in every year from 1950 to 1967 (Figure 11). It dropped abruptly in 1968 and remained below the long-term mean in every year from 1969 to 1997 [3]. This persistence was 

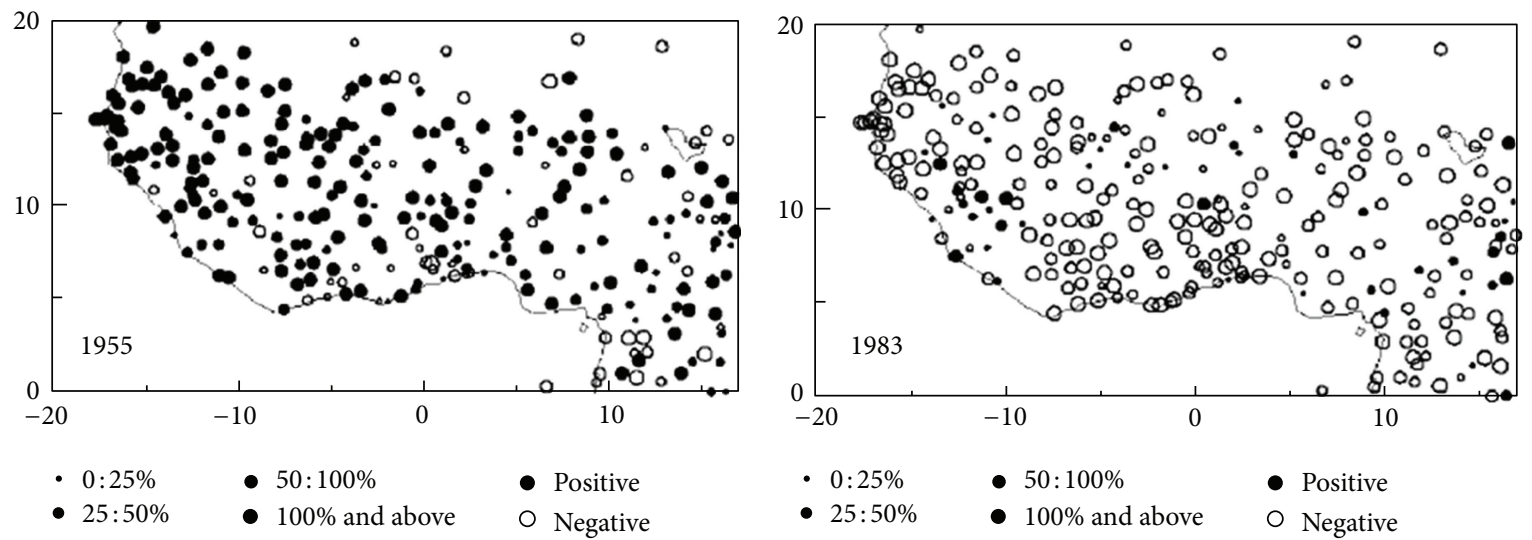

(a)
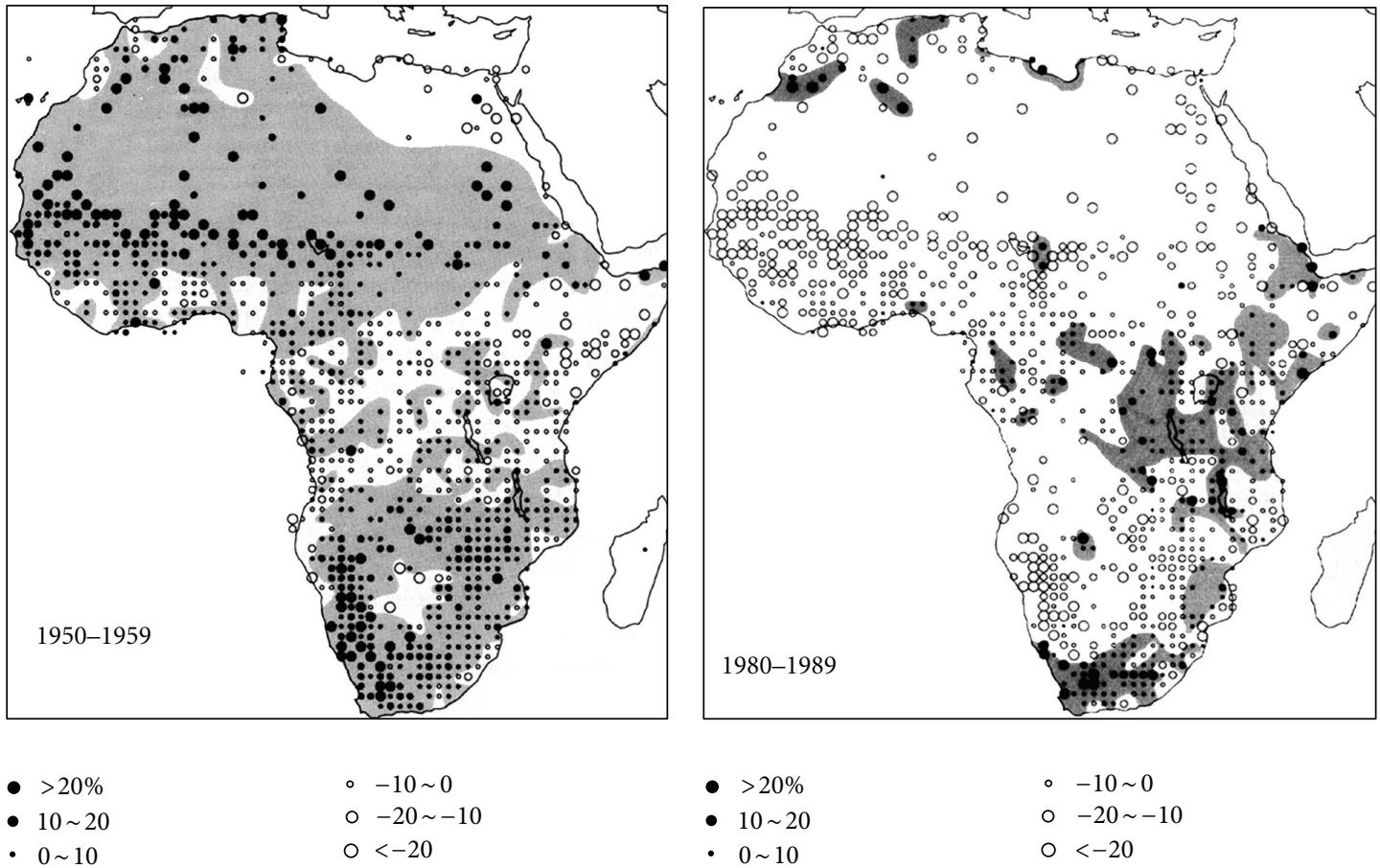

(b)

(c)

FIgURE 13: (a) Rainfall in 1983 and 1955 during the West African rainy season (June through September) (expressed in units of standard departure, based on means for the period 1968-1997) (from [37]). (b) Same but averaged for the decades 1950-59 and 1980-89. In (a) circles indicate rainfall stations; size of the circle indicates magnitude of the anomaly, with open circles indicating negative anomalies and shaded circles indicating positive anomalies (from [76]). In (b) and (c) circles indicate one degree averages.

originally thought to reflect the role of land-surface forcing in perpetuating rainfall anomalies (e.g., [102]). One argument in favor of this interpretation is that the persistence is strongest in the central Sahel, away from the influence of either the Atlantic or Indian Oceans or the Mediterranean [6]. More recent work has shown the issue to be much more complex. Related issues are further discussed in Sections 7 and 8.

The spatial coherence of annual and decadal anomalies is also exceedingly strong. This is illustrated in Figure 13, which shows anomalies in a wet year (1958) and a dry year (1988) [37] and for the decades of the 1950s and the 1980s. In 1955 rainfall was $50 \%$ to more than $100 \%$ above the long-term mean at the vast majority of stations. In 1983 negative anomalies of that same magnitude prevailed at nearly every station. For the 1950s decade rainfall was well above the long-term mean at stations throughout the Sahel, while the opposite pattern prevailed in the 1980s at virtually every station throughout the Sahel and Guinea coast [102].

The pattern of opposition between the Sahel and the more humid Guinea coast to the south, termed the rainfall dipole, is one of two major modes of rainfall variability over West Africa. The other is anomalous conditions of the same sign throughout the region. Nicholson and Grist [103] developed a conceptual model of these modes (see also [36]) that relates 

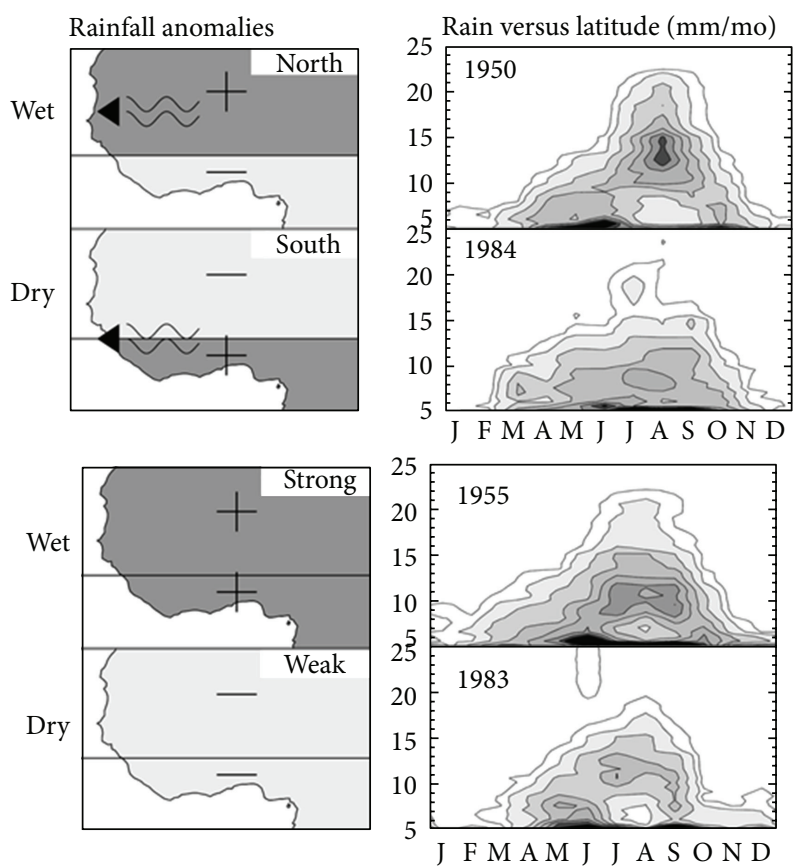

Rainfall

Above normal Below normal

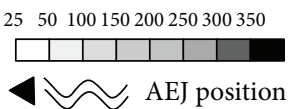

Figure 14: (left) Schematic illustrating the four most common rainfall anomaly patterns over West Africa (from [36]). Light shading indicates below normal rainfall; dark shading indicates above normal rainfall. These are associated with a north or south displacement of the tropical rainbelt or an intensification or weakening of the tropical rainbelt over West Africa. The AEJ position is also indicated. (right) Rainfall as a function of latitude in the months of June through September for 1950 and 1984 (dipole years with a north/south displacement of the rainbelt, respectively and 1955 and 1983, non-dipole years with an intensification/weakening of the rainbelt, respectively).

the dipole to a latitudinal shift of the tropical rainbelt over West Africa and relates the mode with anomalies of uniform sign to intensification or weakening of the tropical rainbelt. The spatial patterns and latitudinal distribution of rainfall associated with these modes are shown in Figure 14. Notably, the dipole pattern appears to have disappeared in recent decades [104].

Although the spatial coherence is strong in both the north-south and east-west directions, notable differences appear between the western, central, and far eastern Sahel. This was particularly noteworthy during the recovery from the long drying trend $[3,8]$. The contrasts reflect differences in the dominant circulation systems (e.g., degree of development of the TEJ versus AEJ) $[1,36]$, the location with respect to the Saharan Heat Low, and the degree of control by the various oceans (see Section 7).

There is some disagreement as to whether or not there is a relationship between the number of rainfall events and year-to-year variability. There is, however, a strong consensus that it is mainly changes in the peak rainy season months

that determine the year's character $[6,56,58,105]$. Bell and Lamb [56] looked at individual convective events and found a relationship between event size/organization and total annual rainfall. They found that the long decline in Sahel rainfall since the 1950s was linked to a decrease in both size and intensity of events, but not to the overall number of events. Nicholson [102] and Lebel et al. [22] similarly found that the annual rainfall in the Sahel is related primarily to the number of occurrences of very intense systems. For example, the difference between a wet August and a dry August at Sahelian stations could be merely one or two events with rainfall on the order of $40 \mathrm{~mm}$ to $180 \mathrm{~mm}$ per day. In the dry August there were few events with more than $50 \mathrm{~mm}$ per day at the stations examined. However, Le Lay and Galle [58] concluded that the long decline in annual rainfall was linked mainly to a decrease in the number of rain events, in agreement with Balme et al. [106]. Frappart et al. [107], examining various locations in Mali, suggested that the role of the number of events varies by region.

\section{Atmospheric Circulation and Links to Rainfall and Its Variability}

Some of the earliest studies on interannual variability in the Sahel related changes in rainfall primarily to anomalous latitudinal excursions of the ITCZ [108, 109]. Other studies clearly demonstrated that the link between ITCZ position and Sahel rainfall was tenuous at best (e.g., $[7,110])$, but a relationship to the intensity of the ITCZ (as defined by rainfall intensity) was apparent.

A major paradigm shift has occurred, in that it is now well established that interannual variability instead is linked to changes in higher-level circulation features. These include the African Easterly Jet (AEJ), the Tropical Easterly Jet (TEJ), and two low-level westerly jets, the African Westerly Jet (AWJ) over the continent and the West African Westerly Jet (WAWJ) over the Atlantic. The existence of the low-level jets was only recently established. Important circulation features in the region also include a low-level nocturnal jet, the low-level Bodele jet over the Sahara, and the Saharan heat low. Each of these features and its climatic importance, particularly with respect to interannual variability, is described here. Several of them are evident in the zonal mean circulation shown in Figure 15. The spatial configuration of the three major jets is depicted in Figure 6. The TEJ lies in the upper-troposphere around 150 to $200 \mathrm{mb}$, the AEJ lies in the mid-troposphere at 650 to $700 \mathrm{mb}$, and the AWJ is in the lower troposphere, with a core at roughly $850 \mathrm{mb}$.

4.1. African Easterly Jet. The African Easterly Jet has received the most attention because of its role in generating African Easterly Waves. It develops in response to the latitudinal temperature gradient between the Sahara and the Atlantic Ocean to the south [1]. Consequently it has a strong eastwest orientation. The temperature gradient is particularly strong from June through August, while the AEJ exhibits a maximum intensity in May and June, prior to the onset of the Sahel rainy season. Chen [111] suggests the AEJ owes its existence to the Saharan High, along the periphery of which 


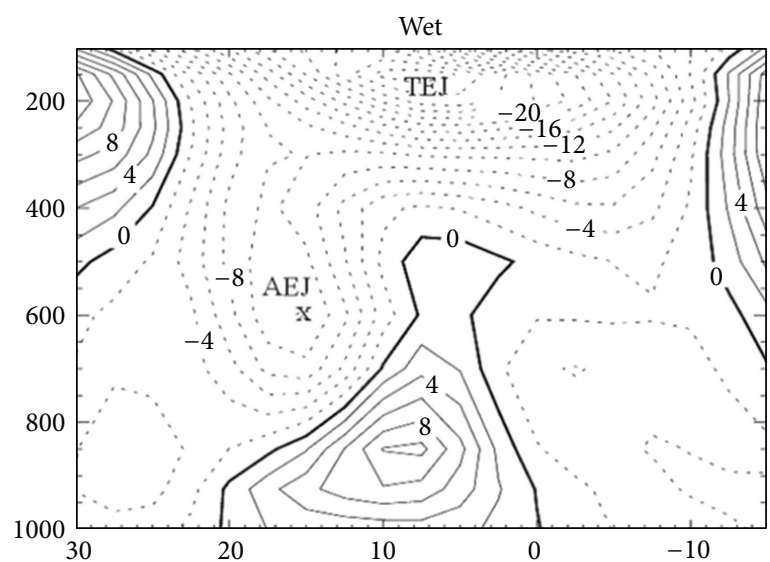

(a)

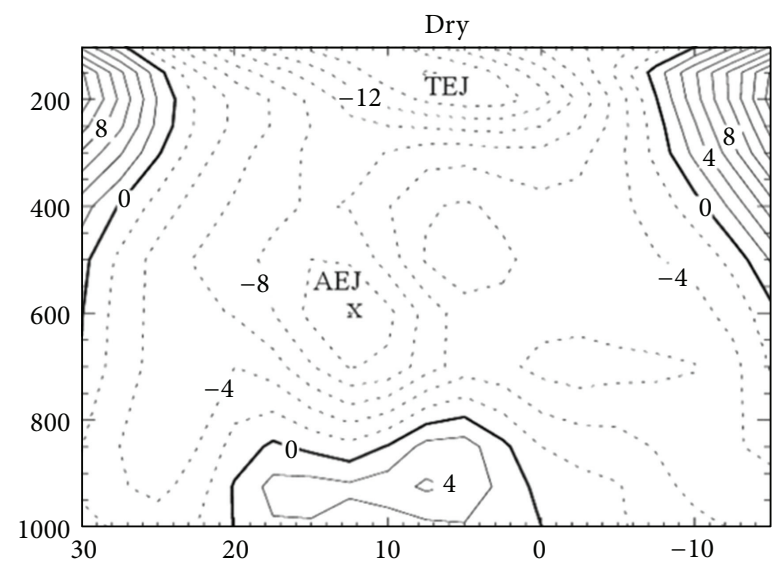

(b)

FIGURE 15: Vertical cross-sections of zonal wind $\left(\mathrm{m} \mathrm{s}^{-1}\right)$ in wet and dry years. Dashed lines/solid lines correspond to easterly/westerly winds. The tropical easterly jet (TEJ) and the mid-tropospheric African easterly jet (AEJ) is indicated (from [30]).

it lies. This is consistent with the role of the temperature gradient. Moist processes contribute to its intensification and meridional extent Cornforth et al. [112]. Aerosols also influence its development [113].

The AEJ is maintained by both the deep and shallow meridional circulations associated with the monsoon, driven by the local Hadley circulation and the Saharan Heat Low, respectively [31,114]. The role of the heat low is most important during the pre- and postmonsoon seasons [115]. During the peak monsoon boundary layer processes become the dominant control. Chen [111] suggests an alternate explanation for its maintenance: Coriolis acceleration associated with divergent northerlies in the mid-troposphere over the ChadSudan region.

Burpee [116] established that the characteristics of the AEJ meet the criteria for combined barotropic-baroclinic instability. Since the time of his analysis it has thus been assumed that this instability is the major factor in the development of easterly waves over West Africa. More recent studies have suggested that this instability is a necessary but insufficient condition for wave development (e.g., [117]). The $\mathrm{AEJ}$ is also unstable with respect to convective heating, as shown by a reversal of the potential vorticity gradient in the vicinity of the jet $[117,118]$.

The AEJ is usually treated as a single entity, with zonally symmetric structure and a core lying on average over the western Sahel. Thus, many studies of the jet have assumed a uniform basic state. Hall et al. [119] demonstrate that, instead, the AEJ has a zonally varying structure. Moreover, this jet appears to have two independent cores that merge on occasion [120]. The eastern core is somewhat weaker and several degrees further equatorward.

Nicholson and Grist [1] derived the mean characteristics for both the eastern and western sectors of the AEJ. The jet is strongest in May and June, when its mean core speed is on the order of $12 \mathrm{~m} \mathrm{~s}^{-1}$ in the western sector $\left(10^{\circ} \mathrm{W}\right.$ to $10^{\circ}$ East $)$ and $10 \mathrm{~m} \mathrm{~s}^{-1}$ in the eastern sector $\left(10^{\circ}\right.$ East to $30^{\circ}$ East). Speeds decrease by some $2 \mathrm{~m} \mathrm{~s}^{-1}$ during the Sahelian phase of the monsoon in the boreal summer. The mean monthly speed of either core can attain $16 \mathrm{~m} \mathrm{~s}^{-1}$ during the boreal summer. The intensity of both cores changes markedly from year to year, with the western core being more prominent in wet years and the eastern core being more prominent in dry years.

The latitude of the western core is relatively stable from year to year, on average about $16^{\circ}$ North during the boreal summer [120]. The latitude of the eastern core varies markedly from year to year and is inversely correlated with core intensity. Its mean latitude over the eastern Sahel is $13^{\circ} \mathrm{N}$ during the boreal summer, but ranges from $20^{\circ} \mathrm{N}$ in some wet years to $10^{\circ} \mathrm{N}$ in some dry years. In the boreal winter both cores shift equatorward to about $2^{\circ} \mathrm{N}$.

Intraseasonal shifts are also apparent in the latitude of the AEJ's core. This occurs in response to the passage of Mesoscale Convective Systems, which cause a north-south split in the jet [121]. An "effective Coriolis force" associated with southerly flow at jet-level contributes to the formation of the secondary jet while the northward flow south of the MCS weakens the original jet. This is a meridional circulation associated with the MCS. The original jet is displaced southward and a secondary jet forms to its north, consistent with the split jet observed in JET2000 [13].

4.2. Tropical Easterly Jet. Much less work has been done on the Tropical Easterly Jet, with most studies focusing on the TEJ in the Asian sector, where its core lies (e.g., [122-124]). The TEJ develops as a response to the intense north-south temperature gradient between the Himalayan plateau and the Indian Ocean. It is energetically maintained via tropical divergent circulations associated with the east-west Walker circulation and north-south Hadley circulation. The TEJ's mean speed over the eastern Sahel during the boreal summer is roughly $18 \mathrm{~m} \mathrm{~s}^{-1}$. It has frequently been described as a boreal summer feature, but this jet is also very strong in January through March, when it is located in in the Southern Hemisphere with a core around 5 to $10^{\circ} \mathrm{S}$ [1]. In contrast to the AEJ, the TEJ over West Africa exhibits little latitudinal 
change from year to year but its speed and east-west extent vary greatly [30, 36, 103, 125].

The role played by the TEJ in interannual variability has been well documented. A stronger/weaker TEJ has been linked to wetter/drier conditions in the Sahel (e.g., [30, 36, 126]), western equatorial Africa [82, 120], Ethiopia [127], and India [124] and to a decreased/increased number of cyclones in the Bay of Bengal [128]. Its link to rainfall in equatorial Africa is apparent in both the boreal spring and boreal autumn. It also has been implicated as a factor in the mean climate of West Africa [129-131].

The relationship of TEJ intensity to interannual variability is particularly strong in the Sahel. In some wet years its mean speed over the Sahel in August approaches $30 \mathrm{~m} \mathrm{~s}^{-1}$ (Figure 15) and the jet is evident across the east-west extent of Africa. In dry years, its maximum speed over the Sahel can be less than $10 \mathrm{~m} \mathrm{~s}^{-1}$ and it is evident only in the eastern Sahel. The TEJ's speed and spatial extent have diminished between the 1950 s and the 1990s, commensurate with drier conditions in the Sahel $[103,125,128]$.

Unfortunately, the reasons for its change in intensity are not fully understood. Chen and van Loon [132] noted that the TEJ tends to be weaker during warm phases of the Pacific ENSO. Dezfuli and Nicholson $[82,100]$ noted that its intensity appears to change in relationship to the intensity of the extratropical Southern Hemisphere westerlies during the May-to-June and October-to-December seasons. That seems to be the case during the Sahel rainy season of the boreal summer as well [30]. The stronger jet is also commensurate with cooler upper-troposphere tropical temperatures and latitudinal temperature gradients [36].

The link between the TEJ and rainfall appears to be primarily upper-level divergence associated with the jet core. The divergence results from strong meridional components associated with the TEJ over Africa [1]. This pattern is particularly pronounced in wet years in the Sahel, and this appears to play a role in its impact on rainfall [37]. This is further consistent with the observation that a stronger TEJ is linked not only to more rainfall in the Sahel, but also a more intense rainbelt (e.g., [36, 37]).

An additional mechanism may relate to the dynamic instability of the TEJ $[133,134]$. Both barotropic and combined barotropic-baroclinic instability have been demonstrated. This permits the development of waves on the TEJ. Such waves have been observed over West Africa [135] and their characteristics match those predicted by a numerical simulation of African wave activity [136]. Such waves may play a role in the development of extreme precipitation events in the western Sahel.

\subsection{Low Level Jets}

4.3.1. Bodele Jet. The third easterly jet in the circulation regime over Sahelian Africa is the Bodélé Low-Level Jet. It was first documented by Washington and Todd [137] and was shown to be a factor in the tremendous amounts of dust generated in the Bodélé Depression to the north of Lake Chad. The jet is present in all months except August, but is strongest in January and weakest in July. Its mean speed in the core is $8 \mathrm{~m} \mathrm{~s}^{-1}$. Its easterly flow also has a weak northerly component. The Bodélé Low Level Jet has a strong diurnal cycle, with peak winds occurring in the evening and minimum speeds during the day [138].

The jet's core lies near $18^{\circ} \mathrm{N}$ and $20^{\circ} \mathrm{E}$ at $925 \mathrm{mb}$. This location is the exit region of the gap between the Tibesti and Ennedi massifs. The jet is absent further west where the topography becomes relatively flat. Hence orography effects play a role in its development $[139,140]$.

4.4. African Westerly Jet. The low-level African Westerly Jet (AWJ) was first described by Grist and Nicholson [30]. It is not apparent in all years. Rather, its development appears to be limited to wet years in the Sahel. In these years it is on the order of $10 \mathrm{~m} \mathrm{~s}^{-1}$ during the late boreal summer (July to September) and it extends well into the mid-troposphere. In dry years it all but disappears in the monthly mean and the wind shifts to easterly above the $850 \mathrm{mb}$ level. The westerly maximum then lies in the monsoon layer at about $925 \mathrm{mb}$ and westerly speeds are on the order of 2 to $4 \mathrm{~m} \mathrm{~s}^{-1}$.

The AWJ is not simply part of the southwest monsoon flow. There is a marked directional discontinuity, with the disappearance of the southerly component [1]. Moreover, when the AWJ is apparent, its core is well above the monsoon layer. During August, the height of the Sahel rainy season, the core speed of the AWJ is well correlated with the surface pressure gradient between the latitude of $20^{\circ} \mathrm{S}$ and $20^{\circ} \mathrm{N}$ ( $r=.84$ over 58 years). However, the jet is not a geostrophic response to this gradient. The region is too close to the equator for geostrophic balance and the jet develops in a narrow belt in the sector where the cross-equatorial pressure gradient is weakest. Its origin appears to be linked to inertial instability that develops in response to this pressure gradient $[95,141]$. The inertial instability enhances both the jet and rainfall. The correlation during August between the AWJ speed and Sahel rainfall during the same 58 years is .75 .

4.5. West African Westerly Jet. A low-level westerly jet over the Atlantic was first described by Grodsky et al. [142]. It appears as a near-surface wind maximum at over the equatorial Atlantic and is evident from May through September. This jet, termed the West African Westerly Jet (WAWJ) by $\mathrm{Pu}$ and Cook [143], is best developed around $10^{\circ} \mathrm{N}$ and lies in the region where the trade winds converge. Not to be confused with the AWJ jet over the continent described by [144], this marine jet appears to be the surface manifestation of a midtropospheric westerly wind maximum. Its speed can reach 10 to $15 \mathrm{~m} \mathrm{~s}^{-1}$.

The importance of the WAWJ may lie in the moisture it transports from the Atlantic to the continent in the zone from 8 degrees to 11 degrees north. Although the transport does not extend into the Sahel, there is a strong correlation between the speed of this jet and western Sahel rainfall [142]. The moisture transport by this jet has much greater decadal-scale variability than that associated with the southwest monsoon and it may bring moisture into the region in years when the monsoon is weak [145]. The West African Westerly Jet is also important for stabilizing the regional vorticity balance by introducing strong relative vorticity gradients. 
4.6. Nocturnal Jets in the Monsoon. Examination of the boundary layer at several locations within the West African monsoon showed the existence of a nocturnal low-level jet (NNLJ) [29]. It lies generally within the layer 200 to $400 \mathrm{~m}$ above the surface $[146,147]$. Studies at Niamey, Niger (c. $14^{\circ}$ $\mathrm{N})$ and at Nangatchori, Benin (c. $10^{\circ} \mathrm{N}$ ) showed that this feature tends to occur throughout the year. The nocturnal jet reaches a maximum around the onset of the monsoon and disappears late in the season when the rainbelt commences its southward migration [148].

The development of the jet is linked to the diurnal variation of the boundary layer [29]. This cycle is maximized in the northern part of the monsoon layer, where the meridional pressure gradient is strongest. Typical of arid and semi-arid regions, the West African boundary layer is associated with daytime turbulence and comparatively laminar flow at night. Mean daytime wind speeds are relatively low. An inversion layer develops after sunset, following by the development of the jet. Maximum speeds are commonly on the order of 8 to $10 \mathrm{~m} \mathrm{~s}^{-1}$, but can exceed $15 \mathrm{~m} \mathrm{~s}^{-1}[147,149]$. The direction of the NLLJ depends on which side of the Intertropical Discontinuity it occurs, being generally southwesterly when imbedded with the monsoon flow and northeasterly when imbedded within the Harmattan $[29,147]$.

The NLLJ transports moisture into the monsoon, especially around its onset [148]. This helps to sustain deep convection [150]. It also appears to be responsible for the stratus cloud decks that often form in the Soudanian and Guinean climate zones of West Africa (i.e., south of the Sahel to the Guinea coast) [151].

4.7. Saharan Heat Low. The presence of an intensive heat low in the western Sahara has long been established. Generally assumed to be a passive component of the monsoon system, the Saharan Heat Low (SHL) has been shown by recent research to be a key element in the monsoon system and its variability. A causal link between the strength of the heat low and Sahel rainfall exists on intaseasonal [152], interannual and decadal time scales [153].

The heat low, also called the West African heat low, is a region of exceedingly high surface temperatures and low surface pressure [154]. It is a shallow system, a thermal depression generally below $700 \mathrm{mb}$ [26]. While present throughout the boreal summer, it undergoes synoptic and intraseasonal changes in intensity.

The Saharan Heat Low shows a pronounced seasonal migration. Starting from a location south of the Darfur mountains in the boreal winter (November to March), it migrates northwestward to a location in the western Sahara. It maintains approximately the same location, between the Hoggar and the Atlas mountains, between late June and September [154]. It generally reaches this position about 5 days prior to the onset of the West African monsoon.

Chauvin et al. [71] suggest that the SHL is a bridge between the midlatitudes and the West African monsoon. They identify what they term a west phase and an east phase. In the west phase, maximum temperature is over the coast of Morocco-Mauritania and a minimum appears between Libya and Sicily. The east phase has the opposite temperature structure. The west phase is preceded by large-scale intraseasonal fluctuations in the mid-latitudes, such as Rossby waves. It is concomitant with enhanced convection over the Darfur region, an area shown to trigger African Easterly Waves (e.g., [155]).

The intraseasonal fluctuations in the intensity of the Saharan Heat Low are concentrated in two bands, 3 to 10 day and 10 to 30 day $[70,152]$. Variance in the higher frequency band peaks at roughly 5 days [156]. This suggests a link to wave development and convection, but the link is not clear. Lavaysse et al. [152] identified strong and weak phases of the heat low and evaluated circulation, temperature and convection within them. They showed increased/decreased convection in the central/western Sahel in the strong phase, in response to an increase/decrease in the low-level cyclonic circulation around the heat low. Hence, changes in the intensity of the SHL affect the intensity of the monsoon circulation further south [29].

Lavaysse et al. [26] noted widespread convective activity in the Sahel during a two-week period in September 2006 in which the intensity of the Saharan Heat Low was abnormally weak. This apparent contradiction appears to have resulted from the interaction of the SHL with a mid-latitude depression that brought a cold surge into Libya at $700 \mathrm{mb}$, weakening the low but increasing convection over the Sahel. Hence there are mid-latitude influences on the SHL.

The Saharan Heat Low is also influenced by dust, rainfall, and the inflow of relative cold and statically stable air from the Atlantic. The effects of the dust are two-fold [157]. A direct effect is related to radiative heating, which increases the thickness of the heat low. The second effect is related to the impact of the dust on the AEJ and African easterly waves. The dust intensifies both and through this enhances the intraseasonal variability of the SHL. The inflow from the Atlantic, mainly in the form of a mesoscale sea breeze and associated front, creates a baroclinic zone to the west of the SHL by bringing in cool and moist air [158]. Cuesta et al. [35] noted a conspicuous weakening of the low following rainfall events.

4.8. Saharan Air Layer. The daytime Sahelo-Saharan boundary layer has a split structure with a well-mixed, near-surface convective layer lying beneath a residual layer with more laminar dynamics [159]. This residual layer, termed the Saharan Air Layer or SAL, is a deep layer of hot and dry air characterized by a red haze. The haze is due to mineral dust eroded from the Sahel [160] and is associated with the northeast Harmattan but easterly waves add to the dust concentration in the haze. The east-west extent of the SAL is typically $2000-3000 \mathrm{~km}$, but it can extend some $5000 \mathrm{~km}$, covering an area about the size of the contiguous United States [161]. Where the SAL meets the eastern Atlantic it resides between roughly $900 \mathrm{mb} / 1800 \mathrm{~m}$ and $500 \mathrm{mb} / 5500 \mathrm{~m}$ [85]. It extends even higher over the continent, where its depth decreases from north to south [162].

The SAL is well mixed with relatively uniform conditions of high heat content and low moisture content. A typical temperature in the layer is $44^{\circ} \mathrm{C}$. A typical mixing ratio would 


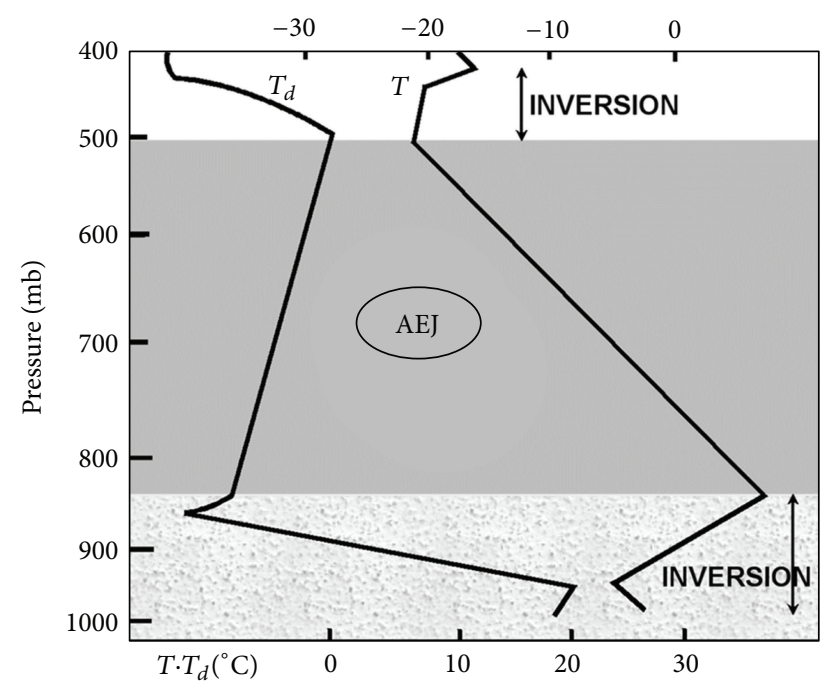

Figure 16: Conceptual model of the Saharan air layer (SAL) over West Africa (from [85]). The Saharan air layer (dark shading, indicating intense dust layer) is trapped between two inversions. Dust is evident below the inversion but in lower concentrations.

be $2 \mathrm{~g} / \mathrm{kg}$ [163]. When the SAL is not present the atmosphere is markedly cooler and more humid. In its absence the relative humidity is some 25 to $45 \%$ lower and the mixing ratio some 2.5 to $5.5 \mathrm{~g} / \mathrm{kg}$ lower [161]. The SAL is bound by subsidence inversions at its top and bottom [85] (Figure 16). These inversions help maintain the integrity of the layer. The dust that defines the layer also helps to maintain its thermal structure [164]. At the top of the SAL lies a region of high relative humidity where altocumulus and stratocumulus layers are often observed [162].

LiDAR observations have shown that there are two dust plumes within the SAL. One originates over the northern Sahara and the other from the Bodélé region of Chad [165]. The Bodéle Jet plays a major role in the development of the latter plume [137].

The SAL has significant impact on meteorological processes over the Sahel by way of its radiative effect, its thermal character, and its dryness. It impacts the African Easterly Jet, African Easterly Wave Development [13] and probably the development of tropical cyclones and hurricanes over the Atlantic [161]. The impact of the SAL on the AEJ is a result of the low static stability of the air mass. This creates a negative PV anomaly and anticyclonic relative vorticity on the poleward side of the AEJ. The low is a key part of the $\mathrm{PV}$-sign reversal that characterizes the instability of the AEJ $[13,118]$. The north-south temperature gradient within the layer is relatively small aloft and thus creates a "cap" on the AEJ's core, thereby determining its vertical extent [162].

\subsection{Links of Major Circulation Features to Rainfall and Its} Variability. The major circulation features associated with the variability of Sahel rainfall on interannual and decadal time scales are the TEJ, the AEJ, the AWJ, and the Saharan heat low. Nicholson has described the influence of the three jets in several publications (e.g., $[20,30,36,37])$. These works did not examine the Saharan heat low directly. However the results of Nicholson and Webster [95] clearly imply its role. That study is also consistent with the concept of a mid-season "monsoon jump", when cross-equatorial pressure gradients surpass a critical threshold needed to establish inertial instability.

As described in Section 3.2, the interannual variability of rainfall takes primarily two forms, a latitudinal displacement or a change of intensity of the tropical rainbelt over West Africa. In the former case, the well-known dipole ensues, with rainfall of the opposite sign over the Sahel and Guinea Coast regions. The "node" of the dipole is at roughly $10^{\circ} \mathrm{N}$. In the latter case rainfall anomalies are of the same sign in both regions. The commonality in both cases is the intensity of the Tropical Easterly Jet. The core speed is anomalously high when annual rainfall is above average in the Sahel, anomalously low during dry years in the region. The rainbelt over West Africa lies between the cores of the African Easterly Jet and the Tropical Easterly Jet, a region of strong vertical motion and divergence aloft. An intensification of the rainbelt/vertical motion requires a strong displacement of the two cores with respect to each other and strong vertical shear.

The occurrence of the dipole is determined mainly by the location of the AEJ core, which in turn is modulated by the intensity of the low-level African Westerly Jet over the Guinea Coast region. In the dipole case with wet conditions in the Sahel, the AEJ is displaced northward. In the dipole case with dry conditions in the Sahel it is displaced southward of its mean position.

Nicholson [20] suggested that the wet and dry cases in the Sahel represent two independent dynamic modes, with the switch between modes being associated with inertial instability. The main points of evidence supporting this are the bimodal frequency distributions of annual rainfall and dynamics variables related to it and the existence of critical thresholds (Figure 17) that separate the dry and wet years. These thresholds appear to be a cross-equatorial pressure gradient of $10^{3} \mathrm{mb} / \mathrm{km}$ and an AWJ speed of $7 \mathrm{~m} \mathrm{~s}^{-1}$ [95].

Grist and Nicholson [30] contrast the conditions of the wet and dry mode. The main contrasts are in the intensity of the TEJ and the AWJ and the latitude of the AEJ. However, contrasts are also evident in the structure of the moist layer, the intensity and character of wave activity, and the seasonal evolution of the low-level temperature gradient.

\section{Precipitation and Convection}

Precipitation over the Sahel is related primarily to three types of systems: mesoscale convective complexes, local convective activity, and various synoptic scale systems that represent interactions between the tropics and extra-tropics. The mesoscale systems produce most of the rainfall. Isolated, local, daytime convective activity produces only a small share of the Sahel's rainfall. Although favored by local, near surface conditions of high sensible heat flux, high humidity, and steep lapse rate, the initiation of these local systems is favored by mesoscale ascent [166]. The hybrid tropical-extratropical systems tend to produce precipitation during the Sahel's dry season or in the pre- or postmonsoon seasons. 


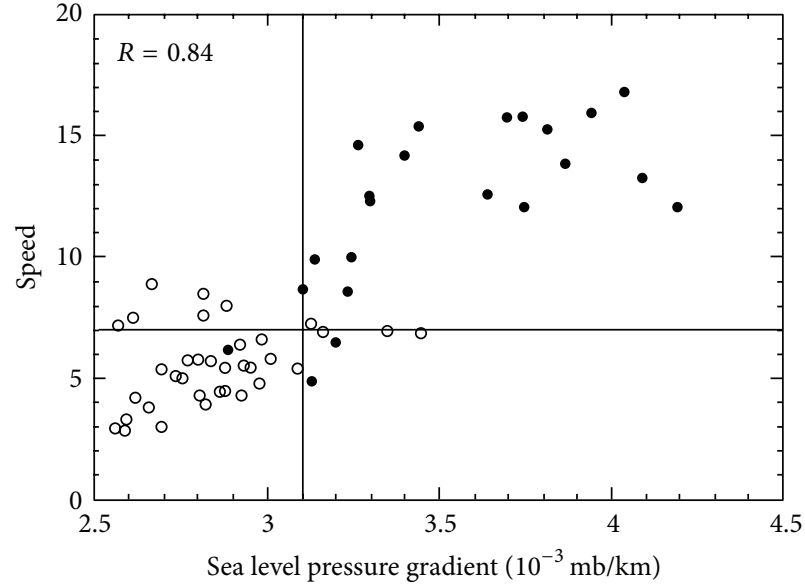

- 1948 to 1969

- 1970 to 2004

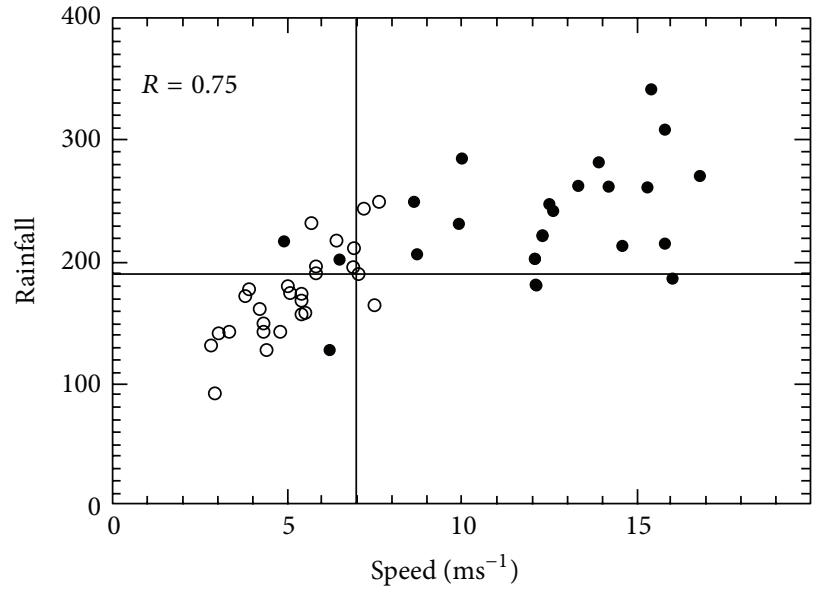

- 1948 to 1969

○ 1970 to 2004

(a)

(b)

FIGURE 17: (a) Speed of the westerlies $\left(\mathrm{m} \mathrm{s}^{-1}\right.$ ) at $850 \mathrm{hPa}$ versus surface pressure gradient for August of the years 1948-2004 (from [95]). Data are averaged for $5^{\circ} \mathrm{W}$ to $5^{\circ} \mathrm{E}$ and the pressure gradient is calculated between $20^{\circ} \mathrm{N}$ and $20^{\circ} \mathrm{S}$. The open circles represent the years $1948-1969$ and the solid circles represent the years 1970-2004. (b) Annual rainfall in the Sahel (averaged within the sector 10-18 $\mathrm{N}$ and from the Atlantic coast to $30^{\circ} \mathrm{E}$ ) versus speed of the westerlies at $850 \mathrm{hPa}$ (from [20]).

Precip feature "without ice scattering"
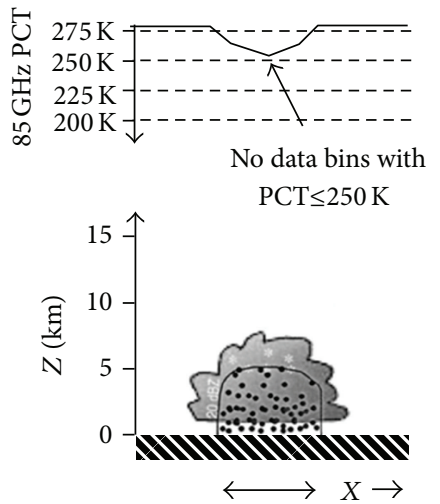

Precip feature area
Precip feature "with ice scattering"
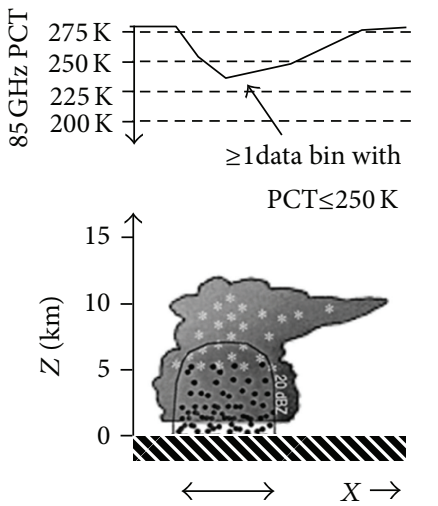

Precip feature area
Precip feature with an MCS
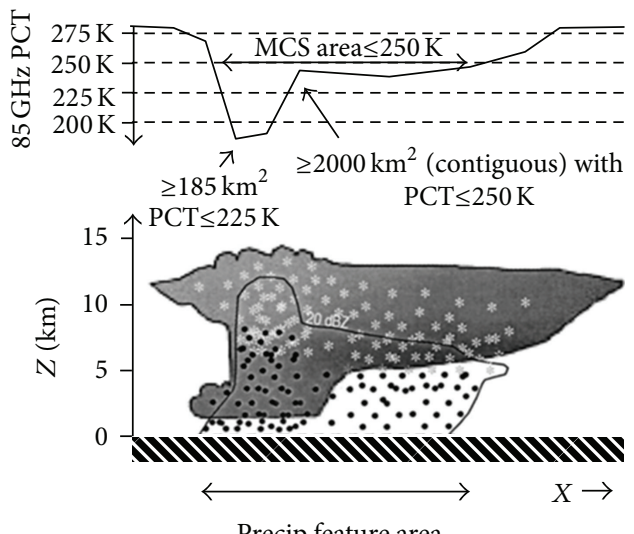

Precip feature area

FIGURE 18: Schematic of typical tropical precipitation features, including mesoscale convective complexes (from [96]).

A typical MCS is shown in Figure 18 and compared with other systems. An MCS is essentially a large, continuous area of deep cloud (at least $2,000 \mathrm{~km}^{2}$ ) in which one or more areas of convective precipitation are imbedded. The average size of MCSs is $10,000 \mathrm{~km}^{2}$. The presence of ice in the upper cloud layers in used by some (e.g., [23]) to distinguish MCSs from other convective systems. Over the Sahel MCSs account for up to $90 \%$ of the precipitation and $50 \%$ of the rainfall in the tropics, although they comprise only $2 \%$ of all rainbearing features in the tropics [167]. The typical MCS is topped by a large anvil of stratiform cloud (Figures 18 and 19). Despite the intense convection associated with these systems, stratiform precipitation accounts for $73 \%$ of the rain area and contributes roughly $40 \%$ of the total rainfall for the tropics as a whole [168]. Over the Sahel the contribution to total rainfall ranges from less than $20 \%$ in the south to more than $80 \%$ in the north [169].

MCSs are in a constant state of evolution. These systems produce intense convective rainfall mainly during the afternoon, with most convective events lasting 3 hours or less over land [170]. As the system evolves in the later hours of the day and into the night, the cloud anvil that tops the system spreads and produces a large area of stratiform cloud [23]. Thus, the stratiform rain typically occurs at night and for a longer period of time, but the rain rate is roughly one fourth the rain rate associated with convective clouds [168]. 


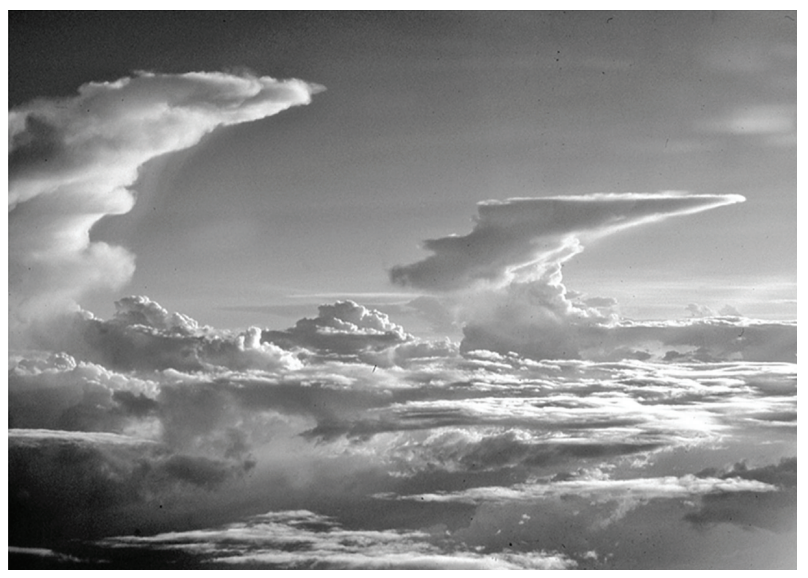

FIGURE 19: Photo of anvil associated with an MCS over West Africa (from [57]).

The mesoscale convective complexes are of two types, rapidly moving squalls and slower moving non-squall systems [168]. During the months of July through September of 1986 and 1987153 squalls were observed over West Africa [171]. These did not produce much rainfall, only $7 \mathrm{~mm}$ per event, on average. A study at Niamey, Niger $\left(13.5^{\circ} \mathrm{N}\right)$ during the AMMA special observing period of 2006 found that MCSs with squalls accounted for about $90 \%$ of the rain there, though the squalls were present in only $17 \%$ of rain events [172]. The squalls occurred along two AEW tracks at around 8 to $16^{\circ} \mathrm{N}$ and 2 to $6^{\circ} \mathrm{N}$. More stratiform precipitation occurred with the squalls moving along the northern track.

Fink and Reiner [173] tracked 81 AEWs and 344 squall lines over West Africa during the boreal summers of 1998 and 1999. They found $42 \%$ of the squalls to be wave-forced, a proportion increasing westward from $20 \%$ in the eastern Sahel to $68 \%$ at the West African coast. Squall occurrence peaks around midnight and has a minimum around noon [171]. Most nocturnal squalls in the Sahel are wave-forced. Wave-forced squalls are particularly frequent in the Sahel and during the peak monsoon season (July to September), when rainfall peaks in the Sahel. Favorable locations of Sahelian squalls are west of the AEW trough and in the region of southerly flow east of the trough. The AEWs appear to be most important in squall initiation, since the AEW-forced and non-forced squalls show little contrast in characteristics [173].

The major issues concerning convection in Sahelian West Africa are its trigger, its association with African Easterly Waves and its association with the African Easterly Jet. Convective episodes tend to arise in the lee of high terrain, consistent with thermal forcing from elevated heat sources [174]. Propagation is generally associated with moderate lowto mid-tropospheric shear, which varies with the latitudinal migration of the AEJ migration and with the phase of the West African monsoon. MCSs are usually, but not always, associated with AEWs. However the location within the wave depends on several factors, such as longitude, latitude, and period of the wave (see Section 6).
The location with respect to the AEJ was evaluated by Mohr and Thorncroft [175]. They separately considered weak and intense convective systems over the Sahel, defined respectively as the lowest and highest deciles in the intensity distribution. The peak location of the intense systems migrated throughout the rainy season, following the seasonal migration of the AEJ. The weak systems tended to reside around $10^{\circ} \mathrm{N}$, remaining there from May to August, but shifting eastward as the season progressed. The majority of both weak and intense systems occurred within five degrees of high terrain. Other factors favoring the development of intense convective systems include high potential temperature and high shear in the vicinity of the AEJ. Intense systems with unlikely to occur in wave troughs or in cases of high atmospheric dust-loading in the Sahel [176].

Although most of the rainfall in the Sahel is associated with the West African monsoon and occurs in the peak of the boreal summer, unseasonal rains can occur in the transition seasons and even in the heart of the dry season. These most often affect the western Sahel and can bring as much as $25 \mathrm{~mm}$ to the Sahel in the middle of the dry season. A case in point is the "heug" rains of Mauritania. These can persist for days on end [97].

Most of this unseasonal rainfall is associated with systems that develop as a result of tropical-extratropical interactions. The two systems most commonly described are the "tropical plume" [177] and the Soudano-Saharan depression [97, 98]. The common elements of these systems (Figure 20) are a diagonal trough emanating from the mid-latitude westerlies at upper levels and a surface tropical disturbance, often an AEW. Several cases of tropical-extratropical systems over North Africa are discussed in an extensive series of papers by Knippertz (e.g., [177-182], and by Geb [183]. Many are similar to the classical "tropical plumes", but may differ with respect to synoptic scale features or the continuity of the associated cloud bands. Schepanski and Knippertz [181] examined several systems that resembled the classic "Soudano-Sahelian depression" and concluded these cannot generally be traced to surface-level depressions and call for a revision of the classic picture of these systems. Further examination is warranted because such systems may have played a much greater role in the Sahel in past centuries, contributing to some of the historical wetter episodes experienced by the region [97].

\section{Wave Activity and Links to Convection}

In the mid-1970s it became apparent that a disturbance system termed the African Easterly Wave (AEW) is an extremely important component of the West African monsoon. Classic ideas concerning AEWs include their development from the African Easterly Jet via combined barotropic-baroclinic instability and their role in organizing and/or promoting convection. During the last decade the paradigm has shifted, with many studies emphasizing the mutual interaction between waves and convection, the role of convection as a wave trigger, and the role of additional types of waves on convection over West Africa.

The AEWs are disturbances in the zonal wind field that typically have wavelengths on the order of 2000 to $5000 \mathrm{~km}$ 


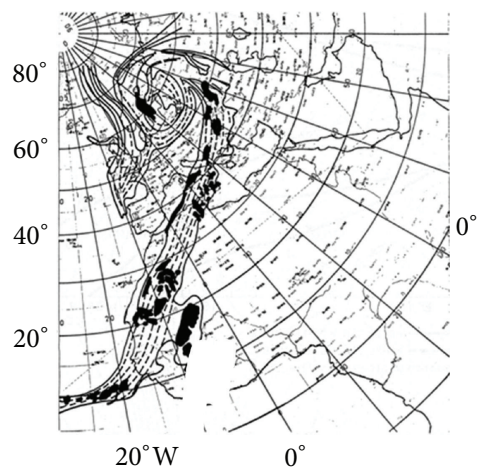

(a)

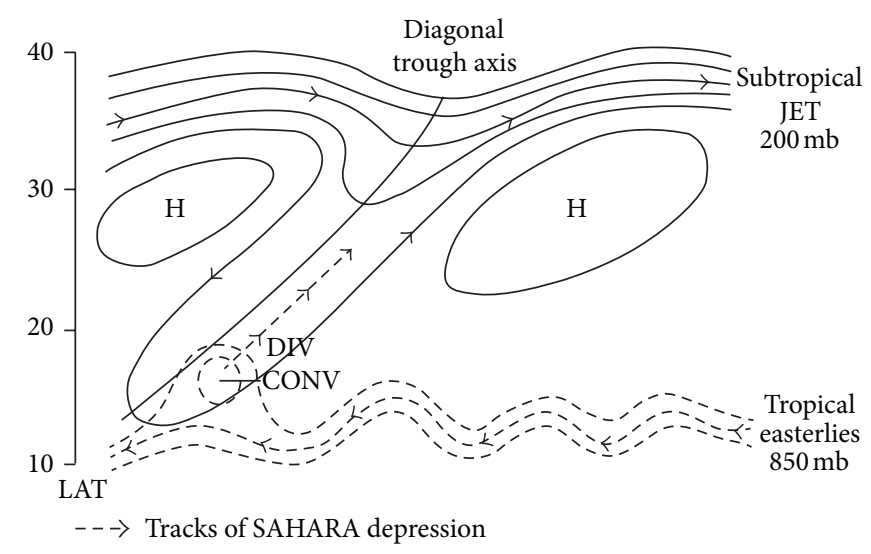

(b)

Figure 20: Development of Soudano-Saharan depressions and diagonal cloud bands over West Africa (from [97, 98]). Diagram on the left depicts a satellite view of a diagonal cloud band and areas of heavy rain within it (shaded areas) in September 1969, a period of tremendous rainfall and flooding in parts of North Africa. Diagram on the right shows the typical circulation pattern that leads to its development.

[68]. They propagate along two east-west tracks [184] and occur in two distinct frequency bands of 3 to 5 days and 6 to 9 days [185]. Along the northerly track $\left(\sim 18^{\circ} \mathrm{N}\right.$ to $\left.20^{\circ} \mathrm{N}\right)$, poleward of the AEJ core, the waves are at low levels. Waves along that track are associated with a low-level potential temperature gradient between the dry, hot Sahara and the cooler and moist monsoon air to the south [186]. They are seldom associated with precipitation [187] and are termed dry disturbances by some authors (e.g., $[188,189])$. Waves on the southern track, at $\sim 9^{\circ} \mathrm{N}$ to $11^{\circ} \mathrm{N}$ and equatorward of the AEJ core, are related to a sign reversal in the meridional potential vorticity gradient. They are usually, but not always, associated with convection and precipitation $[186,190]$. The flow in the two tracks might not be independent; rather they might represent a single AEW [191].

Simulating wet and dry years with a numerical model, Nicholson et al. [135] predicted that AEWs can trigger easterly wave development on the Tropical Easterly Jet in the upper troposphere. The predicted waves are of planetary scale with a period of 5 to 6 days and they develop to the northwest of the mid-level AEW. Observations showed that such a wave developed in July of 1950, a very wet year (Nicholson et al. [136], with characteristics similar to the predicted TEJ waves. Potential vorticity theory suggests that the waves on the TEJ develop via interactions between the surface and the TEJ. This is consistent with role of the surface potential temperature gradient in wave development north of the jet and the strong development of TEJ waves in wet years [186], when that gradient is anomalously strong.

A relatively recent shift in our understanding of AEW generation is the hypothesis that the waves are initiated via convection, rather than purely dynamic instabilities (e.g., [155]). Thorncroft et al. [69] formulated this in the form of the "triggering hypothesis", which suggests that AEWs are the result of a finite thermal disturbance that can grow in the absence of an unstable basic state. Convection, particularly that over the highlands of Darfur in the eastern Sahel, is suggested as a potential mechanism $[69,192]$. The importance of convection is supported by several studies. Cornforth et al. [112], for example, show that moist processes resulted in much more rapid wave growth. Their simulations also showed that moist AEWs were preceded by an increase in mean rainfall. The idea that barotropic-baroclinic instability is not a prerequisite for wave development has been supported by some modeling studies (e.g., $[117,118]$ ).

AEWS are clearly convectively coupled (e.g., [13]). Nevertheless, their structure and development can be largely understood in terms of dry dynamics [68, 119]. Nicholson et al. [136] for example used a dry model to simulate wave development and produced realistic waves for dry years and wet years that matched observed characteristics in those years. Once a wave precursor is triggered, the state of the AEJ still plays a critical role in determining whether or not a wave develops [193]. This suggests that dynamic instabilities are still a prerequisite for AEW development.

Other wave activity over Africa is triggered in the Pacific, generally in association with the Madden-Julian Oscillation (MJO). Convection over the Indian Ocean or the Pacific warm pool in the boreal summer sends Kelvin waves eastward and Rossby waves westward. They meet over Africa, where they modulate the mid-tropospheric temperature structure in ways that favor deep convection [194]. The westerly flow of the Kelvin wave increases boundary layer monsoon flow and moisture supply. The westerly anomalies also increase cyclonic shear on the equatorward flank of the $\mathrm{AEJ}$, enhancing wave development and transient convective activity. MJO-induced waves often trigger convection over the Darfur region [195], where AEWs frequently originate [69]. The Rossby waves appear to be the more important part of the MJO-induced response over Africa, especially on time scales of 25 to 90 days [59, 60, 63].

The Kelvin waves have a wavelength of some $8,000 \mathrm{~km}$ and a period of 6 to 7 days. Mounier et al. [196] suggest their impact on rainfall and convection is of about the same magnitude as that of AEWs. Kelvin waves are more active in dry years than wet years because they are favored by the same 
Pacific SST patterns that are linked to Sahel drought [197]. In dry years they probably contribute more to convection that do the AEWs.

Grist [198] describes the seasonal cycle of AEWs over the Sahel. He shows peak development during July through September, when horizontal shear and barotropic instability also peak. Longer periods waves (6.25 to 7.5 days) provide a greater contribution in the latter half of the season. Some disturbances are apparent at low levels, but generally only the shorter period waves ( 3.75 to 5 days), which have a maximum variance in July. This is consistent with the results of Cornforth et al. [112], who show that the surface signal of AEWs becomes weak during the peak monsoon season. They attribute that to the interaction between convection and the waves.

The relationship between AEWs and convection is complex. Originally it was thought that they principally organize convection. More recent work has shown feedback relationships in which convection can modulate waves, which in turn modulate convection. Early studies suggested that the mesoscale convection systems (MCSs) that bear most of West Africa's precipitation are often imbedded in the northerly flow ahead of the wave trough (see [194]). More recent work has shown the relationship between AEWs and convection to be much more complex.

In regions of deep convection the 2 to 6 day waves produce some $25 \%$ to $35 \%$ of the intraseasonal variance in convection [155]. The waves also appear to modulate annual precipitation amounts $[136,144]$. Taleb and Druyan [199], in contrast, find no correlation between the number of waves and interannual variability.

$\mathrm{Gu}$ et al. [62] concluded that there are two distinct relationships between waves and convection. Southerly wind perturbations lag precipitation south of $15^{\circ} \mathrm{N}$, but lead it north of $15^{\circ} \mathrm{N}$. The relationship can be in-phase or out-ofphase. The relationship shifts as the waves traverse the African continent and also depends on latitude with respect to the AEJ [200]. At $10^{\circ} \mathrm{N}$ convection occurs in northerly flow east of the Greenwich meridian, then shifts into the wave trough. North of the AEJ, at $15^{\circ} \mathrm{N}$, convection remains in the southerly flow throughout it transit across Africa. Some more complex forms of the wave also exist, in which convection has an inverted-V appearance and is wrapped around the trough, which is an area of low wind and clear skies [201]. The lower frequency 6 to 9 day waves tend to have a rainfall maximum in the cyclonic flow to the north and a rainfall minima in the anticyclonic flow to the south [202].

Hall et al. [119] provide a comprehensive review of idealized studies of AEW development in relationship to the African Easterly Jet. They had assumed a zonally uniform basic state. Using a linear primitive equation model, they considered the impact of zonal asymmetries of the AEJ, and showed that these modified the developing dynamic modes and resultant waves. Leroux and Hall [193] similarly showed that the response to intraseasonal variability of the AEJ depends strongly on its basic state. In this case, a convective trigger was utilized. Some configurations of the AEJ failed to produce waves and others produced very strong waves. Requirements for the latter include a strong jet, strong vertical shear, a strong and extended potential vorticity reversal. The strong vertical shear results when the AEJ core is aligned with the maximum of surface westerlies. However, the vertical shear in the upper troposphere appears to be equally important [136].

Grist [198], Grist et al. [144], and Nicholson et al. [136], using both observations and linear dynamic models, also examined the impact of basic state on wave development. In this case, the basic states corresponded to two composites of wet years and two composites of dry years. The four months of June through August were considered. In agreement with Leroux and Hall [193], they demonstrated the need for strong vertical shear to produce strong waves and the presence of this shear when the AEJ core overlies strong surface westerlies. However, it appeared that the major factor responsible for the stronger waves in the wetter years was contrasts in barotropic instability [144]. With the equatorial westerlies extending to the mid-troposhere in wet years, the horizontal shear was particularly strong.

Several other contrasts between the wet and dry cases were noted. These include faster growth rates and phase speeds, stronger waves, and a greater contribution from the longer period waves. In the wet years the waves have a barotropic structure and extend throughout the troposphere. Those of dry years extend only to mid-levels. Two distinct wavelengths are also apparent in wet years, 3 to $4 \mathrm{~km}$ and 6 to $7 \mathrm{~km}$. The latter are planetary scale waves, suggesting interactions between the upper troposphere and the surface. This is consistent with the suggestion of Cornforth et al. [112] that interaction with convection weakens the surface manifestation of the waves during the peak monsoon season.

\section{Large-Scale Factors in Variability: The Role of Sea-Surface Temperatures}

Some of the earliest work on the relationship between Sahel rainfall and sea-surface temperatures was prompted by the drought conditions that commenced in the late 1960s. Seminal papers were published by Lamb [203, 204], who suggested links to SSTs in the equatorial and subtropical Atlantic, and by Folland et al. [205], who highlighted the role of interhemispheric SST gradients.

Since that time there has been vigorous debate but no definitive answers on the major drivers. Some of the less controversial conclusions are that SST patterns play a critical role in the variability (e.g., $[99,206-208])$, that a variety of regional and global SST patterns play a role (e.g., $[209,210])$, that the link to SSTs is probably different for high- and lowfrequency (i.e., interannual and interdecadal) variability [211213], that the relationships are not stationary over time (e.g., $[104,213,214])$, and that external forcing via Saharan dust and/or greenhouse gases is probably playing a role in Sahel rainfall variability (e.g., [99, 208, 215-217]).

Some of the more controversial issues are the impact of ENSO on the Sahel, the relative importance of the various oceans and the Mediterranean, and the extent to which climate models can adequately simulate Sahel rainfall. There is disagreement concerning the models' ability to simulate mean climatology and the long drying trend since the 1970s, 


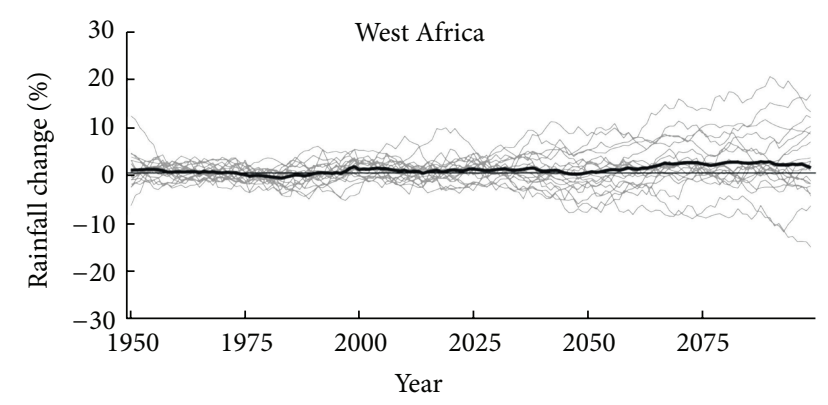

FIgURE 21: Average of precipitation over West Africa in the IPCC 4AR model simulations: twentieth century simulations from 1950 to 2000, and A1B scenario simulations from 2000 to 2100 (from [99]). Each grey line represents one model, and the thicker black line is the multi-model mean.

but universal agreement that the models (Figure 21) cannot produce reliable assessments of future climate change in the region [99, 208, 212, 215, 218-220]. Modeling efforts are hindered by the fact that there are multiple competing physical mechanisms, as described below [219]. The search for a better understanding of Sahel climate variability is complicated by the fact that most studies rely on numerical modeling. Details of the modeling issue are beyond the scope of the review. However, excellent reviews of state-ofart modeling and model intercomparisons can be found in Mohino et al. [214], Patricola and Cook [221], Lau et al. [215], Biasutti et al. [99], Rodriguez-Fonseca et al. [218], Hourdin et al. [222], Druyan et al. [223], Cook et al. [224], Nikulin et al. [225], and Ruti et al. [226].

For the most part, model simulations of Sahel rainfall have confirmed the importance of the two mechanisms proposed by Lamb [203, 204] and Folland et al. [205]: the role of equatorial Atlantic SSTs and the role of interhemispheric SST gradients. Hoerling et al. [227] emphasized the latter, suggesting that the drying trend over the last half of the twentieth century was due to a warming of the South Atlantic relative to the North Atlantic. Joly et al. [212] implicated the former as a major factor in the high frequency variability of Sahel rain, suggesting that its role is the modulation of the northward migration of the West African monsoon. Losada et al. [228] suggested the mechanism is related to the degree of low-level convergence over the Sahel. In agreement with Hoerling et al., they also found that the interhemispheric mode is linked to the low-frequency drying trend. Sun et al. [229] take the link to the Atlantic further south, demonstrating a link to the Antarctic Oscillation via Atlantic SSTs. This is consistent with the work of Nicholson and Webster [95], who show a strong link to the extratropical South Atlantic.

Others have emphasized the influence of the North Atlantic. Polo et al. [230], for example, demonstrate an influence of the North Atlantic Oscillation. Several studies have suggested a relationship to the Atlantic Multidecadal Oscillation (AMO, also termed Atlantic Meridional Overturning). This is the average temperature over the North Atlantic. The relationship is particularly strong for low-frequency variations [231-233], with strong links extending back to at least the beginning of

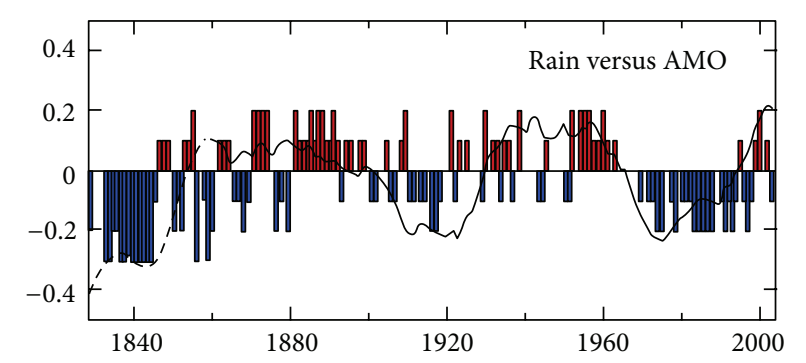

FIgURE 22: Semiquantitative index of Sahel rainfall since 1823 compared with the AMO. The scale of the latter AMO data has been adjusted to match the scale of the SST-based index (from [100]).

the nineteenth century (Figure 22) (Dezfuli and Nicholson, in preparation). The paleoclimate work of Shanahan et al. [234] suggests that the relationship holds on even longer time scales.

On the other hand, model simulations of Hodson et al. [235] suggest that the AMO is not the primary cause of the recent drying trend in the Sahel. This is consistent with the conclusion of Losada et al. [104] that there has been a change in rainfall patterns over the Sahel in recent decades. Mostly notably, the well-known dipole rainfall pattern, with an opposition between the Sahel and Guinea Coast, seems to have disappeared. The suggested reason for its disappearance is that the influence of SSTs in the Gulf of Guinea, which are linked to the dipole [236], and other areas of the Atlantic has been counteracted by Pacific warming [104, 213].

Two of the first papers to emphasize the role of the Pacific and ENSO in modulating Sahel rainfall were Rowell [237] and Janicot and Sultan [65]. Based at least partially on model results, these conclusions were at odds with the conclusions of several observational analyses (e.g., [76, 238-240]). The issue was reconciled by Ward [211], who separately evaluated low- and high-frequency variability and found that ENSO influenced the latter. Further support for a link to ENSO comes from Joly et al. [212] and Losada et al. [104]. Joly and Voldoire noted that the timing of the ENSO events are critical to the teleconnection with Sahel rainfall, which is strongest in the developing phase of el Niño or the decaying phase of some La Niña episodes. Bader and Latif [241] suggest that the Pacific's influence is mainly in the eastern Sahel.

Both model simulations and observations suggest that the Indian Ocean also has a strong influence on Sahel rainfall. This suggests an influence between Sahel rainfall and the Indian monsoon (e.g., [242]). Chung and Ramanathan [243] suggest that both Indian Ocean warming and SST gradients in the Indian Ocean play a role. Bader and Latif [241] conclude that the Indian Ocean was the probable driver of the drying trend in the Sahel from the 1950s to the 1990s. Bader and Latif [244] evaluated the extreme drought year 1983 and concluded that the main factor was Indian Ocean SSTs, showing that they can influence not only decadal scale variability but also interannual. In contrast to most observational studies they suggested that the Atlantic dipole was not the main cause. They also concluded the very intense el Niño of that year had a weak influence at best. Mohino et al. [214] emphasize both 
Indian and Pacific Ocean anomalies, suggesting they can also, like Gulf of Guinea SSTs, displace the rainbelt latitudinally over the Sahel. Notably, their suggested mechanism is most prominent in August, the month that contributes the most to interannual variability. Several authors have suggested that the probably mechanism of influence via the Indian Ocean is equatorial wave dynamics, especially westward propagating Rossby waves [206, 241, 245, 246]. This conclusion is particularly interesting, because studies of intraseasonal variability of Sahel rainfall and disturbances systems show a strong link to equatorial waves, especially Rossby waves (see Section 6).

One of the first papers to examine the link between the Mediterranean and Sahel rainfall is that of Rowell [209]. His observational analysis suggested that during the period 1947 to 1996 the impact of the Mediterranean was on par with that of the Pacific and only somewhat weaker than that of the Atlantic. Model simulations pointed towards moisture flux as the mechanism of the association. Several modeling studies have similarly noted a link between Mediterranean warm events and anomalously high Sahel rainfall. The observational study of Polo et al. [247] suggests that the most direct influence on Sahel rainfall comes from the Mediterranean, but that this may be a fingerprint of larger scale forcing. The suggested mechanisms of the relationship include enhanced evaporation over the Mediterranean [248], enhancement or northward displacement of the southwesterly monsoon flow [88], enhancement of moisture flux and the Saharan Heat Low [249], and increased convergence [250]. Fontaine et al. [88] conclude that the impact is different for the eastern and western Mediterranean Basin, with the eastern Mediterranean having the greater influence on the Sahel. Observations suggest that warming and cooling have a symmetric impact but a model simulation suggests that only warming has an impact.

The conclusion that one can draw from these various studies is that multiple, competing physical mechanisms regulate interannual and decadal variability in the Sahel [219]. The dominant mechanism varies with location within the Sahel and with the time period in question. For that reason it is difficult to identify the contribution of any particular ocean. Moreover, each model has its biases and these influence the degree to which any particular mechanism can be simulated. Hence, the large disparity of model results.

\section{Land Surface Effects, Including Aerosols}

The possibility of the land surface influencing Sahel climate was first addressed by Charney [251]. In response to the occurrence of severe drought in the 1970s, he proposed that overgrazing in the region may have been the cause. The proposed mechanism was a change in surface albedo as a result of the denuding of highly reflective soils. Subsequently other mechanisms were proposed, including such factors as changes in soil moisture and evapotranspiration. These were assumed to accompany a process called "desertification", in which human transformation of the land led to an irreversible decline in productivity.

This stimulated a plethora of model simulations of the impact of such land surface changes (see reviews by
Nicholson [102], Entekhabi [252], Giannini et al. [208]). These have established the potential for changes in the land surface over the Sahel to influence the region's climate $[253,254]$. In most cases, feedback mechanisms were demonstrated by which an existing drought could be intensified rather than triggered (e.g., [255]). However, observational evidence was lacking. At the same time, numerous studies showed that the extent of desertification is the Sahel had been dramatically exaggerated and was generally a reversible process [256-259].

During the last decade or so the nature of research on land surface feedback on Sahel climate has shifted markedly. The changes include use of regional climate models instead of global models (e.g., [260-262]), emphasis on the impacts on individual convective or synoptic systems as opposed to seasonal or large-scale climate (e.g., [263]), consideration of aerosols and the associated Saharan Air Layer (e.g., [159, 164]), and examination of the hypothesis that vegetation feedback can produce abrupt climate change in the Sahel [264]. Recent research in each of these areas is reviewed.

8.1. Land Surface Processes in Regional Models. Perhaps the most important result of the use of regional models to study land surface processes is the uniform consensus that interactive land surface schemes improve the performance of climate models [216, 265-267]. They improve the simulation of hydrological processes, circulation features, and enhance predictive capacity. The net result is a confirmation that landatmosphere interaction is an inherent feature of the mean climatology of the region.

Some of the most promising working on land surface processes is the studies linking them to convection. In semiarid regions the surface fluxes of heat and moisture are strongly impacted by the occurrence of convective rainfall [268], but the so-produced surface anomalies also influence the development of convective rainfall. The relevant characteristic is not the overall state of the land surface, but the spatial heterogeneity of the characteristics of moisture and temperature that play a role (e.g., [269-271]. This conclusion, also reached long ago in early modeling experiments (e.g., [272]), has stood the test of time.

8.2. Relationship between Land-Surface Characteristics and Convection. Most of the work on the links between the land surface and convection has been done with model simulations. These have concluded that surface flux anomalies related to soil moisture and temperature can induce secondary circulations that impact boundary layer depth and cloud development and trigger convection [273, 274]. The surface fluxes have an impact on the diurnal cycle of convection [275]. The coupling of the atmosphere and land surface also appears to produce unstable modes that do not exist in the atmosphere-only part of the system [276]. The result is wave disturbances, the propagation of which is governed by the spatial configuration of atmospheric and soil moisture anomalies. In the Sahel rainfall-induced anomalies can persist for several days after a storm, long enough to modify the overlying boundary layer [277]. Boundary layer changes are linked mainly to long length scales of surface 
heterogeneities [268] because advective effects may override the influence of the land-surface at smaller scales [278]. Squall-line rainfall, on the other hand, shows the strongest response to anomalies on small length scales comparable to that of convection.

Observational studies have produced convincing evidence of the impact of land-surface heterogeneities on convection in the semi-arid Sahel, particularly the drier northern sector. The first of these was that of Taylor and Lebel [279], who used data from the HAPEX-Sahel field experiment of 1992 [280]. They found that the probability of rainfall at a given location was strongly correlated with that location having received antecedent rainfall from a previous event. In other words, once a location has received significant rainfall, it is more likely than other locations to receive rainfall from subsequent disturbances that pass by.

More recent observational studies have provided more detail into the mechanisms involved in the feedback. Dry anomalies (areas of higher temperature and lower moisture than the surroundings) can be several hundred kilometers and larger. These "hot spots" generate anomalous heat lows during the day and cyclonic vorticity at night [269]. These vortices may influence the characteristics of African easterly waves in the northern Sahel and thereby influence rainfall. These vortices are thus both a cause and effect of the rainfall [281]. Soil moisture anomalies on the scale of 10 to 40 kilometers appear to exert strong control on storm initiation [270]. An interesting case study of such an effect was made for a convective system that occurred over northern Mali during the AMMA Special Observing Period [263]. The impacts of soil moisture patches are evident even at scales of $200 \mathrm{~km}$ [282]. The initiation of convection by such patches is favored when the soil inhomogeneity is superimposed upon a convergence zone [283]. However, the process is also affected by other factors, such as humidity in the boundary layer and by convective available potential energy (CAPE).

The impact of soil moisture heterogeneities is strongly dependent on the stage of convection. Convection is often initiated over strong moisture gradients or over the dry "hot spots". However, dry soil appears to weaken mature systems [271] while moisture soil will enhance mature convective systems [263].

One of the still open questions is whether the feedback between the land surface and convection merely modifies the spatial distribution of rainfall or affects the overall amount as well. In modeling studies by Lauwaet et al. [284, 285] the surface changes introduced did not influence the amount of rainfall, despite the changes in surface fluxes and CAPE. Model simulations of Gantner and Kalthoff [271] suggest that the lack of a net impact may be a result of the contrasting impact on developing versus mature convective systems. The triggering of convection was favored by drier surfaces and/or soil moisture inhomogeneities, but mature systems weakened when they approached drier surfaces. Gaertner et al. [286] found that introducing a soil moisture perturbation into a model had different effects at different scales: a reduction in rainfall over the wet path itself but a net increase in rainfall over a larger area. Moufouma-Okia and Rowell [287], using a regional climate model, found that soil moisture anomalies had little impact on the overall amount of rainfall, creating only small and random intraseasonal, interannual and spatial variations. However, they noted that the conclusion may be model dependent or influenced by the initial soil moisture data introduced into the model. Hence the question is very open.

8.3. Impact of Aerosols. The origin of the dust layer over West Africa is fine material eroded from the dry remnants of Holocene lakes that once spread across the Sahel [160]. African Easterly Waves play an important role in the mobilization of the dust, although extratropical disturbances also play a role in the western Sahel [288]. Some $20 \%$ of the entrainment into the atmosphere over North Africa is linked to AEWs [289]. The dust-loading over the Sahel increased tremendously between the 1950s and the 1980s, a consequence of the long period of drought [290].

The main impact of the dust is on the atmospheric radiation budget. However, the particulates also serve as ice nuclei and cloud condensation nuclei [291-293]. The radiative effects depend on the composition of the dust, that is, on its relative role in absorbing versus reflecting radiation (see review in [102]). Hence the radiative effects are different for the mineral-based Saharan dust and the smoke introduced by biomass burning [294]. For the most part, the dust acts as an "elevated heat pump" [215], warming the mid-troposphere but cooling the surface $[295,296]$. Maximum heating is in the layer $850 \mathrm{mb}$ to $700 \mathrm{mb}$ [294].

The dust appears to intensify the African Easterly Jet, consistent with the mid-level heating, and weaken the Tropical Easterly Jet [216]. Dust outbreaks also affect the Saharan Heat Low. The radiative effect increases its thickness, but the impact of the dust on the AEJ and AEWs affects the heat low. Most studies conclude that the net effect is to reduce precipitation over the Sahel [296, 297], particularly that associated with deep convection [294]. Lau et al. [215], however, suggest that the dust can strength the monsoon and shift it northward. This implies an increase in rainfall over the Sahel.

8.4. Abrupt Climate Change. An outgrowth of the research on land-surface processes has been the hypothesis that these processes can lead to abrupt climate change. The issue has been related primarily to the question of the creation of the Sahara Desert, but it has implications for the Sahel as well [298]. Reviews are provided by Rietkerk et al. [264] and Kabat et al. [299].

This hypothesis results from contemporaneous findings in climatology, paleoclimatology, and ecology. A dust core in the Atlantic just off the West African coast suggested that, in the Sahara, the transition from savanna to desert which took place a few thousand years ago may have occurred within a few hundred years [300]. While that finding contradicts the more conventional view of the termination of the African humid period (e.g., [301]), climate models that included interactive vegetation were able to replicate such an abrupt transition $[302,303]$. These models have also shown an accompanying feedback of the vegetation on precipitation. 
At the same time, ecological theory was suggesting that vegetation-climate-nutrient feedbacks were such that in arid and semi-arid regions the vegetation is self-organizing [304, 305]. A corollary to this is that very rapid transitions from wet and vegetated ground to dry and bare ground could occur in the presence of an external climate trigger [306, 307]. The relevant feedbacks with vegetation cover include soil moisture, shading, and nutrient retention [308-312]. When critical thresholds in the climate-vegetation system are surpassed, catastrophic shifts in the vegetation state can occur.

\section{Summary}

Rainfall in the Sahel has shown some degree of recovery since the extreme dry episode of the 1970s and 1980s. However, certain characteristics of the rainfall regime appear to have changed. There is less spatial coherence and less temporal persistence. The contrast between conditions in the eastern and western Sahel is becoming increasingly stronger. The peak month appears to have shifted from August to July.

Most recent work on the Sahel has been in the context of the West African monsoon overall. New paradigms for the monsoon and associated ITCZ have emerged. These emphasize features in the upper atmosphere, as well as the Saharan Heat Low. Feedback mechanisms have also been emphasized, especially the coupling of convection with atmospheric dynamics. Many researchers are arguing the viewpoint that convection is a trigger/driver, as opposed to a passive response to atmospheric dynamics. The role of land surface effects on convection is also becoming increasingly demonstrated. The role of tropical/extratropical interaction has also been brought to the forefront during the last decade by way of studies of hybrid systems such as diagonal troughs and evidence of the role of the Mediterranean in modulating Sahel rainfall.

An interesting result that emerges from recent research is the contrast in the Sahel rainfall regime during the premonsoon season and the peak monsoon season. During the former (May to late June/early July), the tropical rainbelt lies south of the Sahel, around $5^{\circ} \mathrm{N}$. During the peak monsoon season the rainbelt is centered around $10^{\circ} \mathrm{N}$. Lebel et al. [22] term these the ocean and continental regimes, respectively. The shift between the two locations/regimes is abrupt (the "monsoon jump").

It has long been established that interannual and decadal variability in the Sahel is related primarily to anomalies in the months of August and September. The long drying trend is clearly linked to conditions in those months. This is considered to be the peak monsoon season, as well as the period of dominance of the "continental" regime. Recent studies have emphasized how the precipitation character and its dynamic controls differ during the continental regime and the preceding premonsoon season/ocean regime. With the shift between the ocean and continental regimes, the horizontal wind shear over the Sahel increases markedly, the vertical shear decreases, and the AEJ weakens. The contribution of stratiform rain increases, rainfall becomes less intense, and fewer squall lines occur. The influence of the Indian and Pacific Oceans appears to be strongest during the continental regime than during the ocean regime. At this time, wave activity is more closely coupled to convection and to squalls. The relationship of rainfall to the surface ITCZ becomes weaker (it is weakest in August). Longer period waves (6.25 to 7.5 days) also provide a greater contribution at this time.

Many studies have examined the relationship between the Sahel and large-scale processes. Very new results include the roles played by the Madden-Julian Oscillation and by equatorial waves. These are tied into global sea-surface temperature fluctuations. In the past, emphasis has been placed on the Atlantic Ocean in the context of interannual variability over the Sahel. Both observations and numerical simulations identify contributions of each of the global oceans.

The oceans manifest their influence in several ways, but most markedly in changes in several circulation features: the Tropical Easterly Jet, the African Easterly Jet, the low-level African Westerly Jet, and the Saharan Heat Low. The result is two major modes of rainfall variability, one associated with a latitudinal displacement of the tropical rainbelt over West Africa and one associated with a general intensification or weakening of the rainbelt. These modes are associated with different dynamic states and their existence and contrasts likely play a role in the sometimes contradictory conclusions that have been drawn concerning the role of the oceans. Wet or dry conditions in the Sahel can be associated with either mode. However the common factors in producing wet conditions appear to be pressure and temperature patterns over the Atlantic and the intensity of the Tropical Easterly Jet over West Africa.

\section{References}

[1] S. E. Nicholson and J. P. Grist, "The seasonal evolution of the atmospheric circulation over West Africa and equatorial Africa," Journal of Climate, vol. 16, pp. 1013-1030, 2003.

[2] A. Ali and T. Lebel, "The Sahelian standardized rainfall index revisited," International Journal of Climatology, vol. 29, no. 12, pp. 1705-1714, 2009.

[3] S. Nicholson, "On the question of the "recovery" of the rains in the West African Sahel," Journal of Arid Environments, vol. 63, no. 3, pp. 615-641, 2005.

[4] P. J. Lamb, "Sub-Saharan rainfall update for 1982: continued drought," Journal of Climatology, vol. 3, no. 4, pp. 419-422, 1983.

[5] P. J. Lamb and R. A. Peppler, "Further case studies of tropical Atlantic surface atmospheric and oceanic patterns associated with sub-Saharan drought," Journal of Climate, vol. 5, pp. 476488, 1992.

[6] S. E. Nicholson and I. M. Palao, "A re-evaluation of rainfall variability in the Sahel. Part I. Characteristics of rainfall fluctuations," International Journal of Climatology, vol. 13, no. 4, pp. 371-389, 1993.

[7] S. E. Nicholson, "The nature of rainfall fluctuations in subtropical West Africa (Guinea Sahel Soudan)," Monthly Weather Review, vol. 108, no. 4, pp. 473-487, 1980.

[8] T. Lebel and A. Ali, "Recent trends in the Central and Western Sahel rainfall regime (1990-2007)," Journal of Hydrology, vol. 375, no. 1-2, pp. 52-64, 2009. 
[9] S. Janicot, C. D. Thorncroft, A. Ali et al., "Large-scale overview of the summer monsoon over West Africa during the AMMA field experiment in 2006," Annales Geophysicae, vol. 26, no. 9, pp. 2569-2595, 2008.

[10] J. L. Redelsperger, C. D. Thorncroft, A. Diedhiou, T. Lebel, D. J. Parker, and J. Polcher, "African Monsoon Multidisciplinary Analysis: an international research project and field campaign," Bulletin of the American Meteorological Society, vol. 87, no. 12, pp. 1739-1746, 2006.

[11] A. Boone, P. De Rosnay, G. Balsamo et al., "The AMMA land surface model intercomparison project (ALMIP)," Bulletin of the American Meteorological Society, vol. 90, no. 12, pp. 18651880, 2009.

[12] T. Lebel, B. Cappelaere, S. Galle et al., "AMMA-CATCH studies in the Sahelian region of West-Africa: an overview," Journal of Hydrology, vol. 375, no. 1-2, pp. 3-13, 2009.

[13] C. D. Thorncroft, D. J. Parker, and R. R. Burton, "The JET2000 project-aircraft observations of the African easterly jet and African easterly waves," Bulletin of the American Meteorological Society, vol. 84, pp. 337-351, 2003.

[14] J. F. Griffiths, World Survey of Climatology, vol. 10, Elsevier, 1972.

[15] C. Zhang, P. Woodworth, and G. Gu, "The seasonal cycle in the lower troposphere over West Africa from sounding observations," Quarterly Journal of the Royal Meteorological Society, vol. 132, no. 621, pp. 2559-2582, 2006.

[16] B. J. Mason, “The GARP Atlantic tropical experiment," Nature, vol. 255, no. 5503, pp. 17-20, 1975.

[17] Y. Y. Yan, "Intertropical Convergence Zone (ITCZ)," in Encyclopedia of World Climatology, J. E. Oliver, Ed., pp. 429-432, 2005.

[18] R. L. Miller, "The intertropical convergence zone," in Encyclopedia of Climate and Weather, S. H. Schneider, Ed., vol. 1, pp. 445-448, 1996.

[19] J. R. Holton, J. M. Wallace, and J. A. Young, "On boundary layer dynamics and the ITCZ," Journal of the Atmospheric Sciences, vol. 28, pp. 275-280, 1971.

[20] S. E. Nicholson, "A revised picture of the structure of the "monsoon" and land ITCZ over West Africa," Climate Dynamics, vol. 32, no. 7-8, pp. 1155-1171, 2009.

[21] R. A. Tomas, J. R. Holton, and P. J. Webster, "The influence of cross-equatorial pressure gradients on the location of nearequatorial convection," Quarterly Journal of the Royal Meteorological Society, vol. 125, no. 556, pp. 1107-1127, 1999.

[22] T. Lebel, A. Diedhiou, and H. Laurent, "Seasonal cycle and interannual variability of the Sahelian rainfall at hydrological scales," Journal of Geophysical Research D, vol. 108, no. 8, pp. 1411, 2003.

[23] S. W. Nesbitt and E. J. Zipser, "The diurnal cycle of rainfall and convective intensity according to three years of TRMM measurements," Journal of Climate, vol. 16, no. 10, pp. 1456-1475, 2003.

[24] P. Peyrillé, J. P. Lafore, and J. L. Redelsperger, "An idealized twodimensional framework to study the West African Monsoonpart I: validation and key controlling factors," Journal of the Atmospheric Sciences, vol. 64, no. 8, pp. 2765-2782, 2007.

[25] C. D. Thorncroft, H. Nguyen, C. Zhang, and P. Peyrille, "Annual cycle of the West African monsoon: regional circulations and associated water vapour transport," Quarterly Journal of the Royal Meteorological Society, vol. 137, no. 654, pp. 129-147, 2011.

[26] C. Lavaysse, C. Flamant, and S. Janicot, "Regional-scale convection patterns during strong and weak phases of the Saharan heat low," Atmospheric Science Letters, vol. 11, no. 4, pp. 255-264, 2010.
[27] P. Peyrillé and J. P. Lafore, "An idealized two-dimensional framework to study the West African Monsoon-part II: largescale advection and the diurnal cycle," Journal of the Atmospheric Sciences, vol. 64, no. 8, pp. 2783-2803, 2007.

[28] G. J. Gu and R. F. Adler, "Seasonal evolution and variability associated with the West African monsoon system," Journal of Climate, vol. 17, pp. 3364-3377, 2004.

[29] D. J. Parker, R. R. Burton, A. Diongue-Niang et al., "The diurnal cycle of the West African monsoon circulation," Quarterly Journal of the Royal Meteorological Society, vol. 131, pp. 28392860, 2005.

[30] J. P. Grist and E. Nicholson, "A study of the dynamic factors influencing the rainfall variability in the West African Sahel," Journal of Climate, vol. 14, no. 7, pp. 1337-1359, 2001.

[31] C. D. Thorncroft and M. Blackburn, "Maintenance of the African easterly jet," Quarterly Journal of the Royal Meteorological Society, vol. 125, no. 555, pp. 763-786, 1999.

[32] D. S. Nolan, C. Zhang, and S. H. Chen, "Dynamics of the shallow meridional circulation around intertropical convergence zones," Journal of the Atmospheric Sciences, vol. 64, no. 7, pp. 2262-2285, 2007.

[33] C. Zhang, D. S. Nolan, C. D. Thorncroft, and H. Nguyen, "Shallow meridional circulations in the tropical atmosphere," Journal of Climate, vol. 21, no. 14, pp. 3453-3470, 2008.

[34] F. Couvreux, F. Guichard, O. Bock, B. Campistron, J. P. Lafore, and J. L. Redelsperger, "Synoptic variability of the monsoon flux over West Africa prior to the onset," Quarterly Journal of the Royal Meteorological Society, vol. 136, no. 1, pp. 159-173, 2010.

[35] J. Cuesta, C. Lavaysse, C. Flamant, M. Mimouni, and P. Knippertz, "Northward bursts of the West African monsoon leading to rainfall over the Hoggar Massif, Algeria," Quarterly Journal of the Royal Meteorological Society, vol. 136, no. 1, pp. 174-189, 2010.

[36] S. E. Nicholson, "The intensity, location and structure of the tropical rainbelt over west Africa as factors in interannual variability," International Journal of Climatology, vol. 28, no. 13, pp. 1775-1785, 2008.

[37] S. E. Nicholson, "On the factors modulating the intensity of the tropical rainbelt over West Africa," International Journal of Climatology, vol. 29, no. 5, pp. 673-689, 2009.

[38] P. Laux, H. Kunstmann, and A. Bárdossy, "Predicting the regional onset of the rainy season in West Africa," International Journal of Climatology, vol. 28, no. 3, pp. 329-342, 2008.

[39] B. Sultan and S. Janicot, "The West African monsoon dynamics. Part II: The "preonset" and "onset" of the summer monsoon," Journal of Climate, vol. 16, pp. 3407-3427, 2003.

[40] R. Marteau, V. Moron, and N. Philippon, "Spatial coherence of Monsoon onset over Western and Central Sahel (1950-2000)," Journal of Climate, vol. 22, no. 5, pp. 1313-1324, 2009.

[41] B. Sultan and S. Janicot, "Abrupt shift of the ITCZ over West Africa and intra-seasonal variability," Geophysical Research Letters, vol. 27, no. 20, pp. 3353-3356, 2000.

[42] P. Drobinski, S. Bastin, S. Janicot et al., "On the late northward propagation of the west African monsoon in summer 2006 in the region of Niger/Mali," Journal of Geophysical Research D, vol. 114, no. 9, Article ID D09108, 2009.

[43] O. Dieng, P. Roucou, and S. Lovet, "Intra-seasonal variability of precipitation in Senegal (1951-1996)," Secheresse, vol. 19, pp. 8793, 2008.

[44] G. A. Dalu, M. Gaetani, and M. Baldi, "A hydrological onset and withdrawal index for the West African monsoon," Theoretical and Applied Climatology, vol. 96, no. 1-2, pp. 179-189, 2009. 
[45] E. Flaounas, S. Janicot, S. Bastin, and R. Roca, "The West Africa monsoon onset in 2006: sensitivity to surface albedo, orography, SST and synoptic scale dry-air intrusions using WRF," Climate Dynamics, vol. 38, pp. 685-708, 2012.

[46] E. Flaounas, S. Janicot, S. Bastin, R. Roca, and E. Mohino, “The role of the Indian monsoon onset in the West African monsoon onset: observations and AGCM nudged simulations," Climate Dynamics, vol. 38, no. 5-6, pp. 965-983, 2011.

[47] P. Camberlin, B. Fontaine, S. Louvet, P. Oettli, and P. Valimba, "Climate adjustments over Africa accompanying the Indian monsoon onset," Journal of Climate, vol. 23, no. 8, pp. 20472064, 2010.

[48] C. Schumacher and R. A. House, "Stratiform precipitation production over sub-Saharan Africa and the tropical East Atlantic as observed by TRMM," Quarterly Journal of the Royal Meteorological Society, vol. 132, no. 620, pp. 2235-2255, 2006.

[49] L. Le Barbé, T. Lebel, and D. Tapsoba, "Rainfall variability in West Africa during the years 1950-90," Journal of Climate, vol. 15, no. 2, pp. 187-202, 2002.

[50] B. Sultan, S. Janicot, and A. Diedhiou, "The West African monsoon dynamics. Part I: documentation of interaseasonal variability," Journal of Climate, vol. 21, pp. 3389-3406, 2003.

[51] S. Sijikumar, P. Roucou, and B. Fontaine, "Monsoon onset over Sudan-Sahel: simulation by the regional scale model MM5," Geophysical Research Letters, vol. 33, no. 3, Article ID L03814, 2006.

[52] R. Ramel, H. Gallé, and C. Messager, "On the northward shift of the West African monsoon," Climate Dynamics, vol. 26, no. 4, pp. 429-440, 2006.

[53] Y. Okumura and S. P. Xie, "Interaction of the Atlantic equatorial cold tongue and the African monsoon," Journal of Climate, vol. 17, pp. 3589-3602, 2004.

[54] S. M. Hagos and K. H. Cook, "Dynamics of the West African monsoon jump," Journal of Climate, vol. 20, no. 21, pp. 52645284, 2007.

[55] A. Sealy, G. S. Jenkins, and S. C. Walford, "Seasonal/regional comparisons of rain rates and rain characteristics in West Africa using TRMM observations," Journal of Geophysical Research D, vol. 108, no. 10, pp. 3-21, 2003.

[56] M. A. Bell and P. J. Lamb, "Integration of weather system variability to multidecadal regional climate change: the West African Sudan-Sahel zone, 1951-98," Journal of Climate, vol. 19, no. 20, pp. 5343-5365, 2006.

[57] S. E. Nicholson, Dryland Climatology, Cambridge University Press, Cambridge, 2011.

[58] M. Le Lay and S. Galle, "Seasonal cycle and interannual variability of rainfall at hydrological scales. The West African monsoon in a Sudanese climate," Hydrological Sciences Journal, vol. 50, no. 3, pp. 509-524, 2005.

[59] E. Mohino, S. Janicot, H. Douville, and L. Z. X. Li, "Impact of the Indian part of the summer MJO on West Africa using nudged climate simulations," Climate Dynamics, vol. 38, pp. 2319-2334, 2012.

[60] S. Janicot, F. Mounier, N. M. J. Hall, S. Leroux, B. Sultan, and G. N. Kiladis, "Dynamics of the West African monsoon. Part IV: analysis of 25-90-day variability of convection and the role of the Indian monsoon," Journal of Climate, vol. 22, no. 6, pp. 1541-1565, 2009.

[61] S. Janicot, F. Mounier, S. Gervois, B. Sultan, and G. N. Kiladis, "The dynamics of the West African monsoon-part V: the detection and role of the dominant modes of convectively coupled equatorial Rossby waves," Journal of Climate, vol. 23, no. 14, pp. 4005-4024, 2010.

[62] G. Gu, R. F. Adler, G. J. Huffman, and S. Curtis, "African easterly waves and their association with precipitation," Journal of Geophysical Research D, vol. 109, no. 4, Article ID D04101, 12 pages, 2004.

[63] S. L. Lavender and A. J. Matthews, "Response of the West African monsoon to the Madden-Julian oscillation," Journal of Climate, vol. 22, no. 15, pp. 4097-4116, 2009.

[64] M. J. Ventrice, C. D. Thorncroft, and P. E. Roundy, "The madden-julian oscillation's influence on african easterly waves and downstream tropical cyclogenesis," Monthly Weather Review, vol. 139, pp. 2704-2722, 2011.

[65] S. Janicot and B. Sultan, "Intra-seasonal modulation of convection in the West African monsoon," Geophysical Research Letters, vol. 28, no. 3, pp. 523-526, 2001.

[66] F. Mounier, S. Janicot, and G. N. Kiladis, "The west African monsoon dynamics. Part III: the quasi-biweekly zonal dipole," Journal of Climate, vol. 21, no. 9, pp. 1911-1928, 2008.

[67] E. D. Maloney and J. Shaman, "Intraseasonal variability of the West African monsoon and Atlantic ITCZ," Journal of Climate, vol. 21, no. 12, pp. 2898-2918, 2008.

[68] S. Leroux, N. M. J. Hall, and G. N. Kiladis, "A climatological study of transient-mean-flow interactions over West Africa," Quarterly Journal of the Royal Meteorological Society, vol. 136, no. 1, pp. 397-410, 2010.

[69] C. D. Thorncroft, N. M. J. Hall, and G. N. Kiladis, "Threedimensional structure and dynamics of African easterly waves. Part III: genesis," Journal of the Atmospheric Sciences, vol. 65, no. 11, pp. 3596-3607, 2008.

[70] R. Roehrig, F. Chauvin, and J. P. Lafore, "10-25 day intraseasonal variability of convection over the Sahel: a role of the Saharan Heat Low and midlatitudes," Journal of Climate, vol. 24, pp. 5863-5878, 2011.

[71] F. Chauvin, R. Roehrig, and J. P. Lafore, "Intraseasonal variability of the saharan heat low and its link with midlatitudes," Journal of Climate, vol. 23, no. 10, pp. 2544-2561, 2010.

[72] E. K. Vizy and K. H. Cook, "A mechanism for African monsoon breaks: mediterranean cold air surges," Journal of Geophysical Research D, vol. 114, no. 1, Article ID D01104, 2009.

[73] R. Roca, J. P. Lafore, C. Piriou, and J. L. Redelsperger, "Extratropical dry-air intrusions into the West African monsoon midtroposphere: an important factor for the convective activity over the Sahel," Journal of the Atmospheric Sciences, vol. 62, no. 2, pp. 390-407, 2005.

[74] S. E. Nicholson, "The nature of rainfall variability in Africa south of the equator," Journal of Climatology, vol. 6, no. 5, pp. 515-530, 1986.

[75] S. E. Nicholson, "Revised rainfall series for the West African subtropics," Monthly Weather Review, vol. 107, no. 5, pp. 620$623,1979$.

[76] S. E. Nicholson, B. Some, and B. Kone, "An analysis of recent rainfall conditions in West Africa, including the rainy seasons of the 1997 El Nino and the 1998 La Nina years," Journal of Climate, vol. 13, no. 14, pp. 2628-2640, 2000.

[77] M. D. Dennett, J. Elston, and J. A. Rodgers, "A reappraisal of rainfall trends in the Sahel," Journal of Climatology, vol. 5, no. 4, pp. 353-361, 1985.

[78] S. E. Nicholson, "Climatic and environmental change in Africa during the last two centuries," Climate Research, vol. 17, no. 2, pp. 123-144, 2001. 
[79] Y. L'Hote, G. Mahe, and B. Some, "The 1990s rainfall in the Sahel: the third driest decade since the beginning of the century," Hydrological Sciences Journal, vol. 48, no. 3, pp. 493-496, 2003.

[80] A. Dai, P. J. Lamb, K. E. Trenberth, M. Hulme, P. D. Jones, and P. Xie, "The recent Sahel drought is real," International Journal of Climatology, vol. 24, no. 11, pp. 1323-1331, 2004.

[81] Y. L'Hôte, G. Mahé, B. Somé, and J. P. Triboulet, "Analysis of a Sahelian annual rainfall index from 1896 to 2000; the drought continues," Hydrological Sciences Journal, vol. 47, no. 4, pp. 563$572,2002$.

[82] S. E. Nicholson, A. K. Dezfuli, and D. Klotter, "A two-century precipitation data set for the continent of Africa," Bulletin of the American Meteorological Society, vol. 93, pp. 1219-1231, 2012.

[83] S. E. Nicholson, D. Klotter, and A. K. Dezfuli, "Spatial reconstruction of semi-quantitative precipitation fields over Africa during the nineteenth century from documentary evidence and gauge data," Quaternary Research, vol. 78, pp. 13-23, 2012.

[84] H. Faure and J. Y. Gac, "Will the Sahelian drought end in 1985?" Nature, vol. 291, no. 5815, pp. 475-478, 1981.

[85] J. M. Prospero and T. N. Carlson, "Vertical and areal distribution of saharan dust over western equatorial north-atlantic ocean," Journal of Geophysical Research, vol. 77, pp. 5255-5265, 1972.

[86] P. Ozer, M. Erpicum, G. Demarée, and M. Vandiepenbeeck, "The Sahelian drought may have ended during the 1990s," Hydrological Sciences Journal, vol. 48, no. 3, pp. 489-492, 2003.

[87] S. Hastenrath and D. Polzin, "Long-term variations of circulation in the tropical Atlantic sector and Sahel rainfall," International Journal of Climatology, vol. 31, no. 5, pp. 649-655, 2011.

[88] B. Fontaine, P. Roucou, M. Gaetani, and R. Marteau, "Recent changes in precipitation, ITCZ convection and northern tropical circulation over North Africa (1979-2007)," International Journal of Climatology, vol. 31, no. 5, pp. 633-648, 2011.

[89] G. Mahé and J. E. Paturel, "1896-2006 Sahelian annual rainfall variability and runoff increase of Sahelian Rivers," Comptes Rendus, vol. 341, no. 7, pp. 538-546, 2009.

[90] L. Olsson, L. Eklundh, and J. Ardö, "A recent greening of the Sahel-trends, patterns and potential causes," Journal of Arid Environments, vol. 63, no. 3, pp. 556-566, 2005.

[91] S. M. Herrmann and C. F. Hutchinson, "The changing contexts of the desertification debate," Journal of Arid Environments, vol. 63, no. 3, pp. 538-555, 2005.

[92] S. M. Herrmann, A. Anyamba, and C. J. Tucker, "Recent trends in vegetation dynamics in the African Sahel and their relationship to climate," Global Environmental Change, vol. 15, no. 4, pp. 394-404, 2005.

[93] J. W. Seaquist, L. Olsson, J. Ardö, and L. Eklundh, "Broad-scale increase in NPP quantified for the African Sahel, 1982-1999," International Journal of Remote Sensing, vol. 27, no. 22, pp. 5115$5122,2006$.

[94] S. E. Nicholson, B. Some, J. McCollum et al. et al., "Validation of TRMM and other rainfall estimates with a high-density gauge dataset for West Africa-part II: validation of TRMM rainfall products," Journal of Applied Meteorology, vol. 42, pp. 1355-1368, 2003.

[95] S. E. Nicholson and P. J. Webster, "A physical basis for the interannual variability of rainfall in the Sahel," Quarterly Journal of the Royal Meteorological Society, vol. 133, no. 629, pp. 20652084, 2007.

[96] S. W. Nesbitt et al., 2000.
[97] S. E. Nicholson, "Rainfall and atmospheric circulation during drought periods and wetter years in West Africa," Monthly Weather Review, vol. 109, no. 10, pp. 2191-2208, 1981.

[98] H. Flohn, "Tropische zirkulationsformen im lichte der satellitenaufnahmen," Bonner Meteorologishe Abhandlungen, vol. 21, 82 pages, 1975.

[99] M. Biasutti, I. M. Held, A. H. Sobel, and A. Giannini, "SST forcings and Sahel rainfall variability in simulations of the twentieth and twenty-first centuries," Journal of Climate, vol. 21, no. 14, pp. 3471-3486, 2008.

[100] A. K. Dezfuli and S. E. Nicholson, "Re-examination of the relationship between the AMO and Sahel rainfall and the potential for long-termforecasting," In press.

[101] N. A. Elagib and M. M. Elhag, "Major climate indicators of ongoing drought in Sudan," Journal of Hydrology, vol. 409, pp. 612-625, 2011.

[102] S. Nicholson, "Land surface processes and Sahel climate," Reviews of Geophysics, vol. 38, no. 1, pp. 117-139, 2000.

[103] S. E. Nicholson and J. P. Grist, "A conceptual model for understanding rainfall variability in the West African Sahel on interannual and interdecadal timescales," International Journal of Climatology, vol. 21, no. 14, pp. 1733-1757, 2001.

[104] T. Losada, B. Rodríguez-Fonseca, E. Mohino, J. Bader, S. Janicot, and C. R. Mechoso, "Tropical SST and Sahel rainfall: a nonstationary relationship," Geophysical Research Letters, vol. 39, Article ID L12705, 2012.

[105] M. I. Lélé and P. J. Lamb, "Variability of the Intertropical Front (ITF) and rainfall over the West African Sudan-Sahel zone," Journal of Climate, vol. 23, no. 14, pp. 3984-4004, 2010.

[106] M. Balme, T. Lebel, and A. Amani, "Dry years and wet years in the Sahel: quo vadimus?" Hydrological Sciences Journal, vol. 51, no. 2, pp. 254-271, 2006.

[107] F. Frappart, P. Hiernaux, F. Guichard et al., "Rainfall regime across the Sahel band in the Gourma region, Mali," Journal of Hydrology, vol. 375, no. 1-2, pp. 128-142, 2009.

[108] R. A. Bryson, "Drought in Sahelia. Who or what is to blame?" Ecologist, vol. 3, no. 10, pp. 366-371, 1973.

[109] E. B. Kraus, "Subtropical droughts and cross-equatorial energy transports," Monthly Weather Review, vol. 105, pp. 1009-1018, 1977.

[110] M. K. Miles and C. K. Follard, "Changes in the latitude of the climatic zones of the Northern Hemisphere," Nature, vol. 252, no. 5484 , article $616,1974$.

[111] T. C. Chen, "Maintenance of the midtropospheric North African summer circulation; Saharan high and African easterly jet," Journal of Climate, vol. 18, no. 15, pp. 2943-2962, 2005.

[112] R. J. Cornforth, B. J. Hoskins, and C. D. Thorncroft, “The impact of moist processes on the African Easterly Jet-African Easterly Wave system," Quarterly Journal of the Royal Meteorological Society, vol. 135, no. 641, pp. 894-913, 2009.

[113] A. M. Tompkins, C. Cardinali, J. J. Morcrette, and M. Rodwell, "Influence of aerosol climatology on forecasts of the African Easterly Jet," Geophysical Research Letters, vol. 32, no. 10, Article ID L10801, 2005.

[114] K. H. Cook, "Generation of the African easterly jet and its role in determining West African precipitation," Journal of Climate, vol. 12, no. 5, pp. 1165-1184, 1999.

[115] M. C. R. Kalapureddy, M. Lothon, B. Campistron, F. Lohou, and F. Saï, "Wind profiler analysis of the African Easterly Jet in relation with the boundary layer and the Saharan heat-low," Quarterly Journal of the Royal Meteorological Society, vol. 136, no. 1, pp. 77-91, 2010. 
[116] R. W. Burpee, "Origin and structure of easterly waves in lower troposphere of North Africa," Journal of the Atmospheric Sciences, vol. 29, pp. 77-90, 1972.

[117] J. S. Hsieh and K. H. Cook, "Generation of African easterly wave disturbances: relationship to the African easterly jet," Monthly Weather Review, vol. 133, no. 5, pp. 1311-1327, 2005.

[118] J. S. Hsieh and K. H. Cook, "On the instability of the African easterly jet and the generation of African waves: reversals of the potential vorticity gradient," Journal of the Atmospheric Sciences, vol. 65, no. 7, pp. 2130-2151, 2008.

[119] N. M. J. Hall, G. N. Kiladis, and C. D. Thorncroft, "Threedimensional structure and dynamics of African easterly waves. Part II: dynamical modes," Journal of the Atmospheric Sciences, vol. 63, no. 9, pp. 2231-2245, 2006.

[120] A. K. Dezfuli and S. E. Nicholson, "A note on long-term variations of the African easterly jet," International Journal of Climatology, vol. 31, pp. 2049-2054, 2011.

[121] Z. Wang and R. L. Elsberry, "Modulation of the African easterly jet by a mesoscale convective system," Atmospheric Science Letters, vol. 11, pp. 169-174, 2010.

[122] M. V. Ratnam, M. R. Raman, S. K. Mehta et al., "Sub-daily variations observed in Tropical Easterly Jet (TEJ) streams," Journal of Atmospheric and Solar-Terrestrial Physics, vol. 73, no. 7-8, pp. 731-740, 2011.

[123] M. R. Raman, V. V. M. Jagannadha Rao, M. Venkat Ratnam et al., "Characteristics of the Tropical Easterly Jet: long-term trends and their features during active and break monsoon phases," Journal of Geophysical Research D, vol. 114, no. 19, Article ID D19105, 2009.

[124] D. R. Pattanaik and V. Satyan, "Fluctuations of Tropical Easterly Jet during contrasting monsoons over India: a GCM study," Meteorology and Atmospheric Physics, vol. 75, no. 1-2, pp. 51-60, 2000.

[125] V. Sathiyamoorthy, "Large scale reduction in the size of the Tropical Easterly Jet," Geophysical Research Letters, vol. 32, no. 14, Article ID L14802, 2005.

[126] M. Hulme and N. Tosdevin, "The Tropical easterly Jet and Sudan rainfall: a review," Theoretical and Applied Climatology, vol. 39, no. 4, pp. 179-187, 1989.

[127] Z. T. Segele, P. J. Lamb, and L. M. Leslie, "Large-scale atmospheric circulation and global sea surface temperature associations with horn of Africa June-September rainfall," International Journal of Climatology, vol. 29, no. 8, pp. 1075-1100, 2009.

[128] B. R. Srinivasa Rao, D. V. Bhaskar Rao, and V. Brahmananda Rao, "Decreasing trend in the strength of Tropical Easterly Jet during the Asian summer monsoon season and the number of tropical cyclonic systems over Bay of Bengal," Geophysical Research Letters, vol. 31, no. 14, pp. L141031-L141033, 2004.

[129] H. Flohn, "The tropical easterly jet," Bonner meteorologische Abhandlungen, vol. 4, pp. 1-69, 1964.

[130] H. Besler, "The Tropical Easterly Jet as a cause for intensified aridity in the Sahara," Palaeoecology of Africa, vol. 16, pp. 163$172,1984$.

[131] P. J. Webster and J. Fasullo, "Monsoon: dynamical theory," in Encyclopedia of Atmospheric Sciences, J. Holton and J. A. Curry, Eds., pp. 1370-1385, Academic Press, London, UK, 2003.

[132] T. C. Chen and H. van Loon, "Interannual variation of the tropical easterly jet," Monthly Weather Review, vol. 115, no. 8, pp. 1739-1759, 1987.

[133] S. K. Mishra, "Nonlinear barotropic instability of uppertropospheric tropical easterly jet on the sphere," Journal of the Atmospheric Sciences, vol. 50, no. 21, pp. 3541-3552, 1993.
[134] S. K. Mishra and M. K. Tandon, "A combined barotropicbaroclinic instability study of the upper tropospheric tropical easterly jet," Journal of the Atmospheric Sciences, vol. 40, no. 11, pp. 2708-2723, 1983.

[135] S. E. Nicholson, A. I. Barcilon, M. Challa, and J. Baum, "Wave activity on the tropical easterly jet," Journal of the Atmospheric Sciences, vol. 64, no. 7, pp. 2756-2763, 2007.

[136] S. E. Nicholson, A. I. Barcilon, and M. Challa, "An analaysis of west African dynamics using a linearized GCM," Journal of the Atmospheric Sciences, vol. 65, no. 4, pp. 1182-1203, 2008.

[137] R. Washington and M. C. Todd, "Atmospheric controls on mineral dust emission from the Bodélé Depression, Chad: the role of the low level jet," Geophysical Research Letters, vol. 32, article 17701, 2005.

[138] R. Washington, M. C. Todd, S. Engelstaedter, S. Mbainayel, and F. Mitchell, "Dust and the low-level circulation over the Bodélé Depression, Chad: observations from BoDEx 2005," Journal of Geophysical Research D, vol. 111, no. 3, Article ID D03201, 2006.

[139] R. Washington and M. C. Todd, "Atmospheric controls on mineral dust emission from the Bodélé Depression, Chad: the role of the low level jet," Geophysical Research Letters, vol. 32, no. 17, Article ID L17701, pp. 1-5, 2005.

[140] M. C. Todd, R. Washington, S. Raghavan, G. Lizcano, and P. Knippertz, "Regional model simulations of the Bodélé lowlevel jet of Northern Chad during the Bodélé dust experiment (BoDEx 2005)," Journal of Climate, vol. 21, no. 5, pp. 995-1012, 2008.

[141] R. A. Tomas and P. J. Webster, "The role of inertial instability in determining the location and strength of near-equatorial convection," Quarterly Journal of the Royal Meteorological Society, vol. 123, no. 542, pp. 1445-1482, 1997.

[142] S. A. Grodsky, J. A. Carton, and S. Nigam, "Near surface westerly wind jet in the Atlantic ITCZ," Geophysical Research Letters, vol. 30, no. 19, pp. 1-4, 2003.

[143] B. Pu and K. H. Cook, "Dynamics of the West African westerly jet," Journal of Climate, vol. 23, no. 23, pp. 6263-6276, 2010.

[144] J. P. Grist, S. E. Nicholson, and A. I. Barcilon, "Easterly waves over Africa. Part II: observed and modeled contrasts between wet and dry years," Monthly Weather Review, vol. 130, no. 2, pp. 212-225, 2002.

[145] B. Pu and K. H. Cook, "Role of the West African Westerly Jet in Sahel rainfall variations," Journal of Climate, vol. 25, pp. 28802896, 2012.

[146] K. Abdou, D. J. Parker, B. Brooks, N. Kalthoff, and T. Lebel, “The diurnal cycle of lower boundary-layer wind in the West African Monsoon," Quarterly Journal of the Royal Meteorological Society, vol. 136, no. 1, pp. 66-76, 2010.

[147] M. Lothon, F. Said, F. Lohou, and B. Campistron, "Observation of the diurnal cycle in the low troposphere of West Africa," Monthly Weather Review, vol. 136, no. 9, pp. 3477-3500, 2008.

[148] B. Sultan, S. Janicot, and P. Drobinski, "Characterization of the diurnal cycle of the West African monsoon around the monsoon onset," Journal of Climate, vol. 20, no. 15, pp. 40144032, 2007.

[149] C. L. Bain, D. J. Parker, C. M. Taylor, L. Kergoat, and F. Guichard, "Observations of the nocturnal boundary layer associated with the West African monsoon," Monthly Weather Review, vol. 138, no. 8, pp. 3142-3156, 2010.

[150] P. Peyrille and J. Lafore, "An idealized two-dimensional framework to study the West African monsoon. Part II: large-scale advection and the diurnal cycle," Journal of the Atmospheric Sciences, vol. 64, no. 8, pp. 2783-2803, 2007. 
[151] J. M. Schrage and A. H. Fink, "Nocturnal continental low-level stratus over tropical West Africa: observations and possible mechanisms controlling its onset," Monthly Weather Review, vol. 140, pp. 1794-1809, 2012.

[152] C. Lavaysse, C. Flamant, S. Janicot, and P. Knippertz, "Links between African easterly waves, midlatitude circulation and intraseasonal pulsations of the West African heat low," Quarterly Journal of the Royal Meteorological Society, vol. 136, no. 1, pp. 141-158, 2010.

[153] M. Biasutti, A. H. Sobel, and S. J. Camargo, "The role of the Sahara low in summertime Sahel rainfall variability and change in the CMIP3 models," Journal of Climate, vol. 22, no. 21, pp. 5755-5771, 2009.

[154] C. Lavaysse, C. Flamant, S. Janicot et al., "Seasonal evolution of the West African heat low: a climatological perspective," Climate Dynamics, vol. 33, no. 2-3, pp. 313-330, 2009.

[155] A. Mekonnen, C. D. Thorncroft, and A. R. Aiyyer, "Analysis of convection and its association with African easterly waves," Journal of Climate, vol. 19, no. 20, pp. 5405-5421, 2006.

[156] L. Bounoua and T. N. Krishnamurti, "Thermodynamic budget of the five day wave over the Saharan desert during summer," Meteorology and Atmospheric Physics, vol. 47, no. 1, pp. 1-25, 1991.

[157] C. Lavaysse, J. P. Chaboureau, and C. Flamant, "Dust impact on the west african heat low in summertime," Quarterly Journal of the Royal Meteorological Society, vol. 137, no. 658, pp. 1227-1240, 2011.

[158] C. M. Grams, S. C. Jones, J. H. Marsham, D. J. Parker, J. M. Haywood, and V. Heuveline, "The atlantic inflow to the saharan heat low: observations and modelling," Quarterly Journal of the Royal Meteorological Society, vol. 136, no. 1, pp. 125-140, 2010.

[159] C. Messager, D. J. Parker, O. Reitebuch, A. Agusti-Panareda, C. M. Taylor, and J. Cuesta, "Structure and dynamics of the Saharan atmospheric boundary layer during the West African monsoon onset: observations and analyses from the research flights of 14 and 17 July 2006," Quarterly Journal of the Royal Meteorological Society, vol. 136, no. 1, pp. 107-124, 2010.

[160] J. M. Prospero, P. Ginoux, O. Torres, S. E. Nicholson, and T. E. Gill, "Environmental characterization of global sources of atmospheric soil dust identified with the Nimbus 7 Total Ozone Mapping Spectrometer (TOMS) absorbing aerosol product," Reviews of Geophysics, vol. 40, no. 1, pp. 1-31, 2002.

[161] J. P. Dunion and C. S. Velden, "The impact of the Saharan Air Layer on Atlantic tropical cyclone activity," Bulletin of the American Meteorological Society, vol. 85, no. 3, pp. 353-365, 2004.

[162] D. J. Parker, C. D. Thorncroft, R. R. Burton, and A. DiongueNiang, "Analysis of the African easterly jet, using aircraft observations from the JET2000 experiment," Quarterly Journal of the Royal Meteorological Society, vol. 131, no. 608, pp. 1461$1482,2005$.

[163] H. F. Diaz, T. N. Carlson, and J. M. Propsero, "A study of the structure and dynamics of the Saharan air layer over the northern equatorial Atlantic during BOMEX," NOAA Technical Memorandum ERL WMPO-32, 1976.

[164] S. Wong, A. E. Dessler, N. M. Mahowald, P. Yang, and Q. Feng, "Maintenance of lower tropospheric temperature inversion in the Saharan air layer by dust and dry anomaly," Journal of Climate, vol. 22, no. 19, pp. 5149-5162, 2009.

[165] V. M. Karyampudi, S. P. Palm, J. A. Reagen et al., "Validation of the Saharan dust plume conceptual model using lidar, Meteosat, and ECMWF data," Bulletin of the American Meteorological Society, vol. 80, no. 6, pp. 1045-1075, 1999.

[166] F. Couvreux, C. Rio, F. Guichard et al., "Initiation of daytime local convection in a semi-arid region analysed with highresolution simulations and AMMA observations," Quarterly Journal of the Royal Meteorological Society, vol. 138, pp. 56-71, 2012.

[167] S. W. Nesbitt, R. Cifelli, and S. A. Rutledge, "Storm morphology and rainfall characteristics of TRMM precipitation features," Monthly Weather Review, vol. 134, no. 10, pp. 2702-2721, 2006.

[168] C. Schumacher and R. A. Houze Jr., "Stratiform rain in the tropics as seen by the TRMM precipitation radar," Journal of Climate, vol. 16, no. 11, pp. 1739-1756, 2003.

[169] B. Jackson, S. E. Nicholson, and D. Klotter, "Mesoscale convective systems over western equatorial Africa and their relationship to large-scale circulation," Monthly Weather Review, vol. 137, no. 4, pp. 1272-1294, 2009.

[170] L. Ricciardulli and P. D. Sardeshmukh, "Local time- and space scales of organized tropical deep convection," Journal of Climate, vol. 15, no. 19, pp. 2775-2790, 2002.

[171] A. Gaye, A. Viltard, and P. de Félice, "Squall lines and rainfall over Western Africa during summer 1986 and 87," Meteorology and Atmospheric Physics, vol. 90, no. 3-4, pp. 215-224, 2005.

[172] R. N. Ferreira, T. Rickenbach, N. Guy, and E. Williams, "Radar observations of convective system variability in relationship to african easterly waves during the 2006 AMMA special observing period," Monthly Weather Review, vol. 137, no. 12, pp. 4136-4150, 2009.

[173] A. H. Fink and A. Reiner, "Spatiotemporal variability of the relation between African Easterly Waves and West African Squall Lines in 1998 and 1999," Journal of Geophysical Research $D$, vol. 108, no. 11, article 4332, pp. 1-17, 2003.

[174] A. G. Laing, R. Carbone, V. Levizzani, and J. Tuttle, "The propagation and diurnal cycles of deep convection in northern tropical Africa," Quarterly Journal of the Royal Meteorological Society, vol. 134, no. 630, pp. 93-109, 2008.

[175] K. I. Mohr and C. D. Thorncroft, "Intense convective systems in West Africa and their relationship to the African easterly jet," Quarterly Journal of the Royal Meteorological Society, vol. 132, no. 614 , pp. 163-176, 2006.

[176] S. D. Nicholls and K. I. Mohr, "An analysis of the environments of intense convective systems in West Africa in 2003," Monthly Weather Review, vol. 138, pp. 3721-3739, 2010.

[177] P. Knippertz and J. E. Martin, "Tropical plumes and extreme precipitation in subtropical and tropical West Africa," Quarterly Journal of the Royal Meteorological Society, vol. 131, no. 610, pp. 2337-2365, 2005.

[178] P. Knippertz, A. H. Fink, A. Reiner, and P. Speth, “Three late summer/early autumn cases of tropical-extratropical interactions causing precipitation in Northwest Africa," Monthly Weather Review, vol. 131, no. 1, pp. 116-135, 2003.

[179] P. Knippertz and J. E. Martin, "The role of dynamic and diabatic processes in the generation of cut-off lows over Northwest Africa," Meteorology and Atmospheric Physics, vol. 96, no. 1-2, pp. 3-19, 2007.

[180] F. Meier and P. Knippertz, "Dynamics and predictability of a heavy dry-season precipitation event over West Africasensitivity experiments with a global model," Monthly Weather Review, vol. 137, no. 1, pp. 189-206, 2009. 
[181] K. Schepanski and P. Knippertz, "Soudano-Saharan depressions and their importance for precipitation and dust: a new perspective on a classical synoptic concept," Journal of Climate, vol. 137, pp. 1431-1445, 2011.

[182] P. Knippertz and A. H. Fink, "Dry-season precipitation in tropical West Africa and its relation to forcing from the extratropics," Monthly Weather Review, vol. 136, no. 9, pp. 35793596, 2008.

[183] M. Geb, "Factors favouring precipitation in North Africa: seen from the viewpoint of present-day climatology," Global and Planetary Change, vol. 26, no. 1-3, pp. 85-96, 2000.

[184] J. Zawislak and E. J. Zipser, "Observations of seven African easterly waves in the east Atlantic during 2006," Journal of the Atmospheric Sciences, vol. 67, no. 1, pp. 26-43, 2010.

[185] A. Diedhiou, S. Janicot, A. Viltard, P. De Felice, and H. Laurent, "Easterly wave regimes and associated convection over West Africa and tropical Atlantic: results from the NCEP/NCAR and ECMWF reanalyses," Climate Dynamics, vol. 15, no. 11, pp. 795822, 1999.

[186] I. Pytharoulis and C. Thorncroft, "The low-level structure of African easterly waves in 1995," Monthly Weather Review, vol. 127, no. 10, pp. 2266-2280, 1999.

[187] A. H. Fink, D. G. Vincent, P. M. Reiner, and P. Speth, "Mean state and wave disturbances during Phases I, II and III of GATE based on ERA-40," Monthly Weather Review, vol. 132, pp. 16611683, 2004.

[188] C. Thorncroft and K. Hodges, "African easterly wave variability and its relationship to Atlantic tropical cyclone activity," Journal of Climate, vol. 14, no. 6, pp. 1166-1179, 2001.

[189] T. C. Chen, "Characteristics of African easterly waves depicted by ECMWF reanalyses for 1991-2000," Monthly Weather Review, vol. 134, no. 12, pp. 3539-3566, 2006.

[190] L. M. Druyan, M. Fulakeza, and P. Lonergan, "Mesoscale analyses of West African summer climate: focus on wave disturbances," Climate Dynamics, vol. 27, no. 5, pp. 459-481, 2006.

[191] R. S. Ross and T. N. Krishnamurti, "Low-level African easterly wave activity and its relation to Atlantic tropical cyclogenesis in 2001," Monthly Weather Review, vol. 135, no. 12, pp. 3950-3964, 2007.

[192] G. J. Berry and C. Thorncroft, "Case study of an intense African easterly wave," Monthly Weather Review, vol. 133, no. 4, pp. 752766, 2005

[193] S. Leroux and N. M. J. Hall, "On the relationship between African easterly waves and the African easterly jet," Journal of the Atmospheric Sciences, vol. 66, no. 8, pp. 2303-2316, 2009.

[194] A. J. Matthews, "Intraseasonal variability over tropical Africa during northern summer," Journal of Climate, vol. 17, pp. 24272440, 2004.

[195] G. J. Alaka and E. D. Maloney, "The influence of the MJO on upstream precursors to African Easterly Waves," Journal of Climate, vol. 25, pp. 3219-3236, 2012.

[196] F. Mounier, G. N. Kiladis, and S. Janicot, "Analysis of the dominant mode of convectively coupled Kelvin waves in the West African monsoon," Journal of Climate, vol. 20, no. 8, pp. 1487-1503, 2007.

[197] A. Mekonnen, C. D. Thorncroft, A. R. Aiyyer, and G. N. Kiladis, "Convectively coupled Kelvin waves over tropical Africa during the boreal summer: structure and variability," Journal of Climate, vol. 21, no. 24, pp. 6649-6667, 2008.

[198] J. P. Grist, "Easterly waves over Africa. Part I: the seasonal cycle and contrasts between wet and dry years," Monthly Weather Review, vol. 130, no. 2, pp. 197-211, 2002.
[199] E. H. Taleb and L. M. Druyan, "Relationships between rainfall and West African wave disturbances in station observations," International Journal of Climatology, vol. 23, no. 3, pp. 305-313, 2003.

[200] G. N. Kiladis, C. D. Thorncroft, and N. M. J. Hall, "Threedimensional structure and dynamics of African easterly waves. Part I: observations," Journal of the Atmospheric Sciences, vol. 63, no. 9, pp. 2212-2230, 2006.

[201] C. L. Bain, D. J. Parker, N. Dixon et al., "Anatomy of an observed African easterly wave in July 2006," Quarterly Journal of the Royal Meteorological Society, vol. 137, no. 657, pp. 923-933, 2011.

[202] D. Monkam, "The 6-9 day wave and rainfall modulation in northern Africa during summer 1981," Journal of Geophysical Research D, vol. 108, no. 17, pp. 5-12, 2003.

[203] P. J. Lamb, "Case studies of tropical Atlantic surface circulation patterns during recent sub-Saharan weather anomalies: 1967 and 1968," Monthly Weather Review, vol. 106, pp. 482-491, 1978.

[204] P. J. Lamb, "Large-scale tropical Atlantic surface circulation patterns associated with sub-Saharan weather anomalies," Tellus, vol. 30, pp. 482-491, 1978.

[205] C. K. Folland, T. N. Palmer, and D. E. Parker, "Sahel rainfall and worldwide sea temperatures, 1901-1985," Journal of Forecasting, vol. 1, pp. 21-56, 1986.

[206] A. Giannini, R. Saravanan, and P. Chang, "Oceanic forcing of sahel rainfall on interannual to interdecadal time scales," Science, vol. 302, no. 5647, pp. 1027-1030, 2003.

[207] A. Giannini, R. Saravanan, and P. Chang, "Dynamics of the boreal summer African monsoon in the NSIPP1 atmospheric model," Climate Dynamics, vol. 25, pp. 517-535, 2005.

[208] A. Giannini, M. Biasutti, and M. M. Verstraete, "A climate model-based review of drought in the Sahel: desertification, the re-greening and climate change," Global and Planetary Change, vol. 64, no. 3-4, pp. 119-128, 2008.

[209] D. P. Rowell, "The impact of Mediterranean SSTs on the Sahelian rainfall season," Journal of Climate, vol. 16, no. 5, pp. 849-862, 2003.

[210] K. M. Lau, S. S. P. Shen, K. M. Kim, and H. Wang, "A multimodel study of the twentieth-century simulations of Sahel drought from the 1970s to 1990s," Journal of Geophysical Research D, vol. 111, no. 7, Article ID D07111, 2006.

[211] M. N. Ward, "Diagnosis and short-lead time prediction of summer rainfall in tropical North Africa at interannual and multidecadal timescales," Journal of Climate, vol. 11, no. 12, pp. 3167-3191, 1998.

[212] M. Joly, A. Voldoire, H. Douville, P. Terray, and J. F. Royer, "African monsoon teleconnections with tropical SSTs: validation and evolution in a set of IPCC4 simulations," Climate Dynamics, vol. 29, no. 1, pp. 1-20, 2007.

[213] M. Joly and A. Voldoire, "Role of the Gulf of Guinea in the interannual variability of the West African monsoon: what do we learn from CMIP3 coupled simulations?" International Journal of Climatology, vol. 30, no. 12, pp. 1843-1856, 2010.

[214] E. Mohino, B. Rodríguez-Fonseca, T. Losada et al., "Changes in the interannual SST-forced signals on West African rainfall. AGCM intercomparison," Climate Dynamics, vol. 37, no. 9-10, pp. 1707-1725, 2011.

[215] K. M. Lau, K. M. Kim, Y. C. Sud, and G. K. Walker, "A GCM study of the response of the atmospheric water cycle of West Africa and the Atlantic to Saharan dust radiative forcing," Annales Geophysicae, vol. 27, no. 10, pp. 4023-4037, 2009. 
[216] A. Konare, A. S. Zakey, F. Solmon et al., "A regional climate modeling study of the effect of desert dust on the West African monsoon," Journal of Geophysical Research D, vol. 113, no. 12, Article ID D12206, 2008.

[217] M. Yoshioka, N. M. Mahowald, A. J. Conley et al., "Impact of desert dust radiative forcing on sahel precipitation: relative importance of dust compared to sea surface temperature variations, vegetation changes, and greenhouse gas warming," Journal of Climate, vol. 20, no. 8, pp. 1445-1467, 2007.

[218] B. Rodríguez-Fonseca, S. Janicot, E. Mohino et al. et al., "Interannual and decadal SST-forced responses of the West African monsoon," Atmospheric Science Letters, vol. 12, pp. 6774, 2011.

[219] L. M. Druyan, "Studies of 21st-century precipitation trends over West Africa," International Journal of Climatology, vol. 31, no. 10, pp. 1415-1424, 2011.

[220] H. Paeth and A. Hense, "SST versus climate change signals in West Africa n rainfall: 20th-century variations and future projections," Climatic Change, vol. 65, no. 1-2, pp. 179-208, 2004.

[221] C. M. Patricola and K. H. Cook, "Northern African climate at the end of the twenty-first century: an integrated application of regional and global climate models," Climate Dynamics, vol. 35, no. 1, pp. 193-212, 2010.

[222] F. Hourdin, I. Musat, F. Guichard et al., "Amma-Model intercomparison project," Bulletin of the American Meteorological Society, vol. 91, no. 1, pp. 95-104, 2010.

[223] L. M. Druyan, J. Feng, K. H. Cook et al., "The WAMME regional model intercomparison study," Climate Dynamics, vol. 35, no. 1, pp. 175-192, 2010.

[224] K. H. Cook, G. A. Meehl, and J. M. Arblaster, "Monsoon regimes and processes in CCSM4. Part II: african and American monsoon systems," Journal of Climate, vol. 24, pp. 2609-2621, 2012.

[225] G. Nikulin, C. Jones, F. Giorgi et al., "Precipitation climatology in an ensemble of CORDEX-Africa regional climate simulations," Journal of Climate, vol. 25, pp. 6057-6078, 2012.

[226] P. M. Ruti, J. E. Williams, F. Hourdin et al., "The West African climate system: a review of the AMMA model inter-comparison initiatives," Atmospheric Science Letters, vol. 12, no. 1, pp. 116122, 2011.

[227] M. Hoerling, J. Hurrell, J. Eischeid, and A. Phillips, "Detection and attribution of twentieth-century northern and southern African rainfall change," Journal of Climate, vol. 19, no. 16, pp. 3989-4008, 2006.

[228] T. Losada, B. Rodríguez-Fonseca, S. Janicot, S. Gervois, F. Chauvin, and P. Ruti, "A multi-model approach to the Atlantic Equatorial mode: impact on the West African monsoon," Climate Dynamics, vol. 35, no. 1, pp. 29-43, 2010.

[229] J. Sun, H. Wang, and W. Yuan, "Linkage of the boreal spring antarctic oscillation to the west african summer monsoon," Journal of the Meteorological Society of Japan, vol. 88, no. 1, pp. 15-28, 2010.

[230] I. Polo, A. Ullmann, P. Roucou, and B. Fontaine, "Weather regimes in the Euro-Atlantic and Mediterranean sector, and relationship with West African rainfall over the 1989-2008 period from a self-organizing maps approach," Journal of Climate, vol. 24, no. 13, pp. 3423-3432, 2011.

[231] R. Zhang and T. L. Delworth, "Impact of Atlantic multidecadal oscillations on India/Sahel rainfall and Atlantic hurricanes," Geophysical Research Letters, vol. 33, Article ID L17712, 2006.

[232] T. L. Delworth, R. Zhang, and M. E. Mann, "Decadal to centennial variability of the Atlantic from observations and models. Ocean circulation: mechanisms and impacts," Geophysical Monograph Series, vol. 173, pp. 121-148, 2007.

[233] M. F. Ting, Y. Kushnir, R. Seager, and C. H. Li, "Robust features ofg Atlantic multidecadal variability and its climate impacts," Geophysical Research Letters, vol. 38, Article ID L17705, 2011.

[234] T. M. Shanahan, J. T. Overpeck, K. J. Anchukaitis et al., "Atlantic forcing of persistent drought in West Africa," Science, vol. 324, no. 5925, pp. 377-380, 2009.

[235] D. L. R. Hodson, R. T. Sutton, C. Cassou, N. Keenlyside, Y. Okumura, and T. Zhou, "Climate impacts of recent multidecadal changes in Atlantic Ocean sea surface temperature: a multimodel comparison," Climate Dynamics, vol. 34, no. 7, pp. 1041-1058, 2010.

[236] H. Paeth and P. Friederichs, "Seasonality and time scales in the relationship between global SST and African rainfall," Climate Dynamics, vol. 23, no. 7-8, pp. 815-837, 2004.

[237] D. P. Rowell, "Teleconnections between the tropical Pacific and the Sahel," Quarterly Journal of the Royal Meteorological Society, vol. 127, pp. 1683-1706, 2001.

[238] C. F. Ropelewski and M. S. Halpert, "Global and regional scale precipitation patterns associated with the El-Nino Southern oscillation," Monthly Weather Review, vol. 115, pp. 1606-1626, 1987.

[239] C. F. Ropelewski and M. S. Halpert, "Precipitation patterns associated with the high index phase of the southern oscillation," Journal of Climate, vol. 2, pp. 268-284, 1989.

[240] S. E. Nicholson and J. Kim, "The relationship of the El Nino Southern oscillation to African rainfall," International Journal of Climatology, vol. 17, no. 2, pp. 117-135, 1997.

[241] J. Bader and M. Latif, "The impact of decadal-scale Indian Ocean sea surface temperature anomalies on Sahelian rainfall and the North Atlantic Oscillation," Geophysical Research Letters, vol. 30, no. 22, pp. 2169-2173, 2003.

[242] F. Raicich, N. Pinardi, and A. Navarra, "Teleconnections between Indian monsoon and Sahel rainfall and the Mediterranean," International Journal of Climatology, vol. 23, no. 2, pp. 173-186, 2003.

[243] C. E. Chung and V. Ramanathan, "Weakening of north Indian SST gradients and the monsoon rainfall in India and the Sahel," Journal of Climate, vol. 19, no. 10, pp. 2036-2045, 2006.

[244] J. Bader and M. Latif, "The 1983 drought in the West Sahel: a case study," Climate Dynamics, vol. 36, no. 3, pp. 463-472, 2011.

[245] J. Lu and T. L. Delworth, "Oceanic forcing of the late 20th century Sahel drought," Geophysical Research Letters, vol. 32, Article ID L22706, 2005.

[246] J. Lu, "The dynamics of the Indian Ocean sea surface temperature forcing of Sahel drought," Climate Dynamics, vol. 33, no. 4, pp. 445-460, 2009.

[247] I. Polo, B. Rodríguez-Fonseca, T. Losada, and J. García-Serrano, "Tropical atlantic variability modes (1979-2002) - part I: timeevolving SST modes related to West African rainfall," Journal of Climate, vol. 21, no. 24, pp. 6457-6475, 2008.

[248] T. Jung, L. Ferranti, and A. M. Tompkins, "Response to the summer of 2003 Mediterranean SST anomalies over Europe and Africa," Journal of Climate, vol. 19, no. 20, pp. 5439-5454, 2006.

[249] M. Gaetani, B. Fontaine, P. Roucou, and M. Baldi, "Influence of the Mediterranean Sea on the West African monsoon: intraseasonal variability in numerical simulations," Journal of Geophysical Research-Atmospheres, vol. 115, no. D24, 2010.

[250] B. Fontaine, J. Garcia-Serrano, P. Roucou et al., "Impacts of warm and cold situations in the Mediterranean basins on the 
West African monsoon: observed connection patterns (19792006) and climate simulations," Climate Dynamics, vol. 35, no. 1, pp. 95-114, 2010.

[251] J. G. Charney, "The dynamics of deserts and droughts," Quarterly Journal of the Royal Meteorological Society, vol.101, pp. 193202, 1975.

[252] D. Entekhabi, "Recent advances in land-atmosphere interaction research," Reviews of Geophysics, vol. 33, no. 2, pp. 995-1003, 1995.

[253] A. R. Lare and S. E. Nicholson, "Contrasting conditions of surface water balance in wet years and dry years as a possible land surface-atmosphere feedback mechanism in the West African Sahel," Journal of Climate, vol. 7, no. 5, pp. 653-668, 1994.

[254] N. Zeng, J. D. Neelin, K. M. Lau, and C. J. Tucker, "Enhancement of interdecadal climate variability in the Sahel by vegetation interaction," Science, vol. 286, no. 5444, pp. 1537-1540, 1999.

[255] C. M. Taylor, E. F. Lambin, N. Stephenne, R. J. Harding, and R. L. H. Essery, "The influence of land use change on climate in the Sahel," Journal of Climate, vol. 15, no. 24, pp. 3615-3629, 2002.

[256] S. E. Nicholson, C. J. Tucker, and M. B. Ba, "Desertification, drought, and surface vegetation: an example from the West African Sahel," Bulletin of the American Meteorological Society, vol. 79, no. 5, pp. 815-829, 1998.

[257] S. D. Prince, E. Brown De Colstoun, and L. L. Kravitz, "Evidence from rain-use efficiencies does not indicate extensive Sahelian desertification," Global Change Biology, vol. 4, no. 4, pp. 359374, 1998.

[258] J. F. Reynolds and D. M. Stafford Smith, Global Desertification: Do Humans Cause Deserts? Dahlem University Press, Berlin, Germany, 2002.

[259] S. D. Prince, "Spatial and temporal scales for detection of desertification," in Global Desertification: Do Humans Cause Deserts? J. F. Reynolds and D. M. Stafford Smith, Eds., pp. 23-40, Dahlem University Press, Berlin, Germany, 2002.

[260] C. A. Alo and G. Wang, "Role of dynamic vegetation in regional climate predictions over Western Africa," Climate Dynamics, vol. 35, no. 5, pp. 907-922, 2010.

[261] B. J. Abiodun, J. S. Pal, E. A. Afiesimama, W. J. Gutowski, and A. Adedoyin, "Simulation of West African monsoon using RegCM3 Part II: impacts of deforestation and desertification," Theoretical and Applied Climatology, vol. 93, no. 3-4, pp. 245261, 2008.

[262] X. Zeng, M. Barlage, C. Castro, and K. Fling, "Comparison of land-precipitation coupling strength using observations and models," Journal of Hydrometeorology, vol. 11, no. 4, pp. 979-994, 2010.

[263] C. M. Taylor, P. P. Harrisa, and D. J. Parkerb, "Impact of soil moisture on the development of a sahelian mesoscale convective system: a case-study from the AMMA special observing period," Quarterly Journal of the Royal Meteorological Society, vol. 136, no. 1, pp. 456-470, 2010.

[264] M. Rietkerk, V. Brovkin, P. M. van Bodegom et al., "Local ecosystem feedbacks and critical transitions in the climate," Ecological Complexity, vol. 8, no. 3, pp. 223-228, 2011.

[265] L. M. Druyan, M. Fulakeza, and P. Lonergan, "Land surface influences on the West African summer monsoon: implications for synoptic disturbances," Meteorology and Atmospheric Physics, vol. 86, no. 3-4, pp. 261-273, 2004.

[266] A. L. Steiner, J. S. Pal, S. A. Rauscher et al., "Land surface coupling in regional climate simulations of the West African monsoon," Climate Dynamics, vol. 33, no. 6, pp. 869-892, 2009.
[267] B. J. J. M. van den Hurk and E. van Meijgaard, "Diagnosing land-atmosphere interaction from a regional climate model simulation over West Africa," Journal of Hydrometeorology, vol. 11, no. 2, pp. 467-481, 2010.

[268] D. B. Clark, C. M. Taylor, and A. J. Thorpe, "Feedback between the land surface and rainfall at convective length scales," Journal Hydrometeor, vol. 5, pp. 625-639, 2004.

[269] C. M. Taylor, D. J. Parker, C. R. Lloyd, and C. D. Thorncroft, "Observations of synoptic-scale land surface variability and its coupling with the atmosphere," Quarterly Journal of the Royal Meteorological Society, vol. 131, no. 607, pp. 913-937, 2005.

[270] C. M. Taylor, A. Gounou, F. Guichard et al., "Frequency of sahelian storm initiation enhanced over mesoscale soil-moisture patterns," Nature Geoscience, vol. 4, no. 7, pp. 430-433, 2011.

[271] L. Gantner and N. Kalthoff, "Sensitivity of a modelled life cycle of a mesoscale convective system to soil conditions over West Africa," Quarterly Journal of the Royal Meteorological Society, vol. 136, no. 1, pp. 471-482, 2010.

[272] R. A. Anthes, "Enhancement of convective precipitation by mesoscale variations in vegetative covering in semiarid regions," Journal of Climate \& Applied Meteorology, vol. 23, no. 4, pp. 541554, 1984.

[273] B. Adler, N. Kalthoff, and L. Gantner, "Initiation of deep convection caused by land-surface inhomogeneities in West Africa: a modelled case study," Meteorology and Atmospheric Physics, vol. 112, no. 1-2, pp. 15-27, 2011.

[274] B. Adler, N. Kalthoff, and L. Gantner, "The impact of soil moisture inhomogeneities on the modification of a mesoscale convective system: an idealised model study," Atmospheric Research, vol. 101, no. 1-2, pp. 354-372, 2011.

[275] K. I. Mohr, R. D. Baker, W. K. Tau, and J. S. Famiglietti, “The sensitivity of West African convective-line water budgets to land cover," Journal of Hydrology, vol. 4, pp. 62-76, 2003.

[276] D. J. Parker, "A simple model of coupled synoptic waves in the land surface and atmosphere of the northern Sahel," Quarterly Journal of the Royal Meteorological Society, vol. 134, no. 637, pp. 2173-2184, 2008.

[277] J. Schwendike, N. Kalthoff, and M. Kohler, "The impact of mesoscale convective systems on the surface and boundarylayer structure in West Africa: case-studies from the AMMA campaign 2006," Quarterly Journal of the Royal Meteorological Society, vol. 136, no. 648, pp. 566-582, 2010.

[278] C. M. Taylor, R. J. Harding, A. J. Thorpe, and P. Bessemoulin, "A mesoscale simulation of land surface heterogeneity from HAPEX-Sahel," Journal of Hydrology, vol. 188-189, no. 1-4, pp. 1040-1066, 1997.

[279] C. M. Taylor and T. Lebel, "Observational evidence of persistent convective-scale rainfall patterns," Monthly Weather Review, vol. 126, no. 6, pp. 1597-1607, 1998.

[280] J.-P. Goutorbe, T. Lebel, A. Tinga et al. et al., "Hapex-sahel-a large-scale study of land-atmosphere interactions in the semiarid tropics," Annales Geophysicae-Atmospheres Hydrospheres and Space Sciences, vol. 12, pp. 53-64, 1994.

[281] C. M. Taylor, "Intraseasonal land-atmospheric coupling in the West African monsoon," Journal of Climate, vol. 21, no. 24, pp. 6636-6648, 2008.

[282] C. M. Taylor and R. J. Ellis, "Satellite detection of soil moisture impacts on convection at the mesoscale," Geophysical Research Letters, vol. 33, no. 3, Article ID L03404, 2006.

[283] V. Klupfel, N. Kalthoff, L. Gantner, and C. M. Taylor, "Convergence zones and their impact on the initiation of a mesoscale 
convective system in West Africa," Quarterly Journal of the Royal Meteorological Society, vol. 138, pp. 950-963, 2012.

[284] D. Lauwaet, N. P. M. Lipzig, and K. Ridder, "The effect of vegetation changes on precipitation and Mesoscale Convective Systems in the Sahel," Climate Dynamics, vol. 33, no. 4, pp. 521534, 2009.

[285] D. Lauwaet, N. P. M. van Lipzig, N. Kalthoff, and K. de Ridder, "Impact of vegetation changes on a mesoscale convective system in West Africa," Meteorology and Atmospheric Physics, vol. 107, no. 3, pp. 109-122, 2010.

[286] M. A. Gaertner, M. Domínguez, and M. Garvert, "A modelling case-study of soil moisture-atmosphere coupling," Quarterly Journal of the Royal Meteorological Society, vol. 136, no. 1, pp. 483-495, 2010.

[287] W. Moufouma-Okia and D. P. Rowell, "Impact of soil moisture initialisation and lateral boundary conditions on regional climate model simulations of the West African Monsoon," Climate Dynamics, vol. 35, no. 1, pp. 213-229, 2010.

[288] P. Knippertz and M. C. Todd, "The central west Saharan dust hot spot and its relation to African easterly waves and extratropical disturbances," Journal of Geophysical Research D, vol. 115, no. 12, Article ID D12117, 2010.

[289] C. Jones, N. Mahowald, and C. Luo, "The role of easterly waves on African desert dust transport," Journal of Climate, vol. 16, pp. 3617-3628, 2003.

[290] G. N'Tchayi Mbourou, J. J. Bertrand, and S. E. Nicholson, “The diurnal and seasonal cycles of wind-borne dust over africa north of the equator," Journal of Applied Meteorology, vol. 36, no. 7, pp. 868-882, 1997.

[291] P. J. deMott, K. Sassen, M. R. Poellot et al., "African dust aerosols as atmospheric ice nuclei," Geophysical Research Letters, vol. 30, article 1732, 2003.

[292] W. J. Hui, B. I. Cook, S. Ravi, J. D. Fuentes, and P. D’Odorico, "Dust-rainfall feedbacks in the West African Sahel," Water Resources Research, vol. 44, no. 5, Article ID W05202, 2008.

[293] A. Wiacek, T. Peter, and U. Lohmann, “The potential influence of Asian and African mineral dust on ice, mixed-phase and liquid water clouds," Atmospheric Chemistry and Physics, vol. 10, no. 18 , pp. 8649-8667, 2010.

[294] J. Huang, C. Zhang, and J. M. Prospero, "African aerosol and large-scale precipitation variability over West Africa," Environmental Research Letters, vol. 4, no. 1, Article ID 015006, 2009.

[295] O. Reale, K. M. Lau, and A. da Silva, "Impact of an interactive aerosol on the African Easterly Jet in the NASA GEOS-5 Global Forecasting System," Weather and Forecasting, vol. 26, pp. 504519, 2011.

[296] F. Solomon, N. Elguindi, and M. Mallet, "Radiative and climatic effects of dust over West Africa, as simulated by a regional climate model," Climate Research, vol. 52, article 2012, 2012.

[297] L. Klüser and T. Holzer-Popp, "Relationships between mineral dust and cloud properties in the West African Sahel," Atmospheric Chemistry and Physics, vol. 10, no. 14, pp. 6901-6915, 2010.

[298] C. M. Patricola and K. H. Cook, "Atmosphere/vegetation feedbacks: a mechanism for abrupt climate change over northern Africa," Journal of Geophysical Research D, vol. 113, no. 18, Article ID D18102, 2008.

[299] P. Kabat, M. Claussen, P. A. Dirmeyer et al., Vegetation, Water, Humans and the Climate: A New Perspective on an Interactive System, Springer, Berlin, Germany, 2004.
[300] P. Demenocal, J. Ortiz, T. Guilderson et al., "Abrupt onset and termination of the African Humid Period: rapid climate responses to gradual insolation forcing," Quaternary Science Reviews, vol. 19, no. 1-5, pp. 347-361, 2000.

[301] S. Kroepelin, D. Verschuren, A.-M. Lézine et al., "Climatedriven ecosystem succession in the Sahara: the past 6000 years," Science, vol. 320, pp. 765-768, 2008.

[302] M. Claussen, "Modeling bio-geophysical feedback in the African and Indian monsoon region," Climate Dynamics, vol. 13, no. 4, pp. 247-257, 1997.

[303] Z. Liu, Y. Wang, R. Gallimore et al., "Simulating the transient evolution and abrupt change of Northern Africa atmosphereocean-terrestrial ecosystem in the Holocene," Quaternary Science Reviews, vol. 26, no. 13-14, pp. 1818-1837, 2007.

[304] M. Rietkerk, S. C. Dekker, P. C. De Ruiter, and J. Van De Koppel, "Self-organized patchiness and catastrophic shifts in ecosystems," Science, vol. 305, no. 5692, pp. 1926-1929, 2004.

[305] O. Lejeune, M. Tlidi, and P. Couteron, "Localized vegetation patches: a self-organized response to resource scarcity," Physical Review E, vol. 66, no. 1, Article ID 010901, 2002.

[306] M. Rietkerk and J. Van De Koppel, "Alternate stable states and threshold effects in semi-arid grazing systems," Oikos, vol. 79, no. 1, pp. 69-76, 1997.

[307] R. H. H. Janssen, M. B. J. Meinders, E. H. van Nes, and M. Scheffer, "Microscale vegetation-soil feedback boosts hysteresis in a regional vegetation-climate system," Global Change Biology, vol. 14, no. 5, pp. 1104-1112, 2008.

[308] R. D. Koster, P. A. Dirmeyer, Z. Guo et al., "Regions of strong coupling between soil moisture and precipitation," Science, vol. 305, no. 5687, pp. 1138-1140, 2004.

[309] M. Scheffer, M. Holmgren, V. Brovkin, and M. Claussen, "Synergy between small-and large-scale feedbacks of vegetation on the water cycle," Global Change Biology, vol. 11, no. 7, pp. 10031012, 2005.

[310] P. D’Odorico, K. Caylor, G. S. Okin, and T. M. Scanlon, “On soil moisture-vegetation feedbacks and their possible effects on the dynamics of dryland ecosystems," Journal of Geophysical Research G, vol. 112, no. 4, Article ID G04010, 2007.

[311] S. C. Dekker, M. Rietkerk, and M. F. P. Bierkens, "Coupling microscale vegetation-soil water and macroscale vegetationprecipitation feedbacks in semiarid ecosystems," Global Change Biology, vol. 13, no. 3, pp. 671-678, 2007.

[312] S. C. Dekker, H. J. De Boer, V. Brovkin, K. Fraedrich, M. J. Wassen, and M. Rietkerk, "Biogeophysical feedbacks trigger shifts in the modelled vegetation-atmosphere system at multiple scales," Biogeosciences, vol. 7, no. 4, pp. 1237-1245, 2010. 

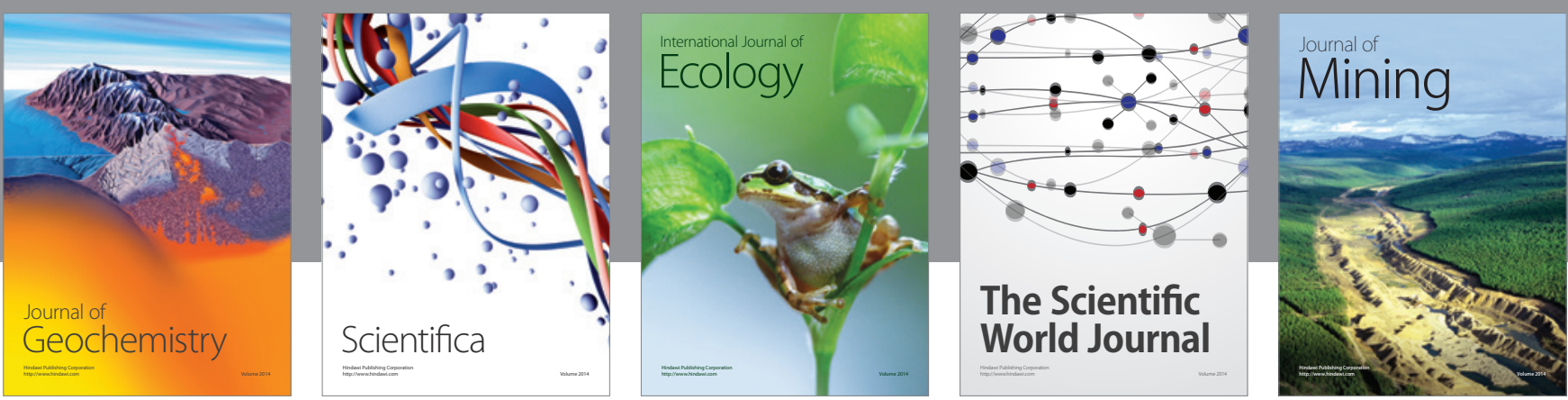

The Scientific World Journal
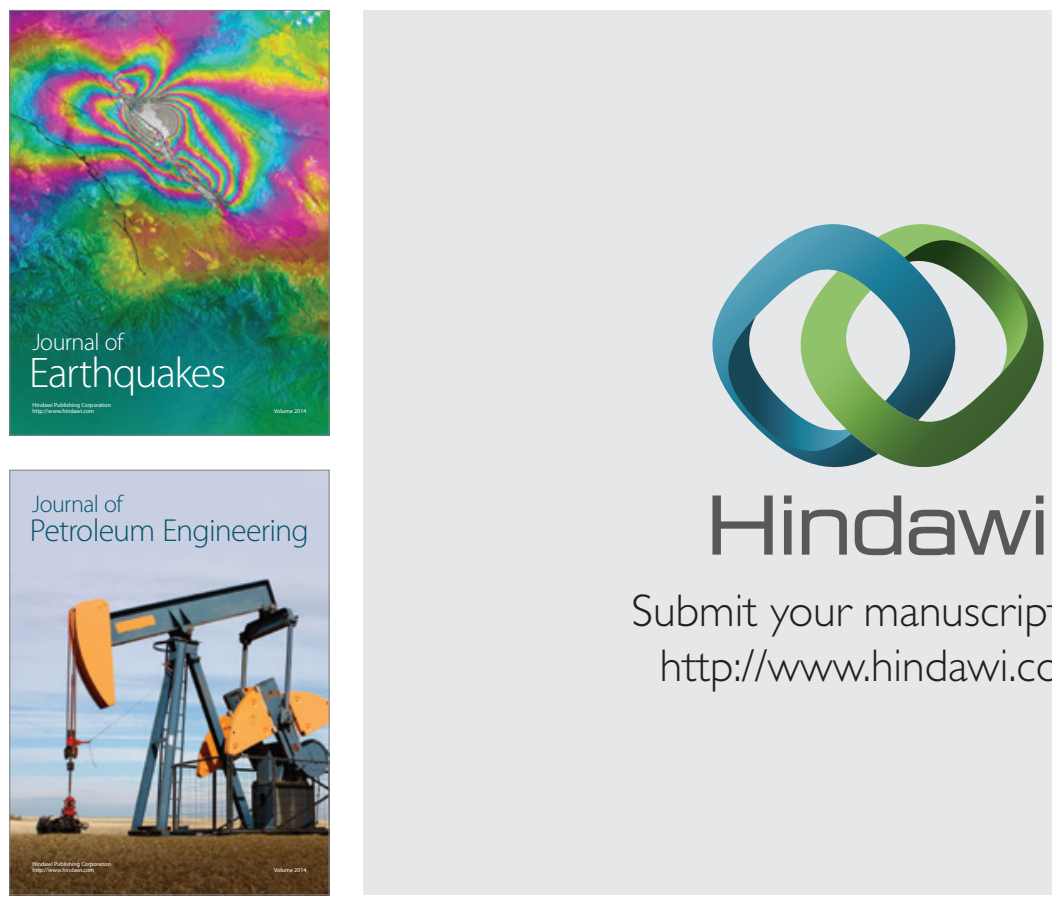

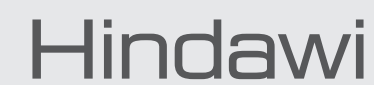

Submit your manuscripts at

http://www.hindawi.com
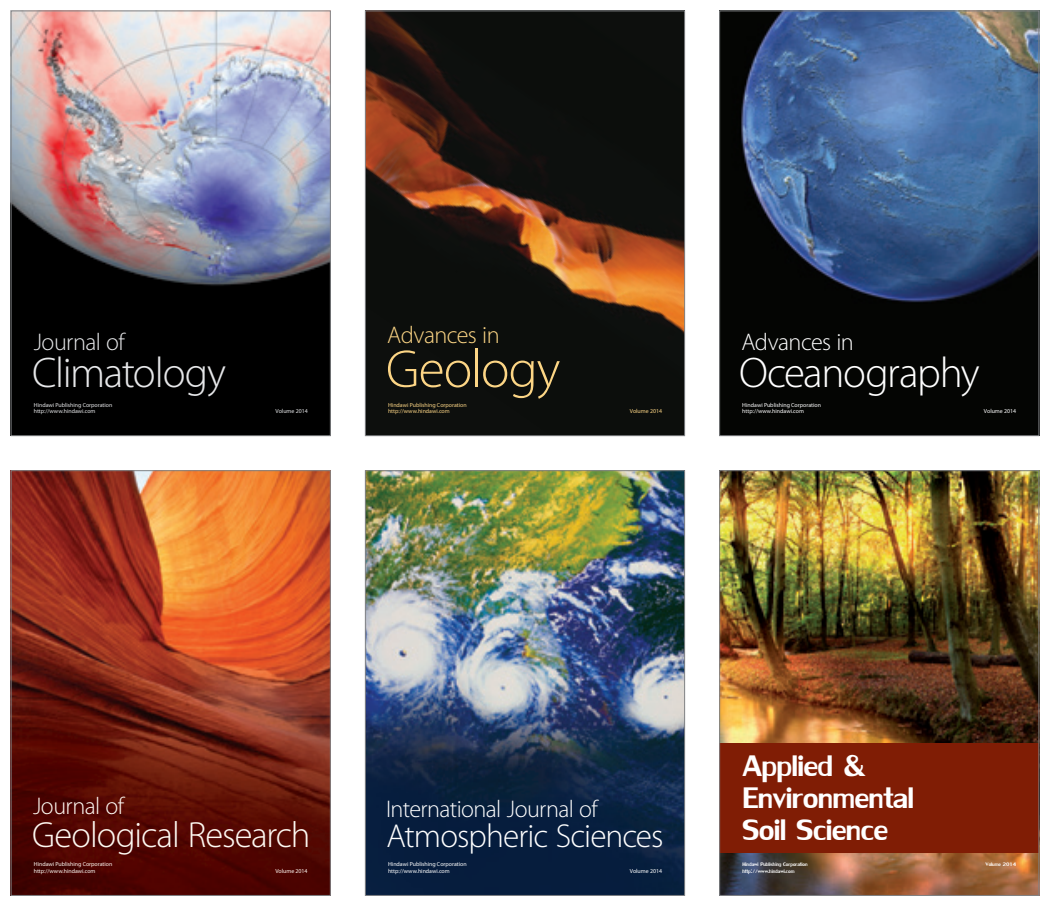
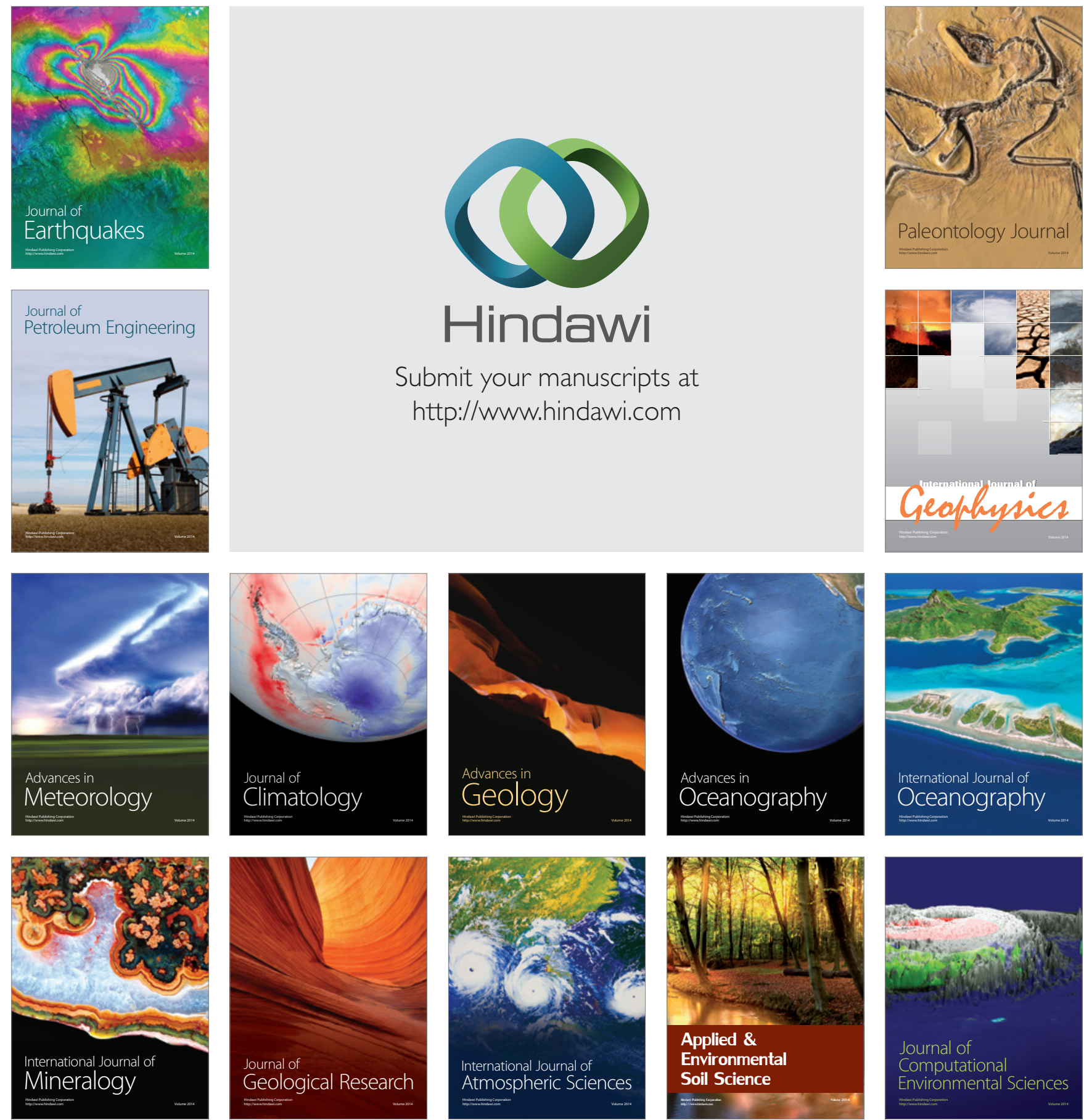